\title{
Dynamics of the neuronal cytoskeleton during apoptosis
}

Citation for published version (APA):

Nuydens, R. M. (1999). Dynamics of the neuronal cytoskeleton during apoptosis. [Doctoral Thesis, Maastricht University]. Universiteit Maastricht. https://doi.org/10.26481/dis.19991001rn

Document status and date:

Published: 01/01/1999

DOI:

10.26481/dis.19991001rn

Document Version:

Publisher's PDF, also known as Version of record

\section{Please check the document version of this publication:}

- A submitted manuscript is the version of the article upon submission and before peer-review. There can be important differences between the submitted version and the official published version of record.

People interested in the research are advised to contact the author for the final version of the publication, or visit the DOI to the publisher's website.

- The final author version and the galley proof are versions of the publication after peer review.

- The final published version features the final layout of the paper including the volume, issue and page numbers.

Link to publication

\footnotetext{
General rights rights.

- You may freely distribute the URL identifying the publication in the public portal. please follow below link for the End User Agreement:

www.umlib.nl/taverne-license

Take down policy

If you believe that this document breaches copyright please contact us at:

repository@maastrichtuniversity.nl

providing details and we will investigate your claim.
}

Copyright and moral rights for the publications made accessible in the public portal are retained by the authors and/or other copyright owners and it is a condition of accessing publications that users recognise and abide by the legal requirements associated with these

- Users may download and print one copy of any publication from the public portal for the purpose of private study or research.

- You may not further distribute the material or use it for any profit-making activity or commercial gain

If the publication is distributed under the terms of Article $25 \mathrm{fa}$ of the Dutch Copyright Act, indicated by the "Taverne" license above, 
Dynamics of the neuronal cytoskeleton during apoptosis 
Nuydens Rony

Dynamics of the neuronal cytoskeleton during apoptosis Proefschrift Maastricht [SBN 90-9012813-1

Vormgeving: Bob Joossen-Meyvis

Druk: JAP-advertising bvba 


\section{Dynamics of the neuronal cytoskeleton during apoptosis}

Proefschrift

ter verkrijging van de graad van doctor aan de Universiteit Maastricht.

op gezag van de Rector Magníficus, Prof. dr. A.C. Nieuwenhuijzen Kruseman, volgens het besluit van het College van Decanen,

in het openbaar te verdedigen

op vrijdag 1 oktober 1999 om 10.00 uur

door

Rony Maria Nuydens

geboren op 17 oktober 1958 te Beerse 


\section{Promotores:}

Prof. dr. M. Borgers

Prof. dr. F.C.S. Ramaekers

\section{Co-promoter:}

Dr. H. Geerts (Janssen Research Foundation, Beerse, Belgium)

\section{Beoordelingscommissie:}

Prof. dr. H.W.M. Steinbusch (voorzitter)

Prof. dr. P. Cras (Universitaire Instelling Antwerpen)

Prof. dr. E. Mandelkow (Universiteit Hamburg)

Dr. B. Schutte

Prof. dr. J. Troost

The investigations described in this thesis were carried out at the department of Cell Physiology, Life Sciences, Janssen Research Foundation, Beerse. Belgium.

The study was supported by the Janssen Research Foundation. 




\section{Table of contents}

List of abbreviations

Chapter 1 General introduction

Chapter 2 Neuronal kinase stimulation leads to aberrant tau phosphorylation and neurotoxicity

Neurobiology of Aging, 16, 3, 465-477, 1995

Chapter 3 Sodium butyrate induces aberrant tau phosphorylation and programmed cell death in human neuroblastoma cells Brain Research, 688, 86-94, 1995.

Chapter 4 Aberrant tau phosphorylation and neurite retraction during NGF deprivation in PCI2 cells

Biochem. Biophys. Res. Commun. 240, 687-6891, 1997

Chapter 5 Okadaic acid-induced apoptosis in neuronal cells: Evidence for an abortive mitotic attempt

J. Neurochem. 70, 1124-1131, 1998

Chapter 6 Bcl-2 protects neuronal cells against taxol-induced apoptosis by inducing multi-nucleation submitted for publication

Chapter 7 Bcl-2 protects against apoptosis-related microtubule alterations submitted for publication

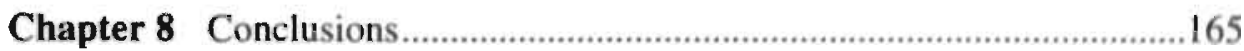

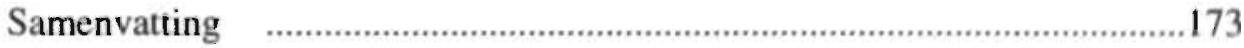

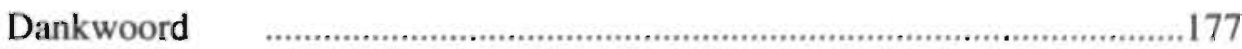

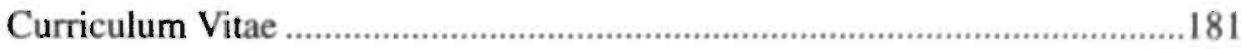

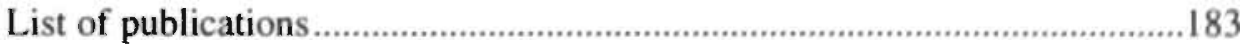





\section{List of abbreviations}

\begin{tabular}{ll} 
AB & B-amyloid protein \\
AD & Alzheimer's disease \\
ALG-3 & apoptosis-linked gene 3 \\
Bcl-2 & B cell lymphoma-2 \\
CDK & cyclin-dependent kinase \\
CKI & cyclin-dependent kinase inhibitor \\
dB-cAMP & dibutyryl cyclic AMP \\
DRG & dorsal root ganglion \\
EIPA & ethyl-isopropyl amiloride \\
ER & endoplasmic reticulum \\
FCS & foetal calf serum \\
FITC & fluoresceine isothiocyanate \\
FTDP-17 & frontotemporal dementia and Parkinsonism linked to chromosome 17 \\
GA & glutaraldehyde \\
GAM & goat anti mouse \\
GAP-43 & growth-associated protein-43 \\
GAR & goat anti rabbit \\
GSK-3B & glycogen synthase kinase \\
HS & horse serum \\
ICE & interleukin-1B converting enzyme \\
MAP & microtubule-associated protein/mitogen-activated protein \\
MIV & mean intensity values \\
NFT & neurofibrillary tangles \\
NGF & nerve growth factor \\
PBS & phosphate buffered saline \\
PHF & paired helical filaments \\
PKA & protein kinase A \\
PMS & phenazine methosulfat \\
PP2A & phosphatase 2A \\
PS & presenilins/phosphatidylserine \\
TBS & tris buffered saline \\
XTT & 2,3-bis (2-methoxy-4-nitro-5sulphophenyl)-2H-tetrazolium-5-carboxanilide \\
& \\
\hline
\end{tabular}





\section{General introduction}

\section{Introduction}

Alzheimer's disease afflicts many people and is a major cause of dementia. The disease is characterized by reduced neuronal functioning, ultimately leading to neuronal cell death resulting in impaired memory function and dementia. The aetiology of Alzheimer's disease is still poorly understood: both genetic and epigenetic factors seem to be involved.

Upon post-mortem examination of Alzheimer's disease brains, there is an anatomically selective loss of certain neuronal populations. Evidence has accumulated indicating that these neurons die through an active process called apoptosis.

Two other typical morphological features are observed in Alzheimer's disease: B-amyloid deposits and neurofibrillary tangles (NFT). The density of NFTs in the brain seems to correspond with the degree of dementia, suggesting a correlation between neurofibrillary pathology and neuronal dysfunction (Arriagada et al., 92). Neurofibrillary tangles are abnormal accumulations of intraneuronal fibrils ultrastructurally referred to as paired helical filaments 
(PHF). They are composed of a modified form of tau (Shea and Fischer, 1996), a microtubule-associated protein (MAP). MAPs are keyplayers in the regulation of cytoskeletal dynamics. Phosphorylation/dephosphorylation. processes modulate the interaction between MAPs and microtubules. In neurons, tau is one of the major MAPs assumed to regulate microtubule dynamics, although the precise mechanisms involved in supporting axonal growth and plasticity are still unknown.

In Alzheimer's pathology the NFTs are composed of aberrantly phosphorylated tati, which results from a disturbed balance between kinase and phosphatase activities. An important consequence of this hyperphosphorylation is a reduction in overall microtubule stability. As microtubules serve as tracks to guide fast axonal transport, this might also lead to a decreased flux of materials necessary for cell survival. Therefore, any impairment of microtubule stability may lead to deficient signal transduction pathways and compromise cellular functioning.

\section{Taxol pathology}

Taxol is a cytostatic compound that is becoming increasingly popular in the treatment of solid tumors such as breast cancer. Taxol is a low molecular weight plant derivative that enhances microtubule assembly in vitro, and has the unique ability to promote the formation of discrete microtubule bundles in cells (Manfredi et al., 1982). In proliferating cells, taxol causes the cells to halt at the $G_{2} / M$ transition phase of the cell cycle, presumably through its interference with the mitotic spindle. This mitotic block eventually leads to cell death through activation of an apoptotic pathway (Shu et al., 1997) initiated by cell-cycle checkpoint controls.

The broad antitumour activity of taxol in cisplatin-sensitive tumors indicates that a combination of taxol and cisplatin may become an important therapeutic approach in the treatment of solid tumors (Rowinski et al., 1991). However, to a lesser degree neutropenia and most importantly peripheral neuropathies are 
the principal side effects, seriously compromising the clinical use of this combination (Rowinski et al., 1993). To help control the neurotoxic effects of the chemotherapeutic drugs taxol and cisplatin, analogs of adrenocorticotropic hormone and neurotrophic factors are being considered (Mizisin and Powell, 1995).

In primary cultures of adult dorsal root ganglion (DRG) cells, the neurotoxic effect usually starts with an axonal retraction before the cytotoxic effect becomes evident (Malgrange et al., 1994), which suggests an effect on the neuronal cytoskeleton.

\section{Tau pathology and microtubule stability}

Microtubules are cellular components that carry out a great number of functions essential for survival and reproduction in eukaryotes. For example they act as guiding tracks for many types of intracellular movements.

Chromosome movement during mitosis, axonal transport in neurons, and endo- and exocytotic pathways are all dependent on a functional microtubule cytoskeleton (Oakley and Oakley, 1995). To meet these demands, microtubules exist in a state of dynamic instability providing them with the necessary flexibility. In neuronal cells, the spatial differences in organization and stability of the microtubule network might be a major determinant in establishing and maintaining the highly polarized cytoarchitecture (Baas, 1999). The stability of microtubules is mainly governed by the concerted action of post-translational modifications (MacRae, 1997) and microtubule-associated-proteins (MAPs). Whether the variation in post-translational modifications indeed causes, or only indicates, the stability of individual microtubules, is still a matter of debate. Quantitative fluorescence microscopy indicated that in axons, acetylated tubulin was more prominent in the proximal parts, while the more labile tyrosinated tubulin was located mainly in the distal parts and the growth cones (Brown et al., 19913). Hence the neuron might preserve some flexibility necessary for re-establishing 
the synaptic circuitry.

However, MAPs are the most likely candidates for the regulation of microtubule dynamics. In neurons, MA.P-2 and tau are the most interesting proteins because they reside in dendrites and axons, respectively. It was shown, with antisense technology, that inhibition of one MAP resulted in a decreased outgrowth of dendrites or axons dependent on the knock-out (Caceres et al., 1990; Caceres et al., 1991), which indicates the importance of MAPs in maintaining the neuronal morphology. Considerable interest has been expressed in tau research because of the possible involvement of tau in Alzheimer's pathology. Site-specific phosphorylation of tau has indeed been shown to be a determining factor in the association between tai and the microtubules, which therefore also influences the microtubule stability. A number of candidate kinases have been shown to phosphorylate tau. Phosphorylation by PKA (Litersky et al., 1996), GSK-3 $\beta$ (Uton et al., 1997) and MARKs (Biernat et al., 1993) all interfere with microtubule binding and stabilization in vitro. Recently, however, it was shown that in SH-SY5Y cells only phosphorylation at Ser 262/356 by PKA prevented the association of tau with microtubules (Xie et al., 1998).

Another possible source for the aberrant phosphorylation of tau is the dysregulation of phosphatase activity. In Alzheimer's diseased brain it has indeed been established that phosphatase activity is decreased in comparison with a control brain (Gong et al., 1995). In this context it is important to note that a substantial amount of phosphatase $2 \mathrm{~A}$ (PP2A) is associated with neuronal microtubules (Sontag et al., 1995), and consequently possesses the spatial organization for the local regulation of the phosphorylation status. Inhibition of PP2A in NT2N cells induced microtubule destabilization through tau phosphorylation which in tum brought about degeneration of axons (Merrick et al.. 1997). A major breakthrough indicative of the probable role of tau in neurodegeneration came from the identification of mutations (Hutton et al., 1998) in the tau gene, and of the link with FTDP-17 (frontotemporal dementia and Parkinsonism linked to chromosome 17). In this form of dementia, neurofibrillary pathology is found in the absence of $\beta$-amyloid deposits. Some of these genetic deficits significantly impair tau-microtubule association and microtubule stability (Jicha et al., 1999). 


\section{Apoptosis versus necrosis}

Neuronal apoptosis or programmed cell death plays an important role during the development of the nervous system. During neurogenesis, a great number of neurons are produced, of which about only half are needed by the mature nervous system (Oppenheim, 1991). Neuronal survival is determined by the supply of neurotrophic factors derived from the innervated tissue. Those neurons not receiving sufficient neurotrophins initiate a genetically determined suicide program (Barde, 1989). This consists of a series of precisely timed processes characterized by a number of features reminiscent for apoptosis, often based on morphological criteria (Kerr et al., 1972). At the early stages the cells shrink and membrane alterations become obvious. Typical is the externalization of phosphatidylserine to the outer leaflet of the cell membrane. The most obvious changes, however, occur in the nucleus: chromatin condensation and marginalization. Biochemically these nuclear aberrations manifest themselves as DNA fragments of single or muitiple nucleosomal size (about 200 basepairs) on agarose gels. In the cytoplasm, however, many organelles, such as mitochondria, do not show major morphological alterations. Finally, the complete cell disintegrates into apoptotic bodies, which are cleared from the tissue by phagocytosis before the cell membrane becomes disrupted. This has important consequences for the neighboring tissue as it does not provoke an immune response (Bar, 1996). Apoptosis can be initiated in single cells and does not necessarily involve entire cell populations or tissues.

Apoptosis is fundamentally different from necrosis, a type of cell death observed after a severe and sudden type of aggression. During necrosis, major changes occur in the mitochondria. These organelles swell and ultimately are unable to maintain the cellular ATP levels. Consequently, the ion homeostasis collapses allowing for water to enter the cytoplasm, which leads to cell swelling. When the cell finally ruptures, the intracellular content is released. This initiates an immune response attracting macrophages, which ultimately remove all remaining debris (Cohen, 1998). 


\section{Apoptosis and neurodegeneration}

Programmed cell death has until now been implicated as a mediator of organogenesis. Compelling evidence, however, also points to a role of apoptosis in some neuropathological conditions, both acute and chronic. The study of the role of apoptosis during neurodegeneration is complicated by the fact that the neuronal loss, and hence the progression of the disease, may take months to years. An apoptotic cell, once it is committed to die and enters the execution phase of this process, can die within an hour and is subsequently removed by phagocytosis. Several lines of evidence point to a possible role of apoptosis during neuronal cell loss in Alzheimer's disease (Su et al., 1994). Interestingly, Lassman et al. (Lassman et al., 1995) established a correlation between the appearance of DNA strand breaks and neurofibrillary tangles. In neurons bearing neurofibrillary tangles, the incidence of DNA strand breaks was three times higher than in non-affected cells.

One of the pathological hallmarks of Alzheimer's disease is the presence of senile plaques composed of aggregated $A \beta$ peptide. Treatment of neuronal cells with $A \bar{\beta}$ induces cell death which shows all the features of apoptosis (Loo et al., 1993; Kim et al., 1998). Moreover, in vivo neurotoxicity was observed after intracerebral application of $A \beta$ (Yankner et al., 1990). The toxicity of $A \beta$ strongly depends on the state of aggregation of the peptide, with the longer 1-42 form being the more amyloidogenic (Games et al., 1995; Tamaoka et al., 1994). More recently, another series of mutations were linked to chromosomes 14 and 1 for presenilines 1 and 2 (PS-1 and PS-2). Both transmembrane proteins are ubiquitously expressed with an essential neuronal localization in the brain. Mutations in the presenilines are responsible for an aggressive and early-onset form of the disease. Also, in these cases the levels of $A \beta 1-42$ over $A \beta 1-40$ are significantly higher (Haass, 1997). The exact function of either of the presenilines is still unknown, but interestingly, presenilines have been linked to cell death through apoptosis. Increased expression of wild-type or mutant PS-2 sensitizes HeLa cells to apoptosis (Janicki et al., 1997). Primary cultures of cortical neurons derived from PS- 1 transgenic rats are significantly more sensitive to trophic factor withdrawal than controls (Czech et al., 1998). 


\section{Genetic regulation of apoptosis}

Programmed cell death is regulated by a large number of genes. A vast amount of information originated from studies on the nematode $\mathrm{C}$. elegans in which a number of these genes were identified. CED-3 and CED-4 have pro-apoptotic, while CED-9 has anti-apoptotic activity (Yuan et al., 1993; Shaham et al., 1992; Hengartner et al. 1992). CED-3 is a member of a family of proteases, caspases, which have presumed activity during the execution phase of apoptosis, and which share homology with the human interleukin- $1 \beta$ converting enzyme, ICE-like proteases. CED-9 on the other hand shares homology with the mammalian bcl-2 family. Bcl-2 has been identified in human B-cell lymphoma, where it is overexpressed due to a $t(14 ; 18)$ chromosomal translocation (Bakshi et al., 1985). Intracellular bcl-2 is inserted into a number of membrane-bound compartments, including the mitochondria, the endoplasmic reticulum (ER) and the nuclear envelope (de Jong et al., 1994).

The precise mechanism by means of which bcl-2 and other members of this family orchestrate the cellular life or death decision is still elusive. The major cytoprotective function of bcl-2 has been attributed to mitochondria which it protects against mitochondrial dysfunctioning during stress (Susin et al., 1996). However, in the ER, bcl-2 has also been reported to regulate $\mathrm{Ca}^{2+}$ homeostasis (Distelhorst et al., 1996). Another type of function is the dimerization with other members of the bcl-2 family of proteins, either pro- or anti-apoptotic, whereby its function is inhibited (Hanada et al., 1995). In this regard it has been established that application of $A \beta 1-42$ to neuronal cells induces changes in the ratio of pro- to anti-apoptotic proteins (Paradis et al., 1996).

It has also been documented that $\mathrm{Bcl}-2$ inhibits neuronal apoptosis elicited by a variety of cytotoxic compounds or growth factor deprivation (Garcia et al., 1992). In models for Parkinson's disease, bcl-2 overexpression protects dopaminergic neurons against MPTP-induced damage (Offen et al., 1998). Elevated levels of $\mathrm{bcl}-\mathrm{X}_{\mathrm{L}}$, an anti-apoptotic protein, protect CNS neurons in a hypoxia-ischemia paradigm (Parsadanian et al., 1998). Also, in an in vitro 
model associated with Aizheimer's disease, bcl-2 has cytoprotective effects. PC12 cells transfected with mutant PS-1 are more sensitive to nerve growth factor (NGF) deprivation. This is inhibited by higher levels of bcl-2 (Guo et al., 1997).

\section{Apoptosis and the mitotic cycle}

In proliferating cells, the cell cycle is regulated by the temporal activation of cyclins, cyclin-dependent kinases (CDK'-s) and cyclin-dependent kinase inhibitors (CKIs) (Arrellano et al., 1997). Neuronal cells are differentiated as they have left the normal cell cycle and assumed a quiescent state at the $\mathrm{G}_{0}$ position of the cell cycle. It has been hypothesized that apoptosis in differentiated cells is the consequence of an abortive attempt by these cells to re-enter the cell cycle (Colombel et al., 1992). Through in vitro systems for neuronal programmed cell death, it has been shown that during the apoptotic cascade numerous genes and proteins are upregulated to levels normally associated with proliferating cells (Freeman et al., 1994). In NGF-deprived sympathetic neurons, as a model of apoptosis, the role of CDK's and CKI's was disclosed. Expression of CKI or of dominant negative CDK4 or CDK6 protected against apoptosis in this system (Park et al., 1997). We have shown that during apoptosis, well-differentiated neurons initiate DNA synthesis and enter mitosis, but proper chromosome alignment at metaphase is impaired (Nuydens et al., 1998). This points to microtubules as possible mediators of this phenomenon (Gorbsky, 1997). In these cell systems the induction of apoptosis is associated with an increased level of aberrantly phosphorylated tau. In mitotic SH-SY5Y neuroblastoma and tau-transfected CHO cells, it has been established that phosphorylation of tau at Ser/Thr-Pro motifs, as normally found in PHF tau, has a cell-cycle-dependent pattern (Pope et al., 1994; Preuss et al., 1995). Also, in Alzheimer's diseased brains, cell cycle disturbances have been observed (Nagy et al., 1998; Busser et al., 1998). It has even been postulated that mitotic kinase activation triggers neurofibrillary tangle formation in the course of the disease (Vincent et al., 1998). 


\section{Scope of this thesis.}

In situations of chronic neurodegeneration, such as Alzheimer's disease, there is evidence of programmed cell death and upregulation of mitosis related genes and proteins in post-mitotic neurones. In $\mathrm{AD}$ this is associated with high levels of abnormally phosphorylated tau. These observations and the anti-apoptotic effect of bcl-2 prompted us to investigate the relationship between markers of apoptosis and the appearance of frustrated mitosis. An interesting question relates to tau phosphorylation, the appearance of mitotic markers and the relation with neuronal cell death.

Using neuronal cell cultures, we adapted a protocol in which hyperstimulation of neuronal kinases initiates aberrant tau phosphorylation with subsequent induction of neurotoxicity (chapter 2 ). In human neuroblastoma cells, application of sodium butyrate-induced aberrant tau phosphorylation and programmed cell death. This excessive stimulation also dramatically influenced the polarized neuronal morphology as assessed by quantitative light microscopy (chapter 3).

In a second group of experiments we used a more established model of neuronal apoptosis. Differentiated PC12 cells, when deprived of NGF, readily retract their neurites and eventually die through apoptosis. We investigated the relationship between kinase activation, tau phosphorylation and morphological differentiation in these cells (chapter 4). Using differentiated human neurons, we further investigated the possible link between the cell cycle and the series of events associated with apoptosis. We evaluated the progression from mitosis to apoptosis morphologically and by flow cytometry. By quantitative immunocytochemistry, the appearance of mitosis-specific epitopes was investigated during the initiation of the apoptotic process (chapter 5). As the morphological changes are a prime event after application of the apoptotic trigger, we focused on the role of microtubules during the process of programmed cell death in differentiated PC 12 cells. It had been documented that microtubule poisons induce apoptosis in a number of proliferating cell systems. We extended these findings with reference to differentiated neuronal cells, including bcl-2 


\section{Chapter 1}

transfected PC1 2 cells, with emphasis on the relationship between mitosis and apoptosis (chapter 6). In a further series of experiments we monitored neuronal morphology and the role of MAPs and post-translational modifications during apoptosis, induced either by microtubule stabilization or destabilization, in differentiated neuronal cells and using bcl-2 transfected cells as a complementary tool (chapter 7). 


\section{References.}

Arellano, M., Moreno, S. Regulation of CDK/cyclin complexes during the cell cycle. Int. J. Biochem. Cell Biol. (1997) 4:559-573.

Arriagada, R.V., Marzloff, K., Hyman, B.T. Distribution of Alzheimer-type pathologic changes in nondemented elderly individuals matches the pattern in Alzheimer's disease. Neurology (1992) 42:1681-1688.

Baas, P. Microtubules and neuronal polarity: Lessons from mitosis. Neuron (1999) 22:23-31.

Bakhshi, A., Jensen, J.P., Goldman, P., Wright, J.J., MeBride, O.W., Epstein, A.L., Korsmeyer, S.J. Cloning the chromosomal breakpoint of $t(14 ; 18)$ human lymphomas: clustering around $\mathrm{JH}$ on chromosome 14 and near a transcriptional unit on 18. Cell (1985) 41:899-906.

Bar, P.R. Apoptosis-the cell's silent exit. Life Sciences (1996) 59:369-78.

Barde, Y.A. Trophic factors and neuronal survival. Neuron (1989) 2:1525-1534.

Biernat, J., Gustke, N., Drewes, G., Mandelkow, E.M., Mandelkow, E. Phosphorylation of Ser262 strongly reduces binding of tau to microtubules: distinction between PHF-like immunoreactivity and microtubule binding. Neuron (1993) 11:153-63.

Brown, A., Li, Y., Slaughter, E., Black, M. Composite microtubules of the axon: quantitative. analysis of tyrosinated and acetylated tubulin along individual axonal microtubules. J. Cell Sci. (1993) 104:339-352.

Busser, J., Geldmacher, D.S., Herrup, K. Ectopic cell cycle proteins predict the sites of neuronal cell death in Alzheimer's disease brain. J. Neurosci. (1998) 18:2801-2807.

Caceres, A., Potrebic, S., Kosik, K.S. The effect of tau antisense oligonucleotides on neurite formation of cultured cerebellar macroneurons. J. Neurosci. (1991) 11:1515-23.

Caceres, A., Kosik, K.S. Inhibition of neurite polarity by tau antisense oligonucleotides in primary cerebellar neurons. Nature (1990) 343: 46I-463.

Cohen, J.J. Apoptosis and its, significance in health and disease. In "Pharmaceutical intervention in apoptotic pathways" (1998), eds. Nagelkerke J.F., Van Dierndonck J.H. and Noteborn M.

Colombell, M., Ollson, C.A.., Ng, P.Y., Buttyan, R. Hormone-regulated apoptosis results from reentry of differentiated prostate cell onto a defective cell cycle. Cancer Res. (1992) 52:4313-4319. 
Czech, C., Lesort, M., Tremp, G., Terro, F., Blanchard, V., Schombert, B., Carpentier, N., Dreisler, S., Bionici, B., Takashima, A., Moussaoui, S., Hugon, J., Pradier, L.

Characterization of human presenilin 1 transgenic rats: increased sensitivity to apoptosis in primary neuronal cultures. Neuroscience (1998) 87:325-336.

de Jong, D., Prins, F. A., Mason, D.Y., Reed, J.C., van Ommen, G.B., Kluin, P.M. Subcellular localization of the bcl-2 protein in malignant and normal lymphoid cells. Cancer Res. (1994) 54:256-60.

Distelhorst, C.W., McCormick, T.S. Bcl-2 acts subsequent to and independent of $\mathrm{Ca}^{2+}$ fluxes to inhibit apoptosis in thapsigargin- and glucocorticoid-treated mouse lymphoma cells. Cell Calcium (1996) 19:473-483.

Freeman, R.S., Estus, S., Johnson, E.M.Jr. Analysis of cell cycle-related gene expression in post-mitotic neurons: Selective induction of cyclin DI during programmed cell death. Neuron (1994) 12:343-355.

Games, D., Adams, D., Alessandrini, R., Barbour, R., Berthelette P. Blackwell, C., Carr, T., Clemens, J., Donaldson, T., Gillespie, F., et al. Alzheimer-type neuropathology in transgenic mice overexpressing V717F beta-amyloid precursor protein. Nature (1995) 373:523-527.

Garcia, I., Martinou, I., Tsujimoto, Y., Martinou, J.C. Prevention of programmed cell death of sympathetic neurons by the bcl-2 proto-oncogene. Science (1992) 258:302-304.

Gong, C.-X., Shaikh, S., Wang, J., Zaidi, T., Grundke-Iqbal, I., Iqbal, K. Phosphatase activity toward abnormally phosphorylated tau: decrease in Alzheimer disease brain. J. Neurochem. (1995) 65:732-738.

Gorbsky, G.J. Cell cycle checkpoints: arresting progress in mitosis. Bioassays (1997) 19:193-197.

Guo, Q., Sopher, B.L., Furukawa, K., Pharn, D.G., Robinson, N., Martin, G.M., Mattson, M.P. Alzheimer's presenilin mutation sensitizes neural cells to apoptosis induced by trophic factor withdrawal and amyloid beta-peptide: involvement of calcium and oxyradicals. I. Neurosci. (1997) 17:4212-4222.

Haass, C. Presenilins: Genes for life and death. Neuron (1997) 18:687-690.

Hanada, M., Aime-Sempe, C., Sato T., Reed, J.C. Structure-funetion analysis of Bc!-2 protein. Identification of conserved domains important for homodimerizarion with Bcl-2 and heterodimerization with Bax. J. Biol. Chem. (1995) 270:11962-9.

Hengartner, M.O., Ellis, R.E., Horvitz, H.R. Caenorhabditis elegans gene ced-9 protects cells from programmed cell death. Nature (1992) 356:494-499. 
Hutton et al. Association of missense and $5^{\prime}$-splice-site mutations in tau with the inherited dementia. FTDP-17. Nature (1998) 393:702-705.

Janicki, S. and Monteneiro, M. Increased apoptosis arising from increased expression of the Alzheimer's disease-associated presenilin-2 mutation (N1411).

J. Cell Biol. (1997) 139:485-495.

Jicha, G.A., Rockwood, J. M., Berenfeld, B., Hutton, M., Davies, P. Altered conformation of recombinant frontotemporal dementia-17 mutant tau proteins.

Neurosci. Lett. (1999) 260:153-156.

Kerr, J.F., Wyllie, A.H. and Currie, A.R. Apoptosis: a basic biological phenomenon with wide-ranging implications in tissue kinetics, Br. J. Cancer (1972) 26:239-257.

Kim, E., Kim, R., Feng Ren, R., Hawver, D., Corey Flanders, K. Transforming growth factor- $\beta$ inhibits apoptosis induced by $\beta$-amyloid peptide fragment $25-35$ in cultured neuronal cells. Mol. Brain Res. (1998) 62:122-130.

Lassmann H. Bancher C. Breitschopf H. Wegiel J. Bobinski M. Jellinger K. Wisniewskn HM. Cell death in Alzheimer's disease evaluated by DNA fragmentation in situ. Acta Neuropathologica (1995) 89:35-41.

Litersky, J.M., Johnson, G.V., Jakes, R., Goedert, M., Lee, M., Seubert, P. Tau protein is. phosphorylated by cyclic AMP-dependent protein kinase and calcium/calmodulin-dependent protein kinase II within its microtubule-binding domains at Ser-262 and Ser-356. Bioch. J. (1996) 316:655-660.

Loo, D., Copani, A., Pike, C., Whittemore, E., Walencewicz, A., Cotman, C. Apoptosis is induced by $\beta$-amyloid in cultured central nervous system neurons.

Proc. Natl. Acad. Sci. (1993) 90:795 I-7955.

MacRac, T.H. Tubulin post-translational modifications. Eur. J. Biochem. (1997), 244:265-278.

Malgrange, B., Delree, P., Rigo, J.M., Baron, H., Monetn, G. Image analysis of neurite regeneration by adult DRG in culture : quantification of neurotoxicity of anticancer agents and of its prevention by NGF or bFGF but not BDNF or NT3.

J. Neurosci. Meth. (1994) 53:111-122.

Manfredi, J.J., Parness, J., Horwitz, S.B. Taxol binds to cellular microtubules. J. Cell Biol. (1982) 94:688-696.

Merrick, S., Trojanowski. J., Lee, V. M.-Y. Selective destruction of stable microtubules and axons by inhibitors of protein serine/threonine phosphatases in cultured human neurons (NT2N cells). J. Neurosci. (1997) 17:5726-5737. 
Mizisin, A.P., Powell, H.C. Toxic neuropathies.

Current Opinion in Neurology (1995) 8:367-71.

Nagy, Z.S., Esiriu, M.M., Smith, A.D. The cell division cycle and the pathophysiology of Alzheimer's disease. Neurosci. (1998) 87:731-739.

Nuydens, R., de Jong, M., Van Den Kieboom, G., Heers, C., Dispersyn, G., Cornelissen, F., Nuyens, R., Borgers, M., Geerts, H. Okadaic acid-induced apoptosis in neuronal cells: evidence for an abortive mitotic attempL. J. Neuroch. (1998) 70:1124-1133.

Orfen, D., Beart, P.M., Cheung, N.S., Pascoe, C.J., Hochman, A., Gorodin, S., Melamed, E., Bernard, R., Bernard, O. Transgenic mice expressing human Bcl-2 in their neurons are resistant to 6-hydroxydopamine and 1-methyl-4-phenyl-1,2,3,6-tetrahydropyridine neurotoxicity. Proc. Nat. Acad. Sci. (1998) 95:5789-5794.

Oakley, B.R., Oakley, C.E. Tubulin and microtubules. Scientific American (1995) 59-67.

Oppenheim, R.W. Cell death during development of the nervous system. Annu. Rev. Neurosci. (1991) 14:453-501.

Park, D., Levine, B., Ferrari, G., Greene, L.A. Cyclin dependent kinase inhibitors and dominant negative cyclin dependent kinase 4 and 6 promote survival of NGF-deprived sympathetic neurons. J. Neurosci. (1997) 17:8975-8983.

Paradis, E., Douillard, H., Koutroumanis, M., Goodyer, C., Leblanc, A. Amyloid beta peptide of Alzheimer's disease downregulates $\mathrm{Bcl}-2$ and upregulates bax expression in human neurons. J. Neurosci. (1996) 16:7533-7539.

Parsadanian, A.S., Cheng, Y., Keller-Peck, C.R., Holtzman, D.M., Snider, W.D. Bel-xL is an antiapoptotic regulator for postnatal CNS neurons. I. Neurosci. (1998) 18:1009-1019.

Preuss, U., Doring. F., Illenberger, S., Mandelkow. E.-M. Cell cycle-dependent phosphorylation and microtubule binding of tau protein stably transfected into Chinese Hamster Ovary cells. Mol. Biol. of the Cell (1995) 6:1397-1410.

Pope, W.B., Lambert, M.P., Leypold, B., Seupaul, R., Sletten, L., Kraff, G., Klein, W.L. Microtubule-associated protein tau is hyperphosphorylated during mitosis in the human neuroblastoma cell line SH-SY5Y. Exp. Neur. (1994) 126:185-194.

Rowinski, E., Gilbert, M., Mc Guire, W. Sequences of taxoi and cisplatin: a phase I and pharmacological study. J. Clin. Oncol. (1991) 9:1692-1703.

Rowinski, E., Chaudry, V.. Forastiere, A. et al. A phase I study and pharmacological study of taxol and cisplatin with granulocyte colony stimulating factor : neuromuscular toxicity is dose-dependent. J. Clin. Oncol. (1993) 11:2010-2020. 
Shaham, S., Horvitz, H.R., An alternatively spliced C. elegans ced-4 mRINA encodes a novel cell death inhibitor. Cell (1992) 86:201-208.

Shea, T. and Fischer, I. Phosphatase inhibition in neuroblastoma cells alters tau antigenicity and renders it incompetent to associate with exogenous microtubules.

FEBS Letters (1996) 380:63-67.

Shu, C., Yang, W., Kuo, M.-L. and Huang, T.-S. Cell cycle $G_{2} / M$ arrest and activation of cyclin-dependent kinases associated with low-dose paclitaxel-induced sub-GI apoptosis. Apoptosis (1997) 2:463-470.

Sontag, E., Nunbakdhì-Craig, V., Bloom, G.S., Mumby, M.C. A novel pool of protein phosphatase $2 \mathrm{~A}$ is associated with microtubules and is regulated during the cell cycle. J. Cell Biol. (1995) 128:1131-1144.

Su, J.H., Anderson, A.J., Cummings, B.J., Cotman, C.W., Immunohistochemical evidence for apoptosis in Alzheimer's disease. Neuroreport (1994) 5:2529-2533.

Susin, S.A., Zamzami, N., Castedo, M., Hirsch, T., Marchetti, P., Macho, A., Daugas, E., Geuskens, M., Kroemer, G. Bcl-2 inhibits the mitochondrial release of an apoptogenic protease. J. Exp. Med. (1996) 184:1331-41.

Tamaoka, A., Kondo, T., Odaka, A., Sahara, N., Sawamura, N., Ozawa, K., Suzuki, N., Shoji, S., Mori, H. Biochemical evidence for the long-tail form (A beta 1-42/43) of amyloid beta protein as a seed molecule in cerebral deposits of Alzheimer's disease. Biochem. \& Biophys. Res. Commun. (1994) 205:834-42.

Utton, M.A., Vandecandelaere, A., Wagner, U., Reynolds, C.H., Gibb, G.M., Miller, C.C., Bayley, P.M., Anderton, B.H. Phosphorylation of tau by glycogen synthase kinase 3 beta affects the ability of tau to promote microtubule self-assembly.

Biochem J. (1997) 323:741-747.

Vincent, I., Zheng, J.-H., Dickson, D.W., Kress, Y., Davies, P. Mitotic phosphoepitopes precede paired helical filaments in Alzheimer's disease.

Neurobiol. Of Aging (1998) 19:287-296.

Xie, H., Litersky, J.M., Hartigan, J.A., Jope, R.S., Johnson, G.V. The interrelationship between selective tau phosphorylation and microtubule association.

Brain Res. (1998) 798:173-83.

Yankner, B., Caceres, A., Duffy, L. Nerve growth factor potentiates the neurotoxicity of beta amyloid. Proc. Natl. Acad. Sci. (1990) 87:9020-9023.

Yuan, J., Shaham, S., Ledoux, S., Ellis, H.M., Horvitz, H.R. The C. elegans cell death gene ced-3 encodes a protein similar to mammalian interleukin-1 $\beta$-converting enzyme. Cell (1993), 75:641-652. 



\section{Neuronal kinase stimulation leads to aberrant tau phosphorylation and neurotoxicity}

Rony Nuydens, Mirjam de Jong, Roger Nuyens, Frans Cornelissen, Hugo Geerts

Department of Cell Physiology, Life Sciences, Janssen Research Foundation, Beerse, Belgium

Neurobiology of Aging, 16, 3, 465-477, 1995

Abstract

Neurofibrillary tangles in Alzheimer's disease brain consist mainly of abnormally phosphorylated tau proteins, organized in paired helical filaments. Induction of tau phosphorylation in living neurons by hyperstimulation is monitored by specific monoclonal antibodies, such as AT8 and PHF-1. By quantitative immunocytochemistry, we show that aberrant phosphorylation at the Ser199/Ser202 epitope (AT-8) and at the Ser 396 epitope (PHF-1) are moderately induced, proportionally to the degree of kinase stimulation. While AT8 expression is prominent after $48 \mathrm{hrs}$, cell death becomes significant at $72 \mathrm{hrs}$ and is related to 
the degree of stimulation and the expression level of aberrant tau phosphorylation. Time-lapse videomicroscopy of individual neuroblastoma cells suggest that hyperstimulation leads to a form of morphological over-differentiation. Immediately before cell death, some cells tend to display some features of mitosis. The data suggest a strong correlation between the expression of specific PHF-epitopes and subsequent cell death. The extended time scale of toxicity in this model may be appropriate to study in more detail the steps leading to aberrant phosphorylation associated neurotoxicity.

\section{Introduction}

Alzheimer's disease is characterized by two key neuropathological hallmarks, i.e. neurofibrillary tangles and B-amyloid deposits. A modified form of tau makes up most of the neurofibrillary tangles (Brion et al., 1985). These modifications are thought to be a consequence of impaired kinase/phosphatase equilibrium (Gong et al., 1993) leading to aberrant phosphorylation, both in stochiometry and at inappropriate positions along the tau protein. It has not been possible so far to implement neurofibrillary tangle-related pathology in vivo. Therefore, only in vitro cell culture models are available to study the sequence leading to neurodegenerative modifications of the cytoskeleton. The study of the aberrant phosphorylation sites on the tau protein has been greatly simplified by the availability of very specific monoclonal antibodies. The phosphate-sensitive AT- 8 antibody recognizes the aberrant phosphorylation site at Ser 199 and/or Ser 202 (Mercken et al., 1992), whereas the PHF-1 antibody recognizes only the phosphorylated Ser 396 position 
(Bramblett et al., 1993). Other interesting antibodies include the phosphorylation-sensitive $\mathrm{C} 5$ and $\mathrm{M} 4$, reacting respectively to the residues 386-406 and the region between 198-250 (Hasegawa et al., 1993). Blocking phosphatase activity with okadaic acid, a phosphatase $2 \mathrm{~A}$ inhibitor rapidly induces AT-8 epitopes in LA-N-5 cells (Vandermeeren et al., 1993) and in cultured rat cortical neurons (Arias et al., 1993). In addition glutamate induces Alz-50 epitopes in primary hippocampal neurons (Mattson, 1990) and AT8 epitopes in cerebral cortex cultures (Sindou et al., 1994). Extensive kinase stimulation by a mixture of NGF, db-cAMP, Na-butyrate and gangliosides (also termed hyperstimulation) has been shown to induce aberrant phosphorylation epitopes in the human IMR32 cell line, but not in the SK-N-MC and SK-N-SH cell line (Ko et al., 1990). We have studied the effects of such a hyperstimulation in the human neuroblastoma cell line TR 14 (Rupniak et al., 1984) and in rat neonatal hippocampal cultures by means of quantitative immunocytochemistry of AT- 8 and PHF-1. We extend this model to include toxicity as an end-point and investigate the relationship between tau phosphorylation and subsequent cell death. Furthermore, using time-lapse videomicroscopy we document the dramatic morphological changes following aberrant tau-phosphorylation and events immediately prior to cell death.

\section{Materials and methods}

\section{Materials}

TR14 neuroblastoma cells (gift of Dr. G. Carmeliet, Center for Human Genetics - KU Leuven) were grown at $37^{\circ} \mathrm{C}$ in DME/F12 medium supplemented with $10 \%$ FCS in a hurnidified incubator supplied with $95 \%$ air and $5 \% \mathrm{CO}_{2}$. For the actual experiments the cells were harvested from flasks by mild trypsinization and plated on ethanol sterilized and poly-L-lysine (i00 $\mu \mathrm{g} / \mathrm{ml})$ coated coversiips.

Twenty-four hours after plating the medium was changed to differentiation medium (NI medium). This medium consisted of DME/F12 medium suppiemented with $2 \mathrm{mM}$ L-Glutamine, $15 \mathrm{mM}$ HEPES and the N1 
components insulin $(5 \mu \mathrm{g} / \mathrm{ml})$, transferrin $(100 \mu \mathrm{g} / \mathrm{ml})$, progesterone $(20 \mathrm{nM})$, putrescine $(100 \mu \mathrm{M})$ and Na-selenite $(30 \mathrm{nM})$ (Bottenstein and Sato, 1979). For the hyperstimulation medium the following components were added : NGF (100 ng/ml), db-cAMP (1 mM), $0.5 \mathrm{mM} \mathrm{Na-butyrate} \mathrm{and} 10 \mu \mathrm{g} / \mathrm{ml}$ gangliosides (Ko et al., 1990). The mixture of these four components, used at this concentration, was defined as a single strength unit for hyperstimulation. NGF (Nerve Growth Factor) was obtained from Boehringer, db-cAMP (dibutyryl cyclic AMP), gangliosides and Na-butyrate from Sigma and okadaic acid from Kayima Biomedical.

Rat hippocampal neurons were isolated from 14 day old rats as described previously (Geerts et al., 1992). Briefly, rats were killed by decapitation and the hippocampi were dissected on ice. Tissue blocks were trypsinized and mechanically dissociated by repeated suction through a Pasteur pipette. Cell suspension was collected in DMEM containing 10\% FCS and washed twice by mild centrifugation. Finally the resulting cell suspension was plated on ethanol sterilized and poly-L-lysine $(100 \mu \mathrm{g} / \mathrm{ml})$ coated glass coverslips in Nunc Petri-dishes (Gibco Europe, Gent Belgium) with DMEM $+10 \%$ FCS. The next day the medium was changed to Chemically Defined Romijn Medium (Romijn et al., 1984) containing cytosine arabinoside; the medium was further changed every third day. For the hyperstimulation medium the components were added to the Romijn medium.

\section{Immunocytochemistry}

Cells were fixed with $4 \%$ paraformaldehyde in PHEM buffer (Schliwa and Van Blerkom, 1981) for $20 \mathrm{~min}$ at roomtemperature, washed with PHEM buffer and permeabilized with Triton X-100 $0.5 \%$ for $30 \mathrm{~min}$ in PHEM buffer. Unreacted aldehyde groups were reduced during a $20 \mathrm{~min}$ treatment with 0.5 $\mathrm{mg} / \mathrm{ml} \mathrm{NaBH}_{4}$ in PHEM.

Staining was performed at room temperature in Tris-buffered saline (TBS; $10 \mathrm{mM}$ Tris, $140 \mathrm{mM} \mathrm{NaCl}$ and $0,1 \% \mathrm{BSA}, \mathrm{pH} 7.6$ ). After a $30 \mathrm{~min}$ incubation with $5 \%$ Normal Goat Serum the cells were incubated overnight with the primary antibodies diluted in $1 \%$ Normal Goat Serum $1 / 100$ for AT8 (gift of Dr. E. VanMechelen, Innogenetics, Ghent, Belgium) or 1/10 dilution 
for the antibody PHF-1 (gift of Dr. S. Greenberg, White Plains, NY, USA). After washing with TBS the cells were incubated with a $1 / 10$ dilution of $5 \mathrm{~nm}$ gold -conjugated GAR (Goat anti Rabbit) or GAM (Goat anti Mouse) (Amersham) for $3 \mathrm{hr}$. The cells were then washed thoroughly in TBS and finally with Aq. Bidest prior to silver intensification after which the preparations were mounted in Gelvatol.

For immunofluorescence in hippocampal cultures, the same steps were performed, except that the secondary antibody staining was performed with a FITC-conjugated GAM and TRITC-conjugated GAR (Nordic Immunologicals, Tilburg, The Netherlands).

Alkaline phosphatase treatment was performed in $100 \mathrm{mM}$ Tris- $\mathrm{HCl}$ pH 8.0 containing 130 units Alkaline Phosphatase (Boehringer Mannheim, Germany), $10 \mu \mathrm{g} / \mathrm{ml}$ pepstatin, $10 \mu \mathrm{g} / \mathrm{ml}$ leupeptin and $1 \mathrm{mM}$ PMSF for $2.5 \mathrm{hr}$ at $32^{\circ} \mathrm{C}$.

\section{Quantitative epi-polarisation immunocytochemistry}

The preparations with immunogold silver-staining were observed in epi-polarisation mode on a Axiovert 35 microscope (Zeiss Oberkochen, Germany) equipped with a Marzhauser scanning stage and Chalnicon Panasonic Camera, and digitized by a Series 200 Image Processor (Imaging Technology, Woburn, MA, USA). Image analysis was performed in TCL (Delft University, The Netherlands) on a VaxStation 3400 (DEC, Maynard, USA). In each image the total number of cells and the degree of epitope expression were determined by fully automatic dual thresholding. Briefly, cells and neurites were detected by a Have edge-detection routine followed by a holeclose operation. This ensured correction for varying background. The resulting binary image, containing only the cell bodies and neurites was labeled and non-specific small objects. were discarded by rejecting objects with a size below a certain limit. From this labeled image, the epi-polarisation image of each individual (cellular) object $\mathrm{n}$ was reconstructed by anding the original image with a binary image, derived from the labeled image containing only pixels belonging to that cell $\mathrm{n}$. In this image, the colloidal gold signal was detected as bright pixels with saturating grey-values (i.e. 255). These operations ensured that background gold pixels not associated with individual 


\section{Chapter 2}

cells were discarded. The number of the gold pixels associated with the cells was summed and the area fraction was calculated as the total area covered by the gold particles (in pixel) relative to the total cell area (also in pixel).

Measures were taken so that the optical acquisition and the digital detection were reproducible to minimize interexperimental variability.

\section{Quantitative immunofluorescence}

For quantitative immunofluorescence, double-label preparations, were observed on a Zeiss Axiovert microscope in epi-fluorescence mode with a double line-filter (FITC/Texas Red filter, Zeiss \#487924), enabling to detect both fluorescent probes in the same image. The RGB signals of a color camera (SONY 3CCD-DXC 930P) were individually digitized by a frame grabber (Series200, Imaging Technology) so as to separate the contributions of each individual probe into two individual images. This ensured minimal registration differences between the two images. The two images were then analyzed interactively on a DecStation 5000/200 workstation, using the program SCIL (Univ. of Amsterdam. The Netherlands). Briefly, a region of interest containing a long axon, was determined interactively starting from the red fluorescent (Rhodamine) image. This image was binarised automatically by an isodata thresholding algorithm to detect the individual axon after which mean fluorescence intensity was determined along this axon. The binary image of the Red channel was then ANDED with the image of the Green channel (FITC-label) to calculate the mean intensity along the axon corresponding to the FITC-probe.

\section{Quantification of toxicity}

For neurotoxicity measurements, the Live/Dead technique (Molecular Probes, Oregon, USA), was used. This technique measures the fraction of biochemically active cells with regard to the total number of cells. Briefly, cells were labeled with Calcein Acetoxy-Methylester (a membrane permeable and non-fluorescent probe) which is cleaved by intracellular cytosolic esterases and becomes well-retained in living cells, giving an intensely green fluorescent product. Propidium iodide, a nucleic acid stain fluorescing red after excitation 
with blue light, is excluded from living cells and stains only the nuclei of cells with damaged celi mernbranes. The double line filter (FITC/Texas Red filter, Zeiss \#487924) was found to give a clear color distinction between live and dead ce!ls.

Images are taken in epi-fluorescence mode on the Axiovert 35 microscope, equipped with the Marzhauser scanning stage and a color camera (SONY 3CCD-DXC 930P), the RGB signals of which are digitized by a DASM frame grabber (Analogic Devices, USA). Synchronization of the scanning stage and on-line analysis of the images is performed by a DecStation 5000/200 (DEC, Maynard, USA). The RGB signal, in conjunction with the double line filter assures a net distinction between the calcein signal in the green color channel and the propidium iodide signal in the red color channel. On-line analysis is performed by simple thresholding the images obtained in each channel. counting objects and areas, excluding dust particles by setting a lower size limit and calculating the survival parameter.

Cell viability in the hippocampal culture was quantitatively assessed by light microscopic evaluation (phase contrast) of 100 matched hippocampal neurons. Cells exhibiting blebs or without the typical phase contrast halo were considered dead. The same fields were observed over a number of days with the aid of a computerized microscope stage (Marzhauser, W. Germany), so that matched neurons could be followed.

\section{Time-lapse videomicroscopy}

For time-lapse videomicroscopy, cells were mounted in a closeci chamber on the stage of a Zeiss Axiovert microscope. Temperature was constantly adjusted at $37^{\circ} \mathrm{C}$. Cells were observed under phase-contrast illumination with a $10 \mathrm{x}$ objective. Images were taken by a MX5 CCD camera (HCS, Eindhoven, Netherlands) and taped onto a U-matic video-recorder (SONY V5580 P). A field containing several cells was followed over a period of $24 \mathrm{hr}$ in time-lapse mode by using an HC580 animation control unit built by EOS (Barry, U.K.). As a rule, the recorder was instructed to grab two frames every $10 \mathrm{sec}$. This yielded a continuous video-sequence in which movement was accelerated by a factor of about 250 . Phototoxicity was reduced by illuminating the samples 
only during video-taping. This was achieved by a synchronous opening of a Uniblitz shutter (Vincent Associates), the timing of which was controlled by the EOS unit.

\section{Statistics}

Student's t-test was employed for statistical data analysis of cell survival assays, while Mann-Whitney test was used in the quantitative immunocytochemistry experiments.

\section{Results}

The hyperstimulating medium in human TR14 cells Exposure of the human neuroblastoma TR 14 cells for 3 days to the hyperstimulating medium induced a marked differentiation (Fig.1). There was extensive morphological differentiation as evidenced by neurite outgrowth, but a certain number of cells had a shrunken and necrotic appearance characteristic of neurotoxicity. The number of necrotic cells was proportional to the strength of kinase stimulation. Increasing the hyperstimulation doses was indeed correlated with a marked enhancement of neuronal differentiation and with increased morphological signs of cell death.

The AT- 8 and PHF- 1 epitopes were expressed mostly in cell bodies and in proximal parts of the neurites. There was a large increase in staining intensity upon application of the hyperstimulation medium. The expression level of the PHF-1 epitope was always larger than the level of AT8 expression. No apparent difference between spatial localization of these two epitopes was prominent.

Figure 1: Representative fields of immuno-gold silver-staining of TR14 cells $(a, b, c, d, e)$ and $\mathrm{N} 4$ cell cultures $(\mathrm{f})$ in unstimulated $(\mathrm{a}, \mathrm{c})$ and hyperstimulated conditions $(\mathrm{b}, \mathrm{d}, \mathrm{e}, \mathrm{f})$. Immunocylochemistry is pertormed with AT-8 epitope $(a, b, e, f)$ and with PHF-1 (c,d). These images are taken by epi-polarisation illumination and photographed directly from the monitor. Notice the increase in AT3 epitope expression in hyperstimulated TR14 cells (compare 1a to $1 \mathrm{~b}$ ). Similarly, the hyperstimulating medium increases significantly the PHF-1 expression (compare $1 \mathrm{c}$ to $1 \mathrm{~d}$ ). Finally, applying this hyperstimulation to N4. cells fails to induce ATB expression (fig 1t). 


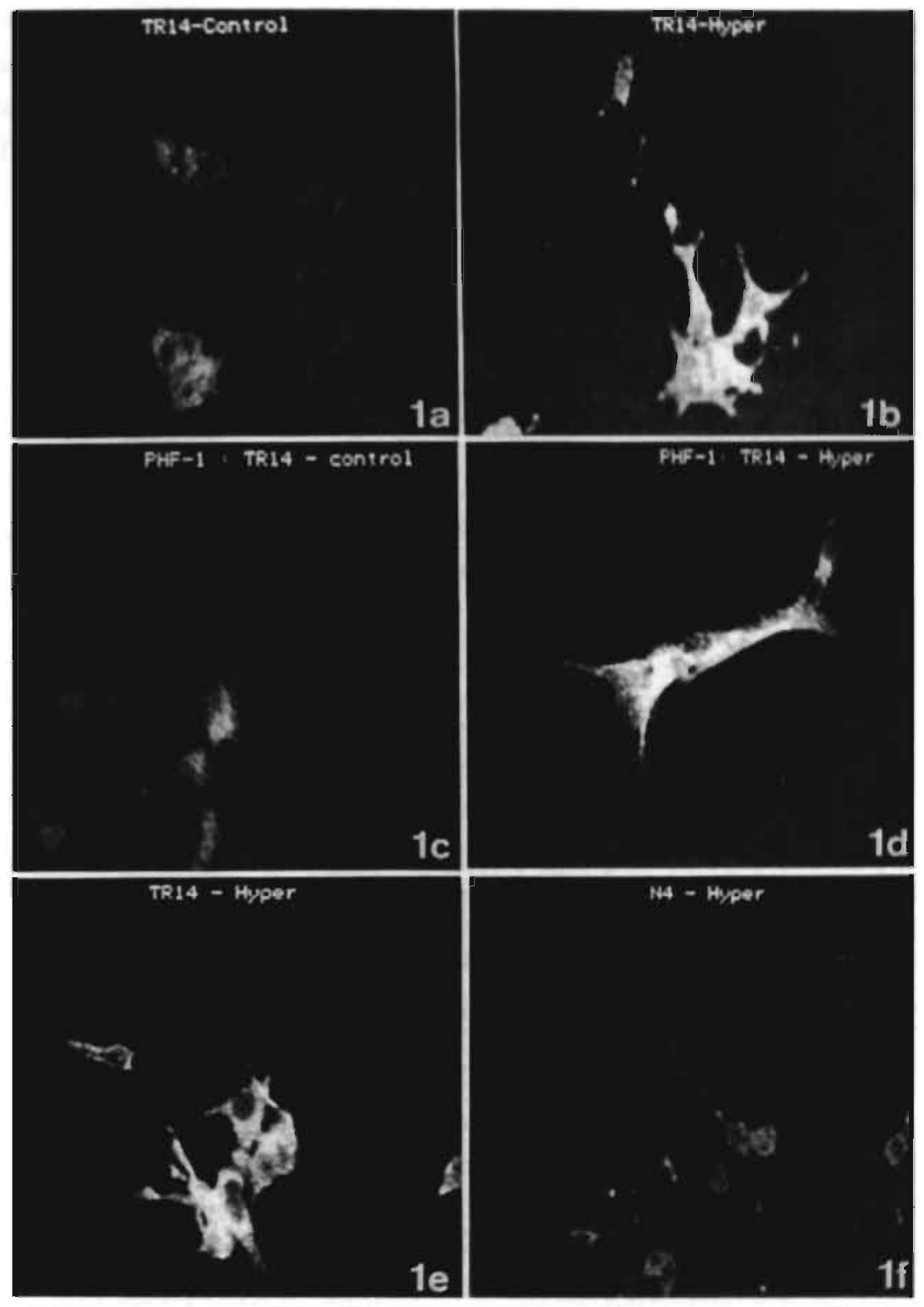


When studying quantitatively the time dependence of AT8 epitope expression (Fig. 2), a large increase became prominent after $48 \mathrm{hr}$. The data also suggested that co-incubating the cells with $10 \mathrm{nM}$ okadaic acid, an inhibitor of protein phosphatase activity, which by itself did not induce any marked increase in AT8 expression, was able to enhance the aberrant phosphorylation of tau in the stimulated cultures, especially at earlier time points. Treatment of the TR14 cells with $1 \mu \mathrm{M}$ okadaic acid induced rapid cell death (data not shown).

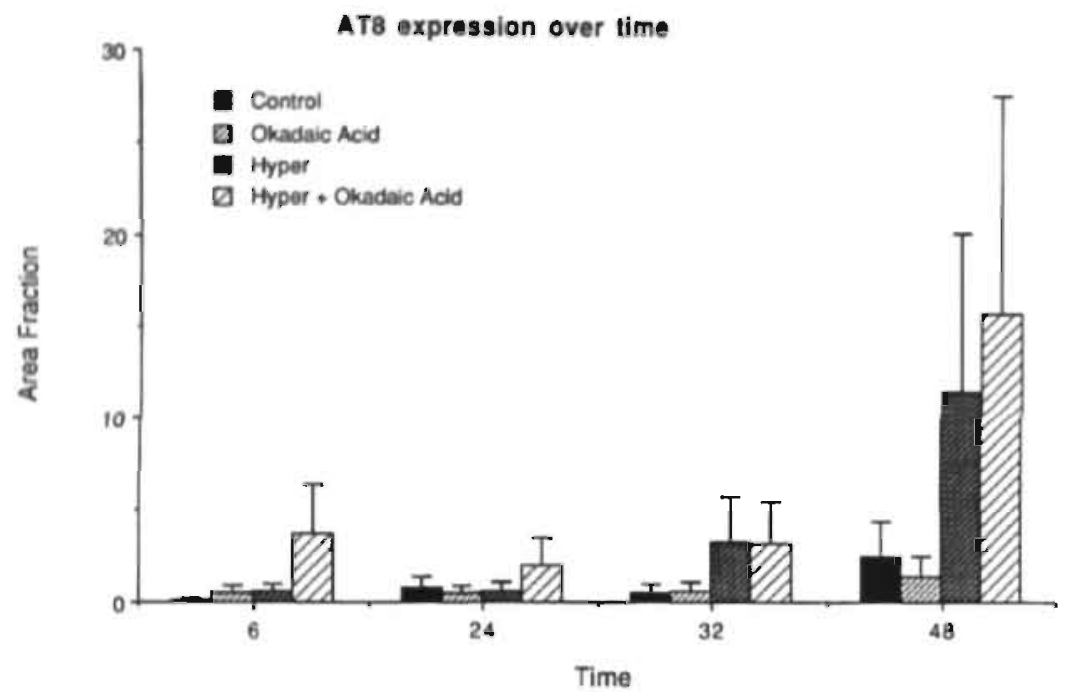

Figure 2: Time-dependent increase in AT-8 epitope expression in TR14 neuroblastoma cells (representative of a typical experiment). Epitope expression is measured as the fraction of area covered by AT-8 related immunogold silver staining contained within the cell body and neurites and normalized with regard to the area of the cell body. It is clear that already after 24 h, AT- 8 epitopes are increasedl. Inhibition of phosphatase activity by okadaic acid $(10 \mathrm{nM})$ further increases expression of AT-8 epitopes, especially at earlier time points.

Quantitative immunocytochemical studies after 3 days of exposure to different strengths of hyperstimulation revealed that the staining of AT- 8 epitopes in the human neuroblastoma cell line TR 14 dose-dependently increased with the doses of hyperstimulation medium. Fig 3 shows the results of a typical experiment. We have observed the same increase in AT8 epitope expression in two other independent experiments. 


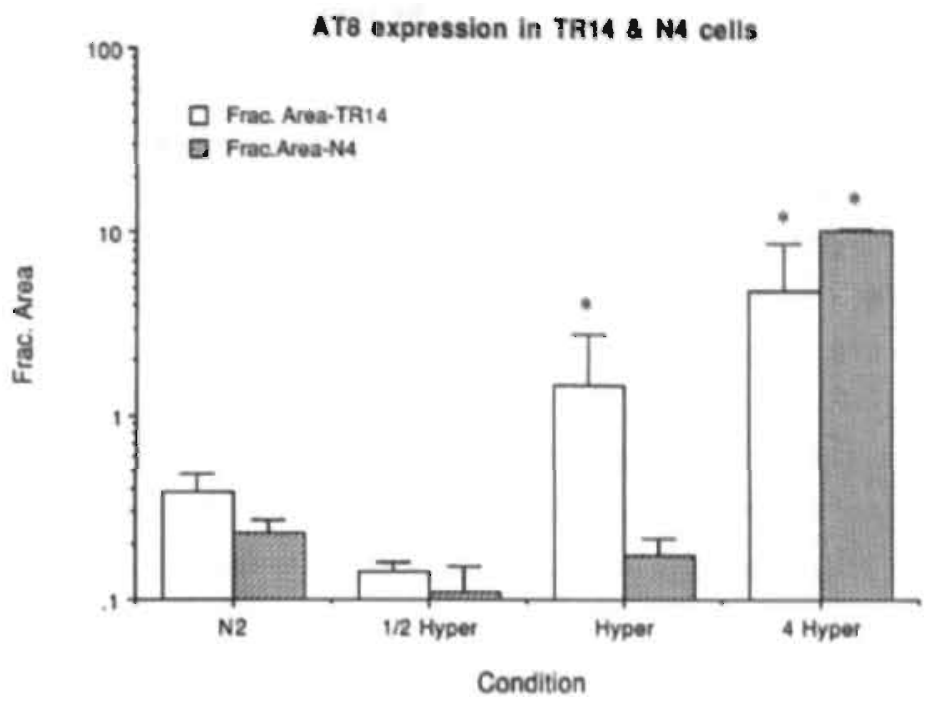

Figure 3: Expression of AT-8 epitope in TR14 cells and in N4 cells, after 3 days of exposure to various strengths of hyperstimulation. It is clear that the expression of this epitope is increased proportionally to the hyperstimulating strength. The increase in N4 cells is much less pronounced at similar hyperstimulation strengths, except at the highest dose where cell detachment due to toxicity interferes in the case of TP14 cells. Mean and SEM are calculated over 45-95 cells in case of TR14 and over 109-233 cells in the case of $\mathrm{N} 4$ cells. $P<0.05$, Mann-Whitney U-test on the mean of area fraction over the population of all cells in the stimulated condition with regard to the cells in the control situation.

When assaying neurotoxicity in a quantitative way, concentration-dependent increase in hyperstimulation strengths resulted in a dose-dependent decrease in viability of TR 14 cells down to $20 \%$ at the highest dose of hyperstimulation medium (Fig. 4). 


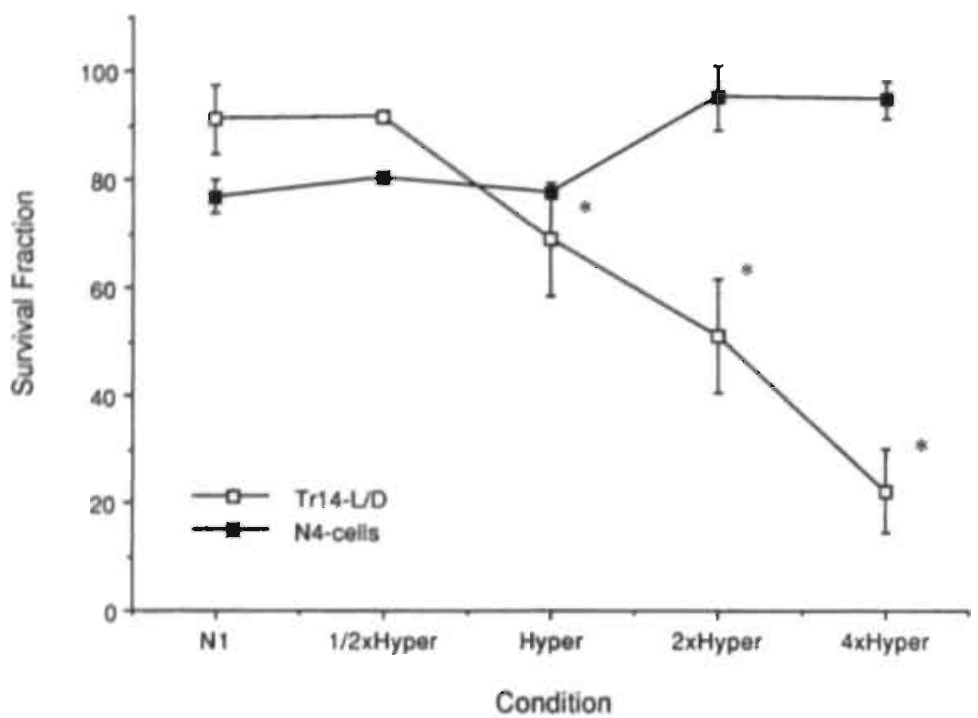

Figure 4: Relative survival of TR14 and N4 cells after 3 days of exposure to various strengths of hyperstimulating medium. The experiment is performed in triplicate. Dose-dependently increasing the strength of kinase stimulation is related to increasing cell toxicity in TR14 cells. The N4 cells do not undergo any neurotoxicity. " $P<0.05$, Student's t-test on paired samples

\section{Hyperstimulating medium on mouse $\mathrm{N} 4$ neuroblastoma cells}

When mouse neuroblastoma cells N4 were treated with the same hyperstimulating medium, a comparable morphological differentiation response was observed. However, within the time window studied ( 3 days), cells almost completely survived, suggesting that these cells were not as sensitive to this form of kinase stimulation. Only at 4 strengths of hyperstimulation medium, there was an increase in AT-8 epitope expression. However, even under these conditions necrotic cells were scarce and most cells had a viable morphological appearance.

It was also clear by quantitative immunocytochemistry that in the mouse neuroblastoma N4 cells the expression of AT8-epitopes becarne prominent only at 4 strengths of hyperstimulation, suggesting these cells needed higher doses 
of kinase stimulation (Fig. 3). In contrast to the effects on human TR14 cells, no toxic effect on mouse neuroblastoma N4 cells was evident (Fig 4).

Effect of calcium overload

We further studied various aspects of this model by exposing the cells to conditions, which lead to intracellular calcium accumulation. The TR14 cells did not express glutamate receptors, as chronic exposure to $1 \mathrm{mM}$ of glutamate failed to stimulate AT-8 epitope expression and subsequent cell toxicity (data not shown).

Chronic exposure for 3 days to high extracellular $\mathrm{K}^{+}$-concentrations (10-50 $\mathrm{mM}$ extracellular) to depolarize cell membranes to a varying degree failed to induce aberrant phosphorylation of tau, as assessed by AT- 8 expression (Table I). However, neurotoxicity became apparent, probably as a consequence of calcium overload. These data suggested that AT8 expression is not associated with calcium-overload induced cell death.

Table 1. Chronic depolarization of TR14 cells leads to toxicity in the absence of AT8 expression.

\section{Condition}

Control

$10 \mathrm{mM} \mathrm{K}$

$15 \mathrm{mM} \mathrm{K}$.

$25 \mathrm{mM} \mathrm{K}^{*}$

$50 \mathrm{mM} \mathrm{K}^{*}$

Hyper

\section{Area Fraction (\%)}

0.07

0.069

0.469

0.082

0.045

20.4

\section{Cell Survival (\%)}

$81 \pm 5$

N/A

N/A

$37.6 \pm 21^{* *}$

$4,3 \pm 7^{* 0}$

$69 \pm 2.1^{\circ}$

Cells are treated for three days with the indicated $\mathrm{K}^{*}$ concentrations added as $\mathrm{KCl}$ to the N1 medium. Cells were fixed and processed for quantitative immunocytochemistry as described in the text. Area fraction is the relative area occupied by AT8 epitope, contained within cell bodies and neurites and normalized with regard to cell area (\# of cells studied range from 39 to 51 ). Cell survival fraction is measured in parallel experiments with the Live/Dead technique (500-1000 cells). This experiment is performed in triplicate. Mean and Standard Deviation are shown. " $P<0.05$, "* $P<0.01$, Student's t-test on paired samples 


\section{Effect of morphological differentiation}

In order to study the relationship between morphological differentiation and expression of aberrant tau epitopes, the TR 14 cells were stimulated with $1 \mathrm{mM}$ db-cAMP. This treatment yielded highly differentiated neurons, where neurites had almost double the length compared to controls. Only a slight increase in epitope expression was observed after 3 days of incubation with this membrane-permeable form of cAMP. A quantitative study of PHF-1 expression, showed that the epitope expression in TR 14 cells is slightly enhanced upon differentiation with $1 \mathrm{mM}$ db-cAMP (area fraction increases from $5.3 \%, \mathrm{n}=96$ cells to $13.9 \%, \mathrm{n}=119$ cells). No toxicity was ever observed under this condition. However, upon exposure to the complete hyperstimulation medium, the area fraction increased to $32.1 \%, \mathrm{n}=109$ cells with a concomitant increase in toxicity .

\section{Time-lapse experiments on the hyperstimulation induced cell death}

In order to document the steps leading to aberrant phosphorylation of tau and subsequent cell death, time-lapse videomicroscopy on human TR 14 cells was used to follow the morphological changes induced during hyperstimulation (Fig. 5). Immediately after application of components at concentrations corresponding to 4 strengths of hyperstimulating medium, ruffling activity at the growth cone markedly increased and neurites became rapidly extended. The induction of differentiation was so drastic, that two daughter cells arising from a mitotic cell, in late telophase already developed extensive neurite extensions, long before complete separation of the cell bodies had taken place. This enhanced activity was sustained until suddenly, dramatic changes took place. The cell rapidly retracted its neurites, leaving only filamentous traces. Typically, the retraction began at the distal end and proceeded retrogradely down to the cell body. At several occasions during the agony of a single cell we observed a tendency for cytokinesis or cytoplasmic cleavage, as if the cell decided to form a midbody incisure, characteristic of late telophase within the mitotic cycle. This process did not complete, as the cell death suddenly became apparent as an implosion of the cell body, leaving a highly rounded and shrunken perikaryon which became very bright in phase-contrast 

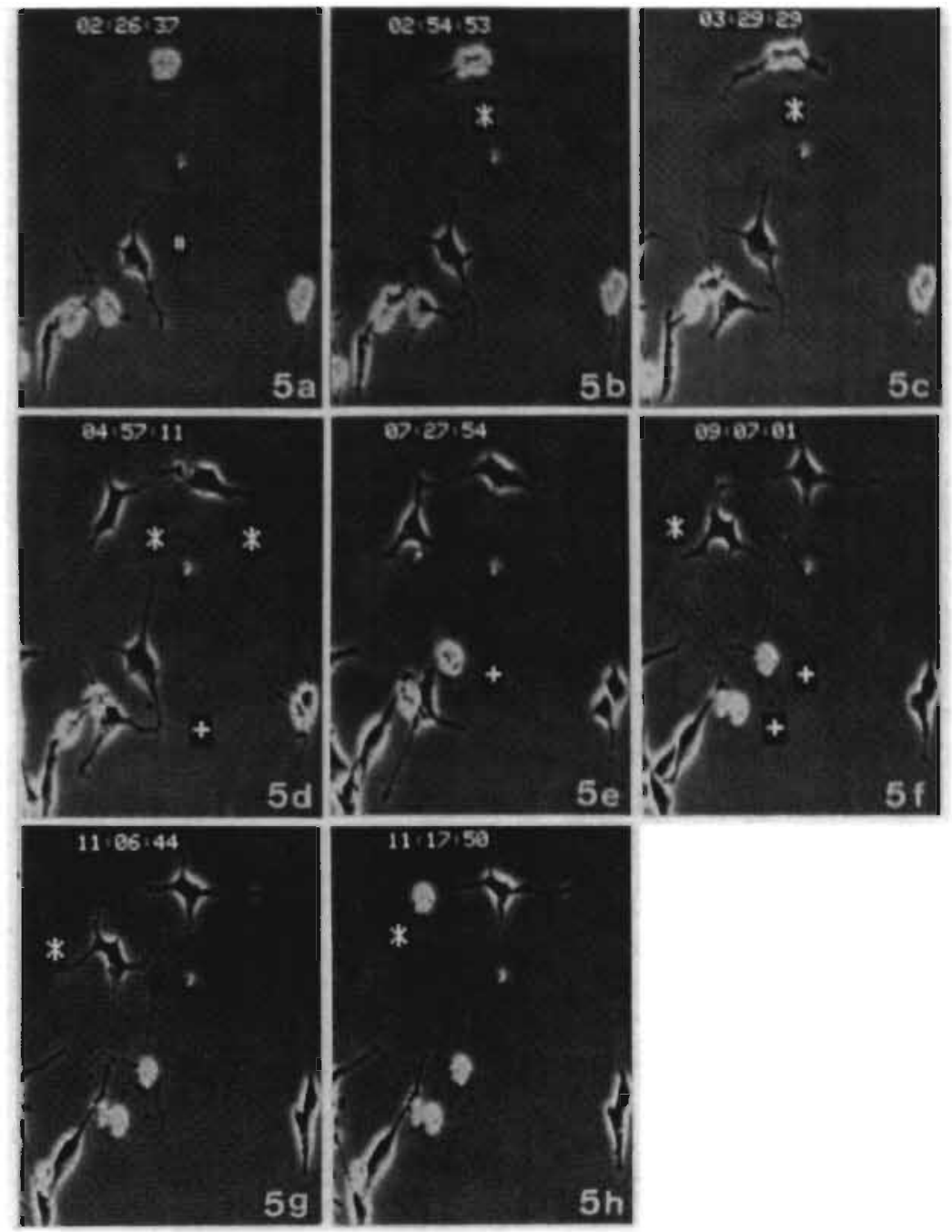

Figure 5: Different images from a time-lapse experiment, showing various stages, after hyperstimulation. Time indication is at the top of the image. Observe the two cells (asterix *). At early times, extensive neurite extension is prominent before cell mitosis is fully completed and cells are completely detached from each other (fig. a,b,c). A more fully differentiated phenotype is visible at later times (d). Notice the appearance of a distorted cell body in (starting in f) (asterix), similar to a cytokinesis or midbody furrow cleavage of late telophase. In (h), which is taken 11 min later, the cell body has imploded and the cell has died. Two other cells are making contact (plus +).

The contact is reached at (d), but at time point $(e)$ one of the two cells dies. Some two hours later the other cell follows the same fate (f). 
microscopy. This process was very fast and lasted usually between 15 and 30 min. All signs of activity then ceased. The sensitivity of the neurons for this aggression was very heterogeneous, as we observed two daughter cells from the same neuroblastoma cell, the one dying after $660 \mathrm{~min}$, whereas the other one survived for an additional $80 \mathrm{~min}$.

\section{Effect of tau hyperphosphorylation on hippocampal neurons}

We further investigated the effect of this hyperstimulating medium on primary cultures of fully differentiated rat neonatal hippocampal neurons. It has been shown previously that appropriate stimulation of hippocampal neurons may induce Alz-50 and AT8 epitope expression (Mattson et al., 1990; Sindou et al., 1994) . In addition, freshly isolated rat brain tau features AT8 epitopes [Goedert et al., 1993; Hasegawa et al., 1993)], showing that the phosphorylated rat tau epitope equivalent to the human Ser199/202 epitope is readily recognized by AT8.

When hippocampal neurons were allowed to attach for $24 \mathrm{hr}$ after isolation in serum-containing medium and then switched to conditioned Romijn medium for 7 days, they develop a mature differentiated phenotype. Axons could then be identified very easily as the longest thin neurite extending from the cell body. Adding the hyperstimulation medium at this point induced AT- 8 epitope expression within 3 days, mainly in the cell body and the proximal parts of the axon (Fig.6) . Double-label immunofluorescence was used to assess the quantitative relationship between phosphorylated (as detected by the monoclonal antibody AT8 in the FITC channel) and total tau (as detected by the polyclonal antiserum in the TRITC channel). Quantitative analysis of the ratio of fluorescence signal revealed that hyperstimulation increased the contribution of the phosphorylated tau epitope along the axon (from 1.08 \pm 0.17 . $\mathrm{n}=41$ cells in the control situation to $1.98 \pm 0.21, \mathrm{n}=32$ cells in the hyperstimulating conditions, $\mathrm{p}<0.01$, Mann-Whitney test).

From fig. 6 it was also clear that expression of any tau epitope was markedly absent in fibroblasts. Morphological observation of cell survival of matched selected cells, shows that after $24 \mathrm{hr}$, cell survival drops to $72 \%$ in stimulated conditions (versus $95 \%$ in control conditions). After two days, cell survival 

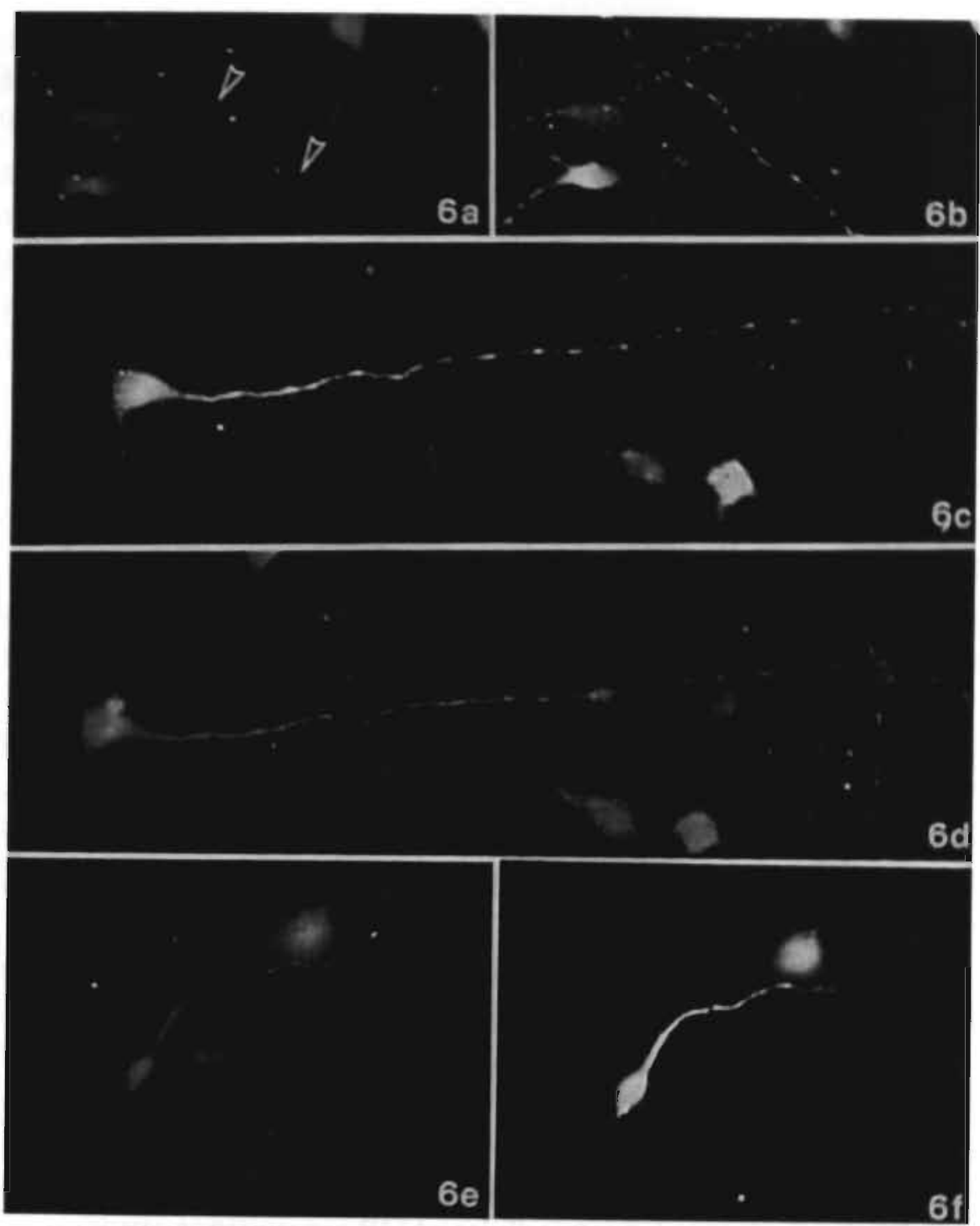

Figure 6: Double-label immunofluorescence of primany rat neonatal hippocampa! neurons, treated for 2 days with control conditions $(a, b)$ or hyperstimulating medium $(c, d, e, f)$. The cells in $(e, f)$ have been treated with alkaline phosphatase after fixation. Expression of AT- 8 is shown with FITC-labeling $(a, c, e)$, whereas modamine is used to visualize polyclonal tau $(b, d, f)$. Notice the axon (arrows in a), the fluorescence is very weak compared to the same axon in $6 \mathrm{~b}$. This ratio of AT8/pTau is increased in hyperstimulating conditions (compare $6 c$ to $6 \mathrm{~d}$ ). This increase in epitope expression is phosphatase dependent (compare $6 e$ to $6 f$ ). 
decreased to $59 \%$ (92\% in control conditions) and after 5 days of hyperstimulation, only $21 \%$ of the cells were alive (versus $69 \%$ in control conditions). At these stage, there was no evidence of any marked toxicity to nonneuronal cells, such as fibroblasts or astrocytes.

\section{Discussion}

\section{The hyperstimulating medium}

This report documents an in vitro system of aberrant tau-phosphorylation in human neuroblastoma and rat neonatal primary hippocampal cultures, based on the excessive stimulation of a variety of protein kinases. It is shown that hyperstimulation of neurons leads to a moderate increase in PHF-epitopes already after $24 \mathrm{hr}$, but that neurotoxicity becomes only evident after 3 days. Furthermore, this neurotoxicity is related to the degree of PHF-epitope expression, as the fraction of surviving cells decreases with increasing level of PHF-epitopes.

Which of the four components in the hyperstimulating mixture can be held responsible for the observed expression of PHF-epitopes, is unclear for the moment.

Protein Kinase A activation has been shown to phosphorylate tau in vitro thereby reducing its electrophoretic mobility on sodium dodecyl sulphate polyacrylamide gels (Robertson et al., 1993). Although this phosphorylation does not include Ser396 (as in PHF-tau) or Ser416 (phosphorylated by calcium/calmodulin kinase II), PKA may be involved in the generation of PHF-tau by acting on yet unidentified sites. However, in rat adipocytes as well as in CHO cells, increasing intracellular CAMP concentration attenuates activation of MAP-kinase by insulin, one of the kinases involved in the phosphorylation of Ser $199 /$ Ser202 site, recognized by the monoclonal antibody AT-8 (Sevetson et al., 1993). In view of the observation that merely differentiating TR14 cells with ImM db-cAMP did not increase PHF- ! expression to a large extent, it is highly unlikely that a cAMP dependent 
pathway gives a major contribution to the observed aberrant phosphorylation. Gangliosides have been considered to potentiate NGF-receptor activity (Matta et al., 1986) and to affect a number of kinases, including A kinase, C kinase (Chan, 1987) . However, most recently ganglioside GMI and GDI have been shown to increase phosphorylation on GAP-43 in intact isolated growth cones. This phosphorylation takes place on a site different from the Ser 4 I, the protein kinase $\mathrm{C}$ phosphorylation site, and is presumably mediated by inhibition of a protein phosphatase (Meiri and Beverly, 1994). This indicates that gangliosides may increase the phosphorylation status by activating protein kinases as well as inactivating phosphatases.

Nerve Growth Factor has been shown to activate a complex pathway after binding to its high-affinity receptor trkA. This includes activation of a MAP-kinase downstream, which in vitro has been documented to increase AT8 expression on recombinant human tau (Drewes et al., 1992). Whether TR 14 cells have NGF-receptors is unclear. Rat hippocampal neurons, on the other hand, have been shown to be unresponsive to NGF (Ip et al., 1993), but another report suggests that NGF at $10 \mathrm{ng} / \mathrm{ml}$ is able to protect rat hippocampal neurons against hypoglycemic damage (Cheng and Mattson, 1991).

The cellular actions of sodium butyrate have been less characterized. In neuronal cells, the compound has been shown to increase the activity of tyrosine hydroxylase, choline acetyltransferase, acetylcholinesterase, catechol-o-methyltransferase and adenylate cyclase and to inhibit the activity of lactate dehydrogenase and pyruvate kinase. In addition, sodium butyrate stimulates the synthesis of GM3 gangliosides and causes cell death only in human neuroblastoma and glioma cells (for a review see Prasad, 1980). There is evidence that sodium butyrate may act at the level of gene transcription by increasing the acetylation of histones, thereby releasing constraints upon the DNA template, probably by selective hypermethylation of transcribed nucleosomal DNA. (Boffa et al., 1994). In fact, treatment of Friend erythroleukemic cells has been shown to increase new RNA transcripts (Reeves and Cserjesi, 1979). Relevant to our discussion is the observation that sodium butyrate causes prominent morphological and biochemical differentiation in neuroblastoma cells in cultures (Prasad, 1980). 
The observed enhancement of aberrant tau expression with okadaic acid suggests that expression of PHF-epitopes may additionally be enhanced by blocking phosphatase activity. This is in line with other observations (Arias et al., 1993; Vandermeeren et al., 1993). This also indicates that this form of kinase stimulation does not saturate the level of aberrantly phosphorylated tau.

\section{The cytotoxic effect of hyperstimulation}

Even in the absence of serum in the medium, proliferation of the TR14 cells still continued, albeit to a much reduced degree. Therefore a method giving the absolute number of living cells and the absolute number of dead cells was. preferred over a classical one-point biochemical cell viability measurement, such as MTT conversion. Furthermore, differentiation enhanced the activity of mitochondrial conversion of MTT, as evidence from an increase in the MTT signal upon a 3-day treatment with $1 \mathrm{mM}$ db-cAMP' (data not shown). This could possibly be attributed to an increase in the number of mitochondria in differentiating conditions. Because the two fluorescent. compounds were just added to the medium without any washing step, detachment of dying cells was reduced, whereas in the case of quantitative immunocytochemistry, the extensive washing steps probably induced a marked detachment of dead cells. Therefore, the level of AT8 or PHF expression in the TR14 cells may be markedly underestimated. On the other hand, the AT8 expression in the N4 neuroblastoma cells, which do not display this degree of neurotoxicity probably reflects a more correct level.

\section{PHF-epitopes in rat hippocampal neurons}

We report the observation that moderate stimulation of kinase activity can trigger increased expression of the PHF-epitope AT8 in fully differentiated neonatal rat hippocampal neurons. The basal level of AT8 expression is already elevated, in line with observations that abnormal phosphorylation of tau recapitulates phosphorylation during development in human and rat (Goedert et al., 1993; Hasegawa et al., 1993). Therefore the overall increase in ratio 
AT8/pTau is moderate, when taken as a measure over the whole axon.

Sustained expression of these AT8 epitopes however, leads to enhanced cell toxicity. Furthermore, the cytotoxic effect associated with enhanced expression of AT8 seems to be specific with regard to the neurons, as fibroblasts and astrocytes, which are present in this primary culture model are relatively spared.

These experiments further suggest that expression of PHF-like epitopes can induce cell toxicity in fully differentiated neurons derived from rat neonatal hippocampus. This is an important observation in view of the well-documented vulnerability of the hippocampal neurons in Alzheimer's disease.

\section{Tau phosphorylation and morphological differentiation}

Aberrantly phosphorylated tau epitopes have been found in situations of extensive neurogenesis (Goedert et al., 1993; Hasegawa et al., 1993). In that context, expression of AT8 and PHF-1 epitopes may be related to neurite outgrowth and microtubule rearrangements. The high basal level of PHF-epitopes in the differentiating rat neonatal hippocampal neurons suggests that morphological differentiation such as axonal growth may involve selective, but reversible phosphorylation of tau at specific sites of rather instable microtubules. Indeed, phosphorylation of tau, especially at the Ser262 site has been shown to significantly reduce tau induced microtubule polymerization (Biernat et al., 1993).

The observation of an accelerated morphological differentiation (as evidenced by extensive and rapid neurite outgrowth) in our time-lapse experiments suggest that this form of sustained kinase stimulation may lead to an exhausting over-differentiation. The process of cell death induced by this hyperstimulating medium may involve an instability of the microtubule function. Indeed, in our time-lapse experiment, we often see a dramatic retraction of neurites, immediately before cell death. Although expression of AT8 or PHF-1 epitopes is not sufficient to decrease MIT polymerization polymerization (Biernat et al., 1993), PHF-tau isolated from the brain of AD patients has been found to markedly reduce microtubule polymerization (Iqbal et al., 1986). 
The morphological appearance of cell body constriction immediately before cell death, as we have observed in one cell is reminiscent of midbody formation in late telophase. Indeed, hyperphosphorylation of tau has been observed during mitosis in the human SH-SY5Y cell line (Pope et all., 1994) and also stimulation of cell cycle events has been linked to cell death in postmitotic Purkinje cells (Feddersen et al., 1992).

\section{This model of moderate pathology creates new opportunities}

The observations on the calcium-overload induced cell death and the absence of PHF-epitopes in this model, suggest that expression of aberrant phosphorylation on Ser199/Ser202 or Ser396 is not linked aspecifically to neuronal cell death. Although calcium-calmodulin dependent kinases have been shown to modify elasticity of the tau protein (Lichtenberg et al., 1988) and to shift the mobility of tau on Western blots, so far no induction of AT8 or PHF-1 epitope has been reported. One explanation still may be that calcium dependent kinases phosphorylate tau on yet unidentified residues, still leading to an aberrant phosphorylation degree.

The phosphorylation degree of tau in neurons is the result of a balanced equilibrium between kinase and phosphatase activity. A defective phosphatase activity has been documented in post-mortem tissue from Alzheimer patients (Gong et al., 1993). Application of a specific phosphatase inhibitor, such as okadaic acid, immediately induces an elevation of PHF-epitopes within the first $3 \mathrm{hr}$ (Arias et al., 1993; Vandermeeren et al., 1993), suggesting that the endogenous phosphatase activity is very high. In addition, the PHF-epitope, PHF-1, is rapidly lost from human biopsy material (Harris et al., 1993). This suggests that basal phosphatase activity even in postmortem tissue is sufficiently elevated to reduce the levels of aberrant tau phosphorylation. Therefore, gently increasing the level of kinase activity may lead to a moderate and more chronic form of pathology. This enables one to look more in detail at different steps for the appearance of PHF-epitopes. Furthermore, this opens the possibility to simulate more realistically the clinical situation, in which the patients may be diagnosed at a relatively late stage.

In summary, this report shows that overstimulation of different kinases in 
human neuroblastoma cells and in rat hippocampal neurons can lead to the expression of PHF-like epitopes and that this is linked to subsequent cell death.

\section{Acknowledgements}

The discussions with Dr. A. Chedarevian are highly appreciated. We are indebted to Dr. Greet Carmeliet (KU Leuven) for the clone of TR 14 ceils and to Prof. M. Joniau (KULAK, Kortrijk) for the clone of N4 cells. We thank Dr. E. van Mechelen (Innogenetics, Ghent, Belgium) for providing the AT8 antibody and to Dr. S. Greenberg (White Plains, New York USA) for the PHF-1 antibody. The skillful photographic work of L. Leijssen, G. Verheyen and G. Jacobs is highly appreciated. 


\section{References}

Arias, C., Sharma, N., Davies, P., Shafit, B. Okadaic acid induces early changes in microtubule-associated protein 2 and tau phosphorylation prior to neurodegeneration in cultured cortical neurons. Journ. of Neurochemistry (1993) 61:673-682.

Blernat, J., Gustke, N., Drewes, G., Mandelkow, EM, Mandelkow, E . Phosphorylation of Ser262 strongly reduces binding of tau to microtubules : distinction between PHF-like immunoreactivity and microtubule binding. Neuron (1993) 11:153-163.

Boffa, L., Mariani, M., Parker, I. Selective hypermethylation of transcribed nucleosomal DNA by sodium butyrate. Exp. Cell Res. (1994) 211:420-423.

Bottenstein and Sato. Growth of rat neuroblastoma cell line in serum-free supplemented medium. Proc. Nat. Acad. Sci USA (1979) 76:514-517.

Bramblett, G.T., Goedert, M., Jakes, R., Merrick, S.E., Trojanowski, J.Q., Lee, V.M. Abnormal Tau Phosphorylation at Ser ${ }^{396}$ in Alzheimer's Disease Recapitulates Development and Contributes to Reduced Microtubule Binding. Neuron (1993) 10:1089-1099.

Brion, JP., Passareiro, H., Nunez, J., Flament-Durand, J. Mise en evidence immunologique au niveau des lesions de degenerescence neurofibrillaire de la maladie d'Alzheimer. Arch. Biol. (Brux) (1985) 95:229-235.

Chan, K. Ganglioside-modulated protein phosphorylation : partial purification and characterization of a ganglioside stimulated protein kinase in brain.

J. Biol.Chem. (1987) 262:5248-5255.

Cheng, B. and Mattson, M. NGF and bFGF protect rat hippocampal neurons against hypoglycemic damage by stabilizing calcium homeostasis. Neuron (1991) 7:1031-1041.

Drewes, G., Lichtenberger, B., Doring, F., Mandelkow, EM., Biernat, J., Goris, J., Doree, M. and Mandelkow, E.. Mitogen activated protein (MAP) kinase transforms tau protein into an Alzheimer-like state. EMBO J. (1992) 11:2131-2138.

Feddersen, R., Ehelenfeldt, R., Yunis, W., Clark, H., Orr, H. Disrupted cerebellar cortical development and progressive degeneration of Purkinje cells in SV40 T antigen transgenic mice. Neuron (1992) 9: 955-966.

Geerts, H., Nuydens, R., Nuyens, R., Cornelissen, F., De Brabander, M., Pauwels, P., Janssen, P., Song. Y., Mandelkow, E.M.. Sabeluzole, a memory enhancing molecule, increases fast axonal transport in neuronal cell cultures. Exp. Neurol. (1992) 117:36-43. 
Goedert, M., Jakes, R., Crowther, R., Six, J., Lubke, U., Vandermeeren, M., Cras, P., Trojanowksi, J., Lee, V. The abnormal phosphorylation of tau protein at Ser202 in Alzheimer's disease recapitulates phosphorylation during development.

Proc.Nat. Acad. Sci. (1993) 90:5066-5070.

Gong, C., Singh, T., Grundke-Iqbal, 1., Iqbal, K. Phosphoprotein phosphatase activities in Alzheimer Disease Brain. J. Neurochem. (1993) 61:921-927.

Harris, K., Oyler, G., Doolittle, G., Vincent, I., Lehman, R, Kincaid, R, Billingsley, M. Okadaic acid induces hyperphosphorylated forms of tau protein in human brain slices. Ann Neurol. (1993) 33:77-87.

Hasegawa, M., Atsushi, Watanabe, Koji, Takio, Masami, Suzuki, Takao, Arai, Koiti, Titani, Yashuo, Ihara . Characterization of two distinct monoclonal antibodies to Paired Helical Filaments : Further evidence for fetal-type phosphorylation of the tau in paired helical filaments. J. Neurochem. (1993) 60:2068-2077.

Ip, N., Li, Yanping, Yancopoulos, G., Lindsay, R. Cultured hippocampal neurons show responses to BDNF, NT-3 and NT-4, but not NGF. J. Neurosci. (1993) 13:3394-3405.

Iq̨bal, K., Iqbal, I., Zaidi, T., Merz, P.A., Wen, G.Y., Shaikh, S.S., Wisniewski, H.M. Defective brain microtubule assembly in Alzheimer's disease. The Lancet (1986) 23:421-426.

Ko, L., Sheu, K. R., Young, O., Thaler, H., and B!ass, J.P. Expressions in cultured human neuroblastoma cells of epitopes associated with affected neurons in Alzheimer's Disease. Am. Journ. Path. (1990) 136:867-879.

Lichtenberg, B., Mandelkow, E.-M., Hagestedt, T., and Mandelkow, E. Structure and elasticity of microtubule-associated protein tau. Nature (1988) 334:359-362.

Matta, S., Yorke, G., Roisen, F. Neuritogenic and metabolic effects of individual gangliosides and their interaction with nerve growth factor in cultures of neuroblastoma and pheochromocytoma cells. Dev, Brain Res. (1986) 27:243-252.

Mattson, M. Antigenic changes similar to those seen in neurofibrillary tangles are elicited by glutamate and $\mathrm{Ca}^{2+}$-influx in cultured hippocampal neurons. Neuron (1990) 2:105-117.

Meiri, K., Beverly, M. Effects of gangliosides GM1 and GDla on GAP-43 phosphorylation and dephosphorylation in isolated growth cones. J. Neurochem. (1994) 62:291-299.

Mercken, M., Vandermeeren, M., Lübke, U., Six, J., Boons, J., Van de Voorde, A., Martin, J., and Gheuens, J. Monoclonal antibodies, with selective specificity for Alzheimer Tau are directed against phosphatase-sensitive epitopes.

Acta Neuropathologica (1992) 84:265-272. 
Pope, W., Lambert, M., Leypold, B., Seupaul, R., Sletten, L., Kraft, G. and Klein, W. Microtubule-associated protein tau is hyperphosphorylated during mitosis in the human. neuroblastoma cell line SH-SY5Y. Exp. Neurology (1994) 126:185-194.

Prasad, K. Butyric acid: a small fatty acid with diverse biological functions. Life Sciences (1980) 27:1351-1358.

Reeves, R., Cserjesi, P. Sodium butyrate induces new gene expression in Friend erythroleukemic cells. J. Biol. Chem. (1979) 254:4283-4290.

Richard, S., Brion, J.P., Couck, A.M., Flament-Durand, J . Accumulation of smooth endoplasmic reticulum in Alzheimer's disease : new morphological evidence of axoplasmic flow disturbances. J. Submicr. Cytol. Pathol. (1985) 21:461-465.

Robertson, J., Loviny, T., Goedert, M., Jakes, R., Murray, K., Anderton, B., Hanger, D. Phosphorylation of tau by cyclic-AMP dependent protein kinase.

Dementia (1993) 4:256-263.

Komijn, H., Van Huizen, F., Wolters, P. Towards an improved serum-free, chemically defined medium for long-term culturing of cerebral cortex tissue.

Neurosc. \& Behav. Rev. (1984) 8:301-334.

Rupniak, T., Rein, G., Powell, J., Ryder, T., Carson, S., Povey, S., Hill, B. Characteristics of a new human neuroblastoma cell line which differentiates in response to cyclic adenosine 3':5' monophosphate. Cancer Res. (1984) 44:2600-2607.

Schllwa, M., Van Blerkom, J. Structural interaction of cytoskeletal elements. J. Cell Biol. (1981) 90:222-235.

Sevetson, B., Kong, X., Lawrence, J. Increasing cAMP attenuates activation of mitogen-activated protein kinase. Proc. Nat. Acad. Sci. (1993) 90: 10305-10309.

Sindou, Ph., Lesort, M., Couratier Ph., Yardin, C., Esclaire, F., Hugon, J. Glutamate increases tau phosphorylation in primary neuronal cultures from fetal rat cerebral cortex. Brain Research (1994) 646:124-128.

Vandermeeren, M., Lubke, U., Six, J., Cras, P. The phosphatase inhibitor okadaic acid induces a phosphorylated paired helical filament epitope in human LA-N-5 neuroblastoma cells. Neurosc. Letters (1993) 153:57-60. 




\section{Sodium butyrate induces aberrant tau phosphorylation and programmed cell death in human neuroblastoma cells.}

Rony Nuydens ${ }^{a}$, Cara Heers ${ }^{b}$, Aline Chadarevian ${ }^{c}$, Mirjam De Jong ${ }^{a}$, Roger Nuyens ", Frans Cornelissen ", Hugo Geerts "

- Department of Cell Physiology, Life Sciences, Janssen Research Foundation., Beerse, Belgium

'Dept of Preclinical Research, Janssen Gmbh, Neuss, Germany

'Dept. Biochemistry, University of Antwerp, Antwerp, Belgium

Brain Research, 688, 86-94, 1995

Abstract

Paired helical filaments, one of the major hallmarks of Alzheimer's disease brains at autopsy, consist mainly of aberrantly phosphorylated tau. This aberrant tau phosphorylation can be induced in the human neuroblastoma cell line TRI4 by a hyperstimulating mixture, consisting of nerve growth factor $(N G F), d b-c A M P$, gangliosides and sodium butyrate(NaBut), (Ko et al., 1990; Nuydens et al., 1994). Evidence is presented that exposing these cells to increasing concentrations of NaBut alone in the 0.5-2 $\mathrm{mM}$ dose-range is sufficient to induce aberrant tau 
phosphorylation within 24 hours, measured by AT- 8 immunocytochemistry and Western blotting. This process is associated with increased morphological differentiation. Furthermore, the aberrant tau phosphorylation is followed by neurotoxicity. This neurotoxicity has features of programmed cell death, such as fragmentation on a DNA agarose gel, fragmented nuclei and chromatin condensation and inhibition by the protein synthesis inhibitor cycloheximide. The mechanism by which NaBut induces these modified tau proteins and neurotoxicity are largely unknown but the data suggest an involvement of cytoskeletal proteins.

\section{Introduction}

Alzheimer's disease is a major problem in the developed countries and affects more than 7 million people worldwide. Its etiology is unknown, but the major hallmarks in brains of Alzheimer's patients at autopsy consist of B-amyloid deposits and neurofibrillary tangles, often associated in senile plaques. The neurofibrillary tangles are composed mostly of modified tau protein (Brion et al, 1985). The tau molecule is aberrantly phosphorylated at a number of serine residues (Bramblett et al., 1993). As a consequence, tau becomes dissociated from the microtubule network and aggregates into insoluble fragments. There exist several monoclonal antibodies that recognize the tau protein only when specific residues are phosphorylated. Among them are the monoclonal antibody AT-8, which recognizes phosphorylation at Ser202 (Goedert et al., 1993), the PHF-1 antibody recognizing the phosphorylated Ser396 residue (Greenberg et al., 1992), and the C5 and M4 antibodies (Hasegawa et al., 1993), recognizing the tau at the phosphorylated Ser396 and Ser236 residues respectively(longest human tau isoform numbering). This degree of aberrant phosphorylation is probably the result of an imbalance between kinase and 
phosphatase activities (Gong et al., 1993). Based upon this observation, there have been a number of in vitro models described in which aberrant tau phosphorylation is induced, mostly by the blocking of phosphatase activity by means of okadaic acid (Arias et al., 1993; Vandermeeren et al., 1993). However, this compound is very toxic and the cells die usually within the first hours. This makes it difficult to study in more detail the individual cellular processes inducing aberrant phosphorylation of tau and the steps further downstream that lead to neurotoxicity. Another method is to moderately stimulate kinase activity by a cocktail of activators, including NGF at 100 $\mathrm{ng} / \mathrm{ml}, 1 \mathrm{mM}$ db-cAMP, the membrane permeable analog of cAMP, $200 \mu \mathrm{M}$ gangliosides and $0.5 \mathrm{mM} \mathrm{NaBut}$. This cocktail has been documented to induce tau phosphorylation in human neuroblastoma cells, as well as in rat primary hippocampal neurons (Ko et al., 1990; Nuydens et al., 1995). In a search for the compound actually responsible for this effect, we applied the four components individually. This report documents the observation that application of NaBut alone is sufficient to induce morphological differentiation, followed by increased AT8-immunoreactivity and cell death. In addition, we show that this form of cell death has features of programmed cell death.

\section{Materials and methods}

\section{Cell culture}

TR14 neuroblastoma cells (gift of Dr. G. Carmeliet, Center for Himan Genetics - KU Leuven) were grown at $37^{\circ} \mathrm{C}$ in DMEM/F12 medium supplemented with $10 \%$ FCS in a humidified incubator supplied with $95 \%$ air and $5 \% \mathrm{CO} 2$. For the actual experiments, the cells were harvested from flasks by mild trypsinization and 50,000 cells were plated on coverslips sterilized with ethanol and coated with poly-L-lysine $(100 \mu \mathrm{g} / \mathrm{ml})$.

Twenty-four hours after plating the medium was changed to differentiation medium (N2 medium). This medium consisted of DMEM/F12 medium supplemented with $2 \mathrm{mM}$ L-glutamine, $15 \mathrm{mM}$ HEPES and the N2 components 
insulin $(5 \mu \mathrm{g} / \mathrm{ml})$, transferrin $(100 \mu \mathrm{g} / \mathrm{ml})$, progesterone $(20 \mathrm{nM})$, putrescine $(100 \mu \mathrm{M})$ and Na-selenite (30 nM) (Bottenstein and Sato, 1979).

For the Western Blot experiments, TR14 cells were grown in Cellfactories ${ }^{\text {क }}$ (NUNC). At subconfluency the medium was changed to DMEM containing N2 components with or without $\mathrm{NaBut}$.

The hyperstimulation medium consisted of the following components : NGF (100 ng/ml), db-cAMP ( $1 \mathrm{mM}), 0.5 \mathrm{mM} \mathrm{NaBut}$ and $10 \mu \mathrm{g} / \mathrm{ml}$ gangliosides (Ko et al., 1990).

NGF (nerve growth factor) was obtained from Boehringer, db-cAMP (dibutyryl cyclic AMP), gangliosides and NaBut from Sigma. Ethyl-iso-propyil amiloride (EIPA), a Na${ }^{+} / \mathrm{H}^{+}$exchange blocker was from Sigma.

\section{Quanitative epi-polarisation immunocytochemistry}

Cells were fixed with $4 \%$ paraformaldehyde in PHEM buffer (Schliwa and Van Blerkom, 1981) for $20 \mathrm{~min}$ at room temperature, washed with PHEM buffer and permeabilized with Triton X-100 0.5\% for 30 min in PHEM buffer. Unreacted aldehyde groups were reduced during a 20 min treatment with $0.5 \mathrm{mg} / \mathrm{ml} \mathrm{NaBH} 4$ in PHEM.

Staining was performed at room temperature in Tris-buffered saline (TBS; $10 \mathrm{mM}$ Tris, $140 \mathrm{mM} \mathrm{NaCl}$ and $0.1 \% \mathrm{BSA}, \mathrm{pH} 7.6$ ). After a $30 \mathrm{~min}$ incubation with $5 \%$ Normal Goat Serum, the cells were incubated overnight with the primary antibody diluted in $1 \%$ normal goat serum (1/100 for AT8, gift of Dr. E. VanMechelen, Innogenetics, Ghent, Belgium). After washing with TBS the cells were incubated with a $1 / 10$ dilution of $5 \mathrm{~nm}$ gold-conjugated GAM (goat anti mouse antibody) (Amersham) for $3 \mathrm{~h}$. The cells were then washed thoroughly in TBS, and finally with bidistilled water, prior to silver intensification, after which the preparations were mounted in Gelvatol.

The preparations with immunogold silver-staining were observed in epi-polarization mode on a Axiovert 35 microscope (Zeiss Oberkochen, Germany) equipped with a Marzhauser scanning stage and Chalnicon Panasonic Camera, and digitized by a Series 200 Image Processor (Imaging Technology, Woburn, MA, USA). Image analysis was performed using the 
image analysis package TCL (Delft University, The Netherlands) on a VaxStation 3100 (DEC, Maynard, USA).

In each image the total number of cells and the degree of epitope expression were determined by fully automatic dual thresholding. Briefly, cells and neurites were detected by a Have edge-detection routine (Verbeek et al., 1988) followed by a holeclose operation. This ensured correction for the varying background. The resulting binary image, containing only the cell bodies and neurites, was labeled and non-specific small objects, i.e. those below a critical size, were excluded. From this labeled image, the epi-polarisation image of each individual (cellular) object $\mathrm{n}$ was reconstructed by ANDING the original image with a binary image, derived from the labeled image containing only pixels belonging to that cell $\mathrm{n}$. In this image, the colloidal gold signal was detected as bright pixels with saturating grey-values (i.e. 255). These operations ensured that background gold pixels not associated with individual cells were disregarded. A mean intensity value (MIV) was calculated as follows

$$
\text { MIV }=\left(? \mathrm{I}_{\text {gold }} * \text { area }_{\text {gold }} / \operatorname{area}_{\text {cell }}\right) / \mathrm{N}
$$

where $\mathrm{N}$ is total number of cells, $\mathrm{I}_{\text {gold }}$ the mean intensity of gold pixels, area the total number of gold pixels and area $\mathrm{cell}_{\text {the }}$ thetal area of the cell. Summation is over all cells.

Measures were taken so that the optical acquisition and the digital detection were reproducible, to minimize interexperimental variability.

\section{Purification of tau}

Purification of tau was performed according to Goedert and Jakes, 1990. In summary the medium in the Cellfactories was removed and cells were detached by incubation for $30 \mathrm{~min}$ in cold TE-PBS buffer $(10 \mathrm{mM}$ Tris- $\mathrm{HCl}, 1$ mM EDTA, 0.1 mM PMSF in PBS, pH 7.4). Cells were collected at $500 \mathrm{~g}$ for 5 minutes and washed twice with TE-PBS. Lysis buffer $(10 \mathrm{mM}$ Tris- $\mathrm{HCl}, \mathrm{pH}$ 8.3, $1 \mathrm{mM}$ EDTA, $5 \mathrm{mM}$ benzamidine, $10 \mu \mathrm{g} / \mathrm{l}$ each of pepstatin $\mathrm{A}$, leupeptin, aprotinin, $1 \mathrm{mM}$ phenylmethylsulfonyl fluoride (PMSF), $10 \mathrm{mM} \mathrm{NaF}, 200 \mu \mathrm{M}$ $\mathrm{Na}_{3} \mathrm{VO}_{4}$, and $1 \mu \mathrm{M}$ okadaic acid) was added and the suspension stored at $-70^{\circ} \mathrm{C}$ until used. After thawing, the cells were sonicated $3 \times 10 \mathrm{sec}$ 
(Braunsonic 1510, Braun, Melsungen) on ice, the homogenate was centrifuged at $12000 \mathrm{~g}$ for $10 \mathrm{~min}$ at $4^{\circ} \mathrm{C}$, and the resultant supernatant was boiled for $10 \mathrm{~min}$. The suspension was cooled down to about $4^{\circ} \mathrm{C}$ and centrifuged for $10 \mathrm{~min}$ at $14000 \mathrm{~g}$. Perchloric acid was slowly added to the supernatant to a final concentration of $2.5 \%(\mathrm{v} / \mathrm{v})$ and was kept on ice for $10 \mathrm{~min}$ with stirring. After another $10 \mathrm{~min}$ spin at $12000 \mathrm{~g}\left(4^{\circ} \mathrm{C}\right)$ the supernatant was neutralized with $3 \mathrm{mM}$ Tris, dialyzed overnight against $1 \mathrm{mM}$ Tris- $\mathrm{HCl}(\mathrm{pH} 7.4), 2 \mathrm{mM}$ $\mathrm{NaCl}, 0.1 \mathrm{mM}$ PMSF and concentrated to approximately $5 \%$ of the initial volume in a speed vacuum apparatus. The purified material was divided into small aliquots, frozen in liquid nitrogen and stored at $-70^{\circ} \mathrm{C}$. Protein concentration was estimated according to Bradford (1976) with bovine serum albumin (BSA) as the standard.

\section{Western blots}

Samples were boiled in electrophoresis sample buffer and separated on $7.5 \%$ SDS-PAGE minigels (Bio-Rad). For immunoblot analysis, equal amounts of proteins were transferred to polyvinylidene difluoride membranes (Bio-Rad) by semi-dry blotting. Blots were blocked for 1 h at $37^{\circ} \mathrm{C}$ with $5 \%$ (wt/vol) non-fat dry milk (Bio-Rad) in Tris-buffered saline containing $0.1 \%$ (vol/vol) Tween 20 (TBST). After washing three times for $15 \mathrm{~min}$ in TBST, blots were incubated with the primary antibody (tau-1 or AT8, $1 \mu \mathrm{g} / \mathrm{ml}$ in TBST) overnight at $4^{\circ} \mathrm{C}$. After another three washes, a biotinylated anti-mouse Ig antibody (Amersham, 1:400 dilution in TBST) was bound for $1 \mathrm{~h}$ at room temperature followed by three washes with TBST. Thereafter blots were incubated with alkaline phosphatase(AP)-coupled streptavidin (Amersham, 1:3000 dilution in TBST) for $30 \mathrm{~min}$. Excess streptavidin-AP was removed by three $5 \mathrm{~min}$ washes in TBST. Bound antibody was detected by use of the BCIP/NBT substrate system (Promega).

\section{Morphological differentiation}

Automatic quantification of morphological differentiation was performed by a fully automated method as described in Cornelissen et al. Briefly, cell cultures were fixed at appropriate times with a solution containing $0.365 \mathrm{~g}$ toluidine 
blue per $50 \mathrm{ml}$ ethanol, yielding very dark images of the cell bodies and their neurites against an essentially white background. The preparations were observed under bright field illumination on a Zeiss Axioskop with the help of a scanning stage (Marzhauser, Germany) in a $8 \times 8$ field scanning mode (covering an area of $16 \mathrm{~mm}^{2}$ ) using a MX5 - CCD camera (HCS, Eindhoven, Netherlands). Images are digitized by a DASM (Analogic Devices, Massachusetts, USA) frame grabber in an Indigo Workstation (Silicon Graphics, Mountain View, California, USA). The fields were closely appositioned such that neurites crossing the boundary of a field could be followed into the adjacent field. Image analysis routines were used to calculate the area of each body, the number of neurites connected to this cell body and the length of each individual neurite. Positive cells were those with at least one single neurite longer than the diameter of the cell body.

\section{Cell viability}

Cell viability was measured by the live/dead technique (Molecular Probes, Oregon, USA). This method measures the number of biochemically acive cells as a fraction of the total number of cells. Briefly, calcein acetoxy-methyl ester (a membrane permeable and non-fluorescent probe) is taken up and becomes well-retained in living cells only, after cleavage by intracellular cytosolic enzymes. The intense green fluorescent product is visualized on a fluorescence microscope in the FITC channel. The nucleic acid stain, propidium iodide, is excluded from living cells and stains only the nuclei of cells with damaged membranes. This signal is red upon excitation with green light. The double line filter (FITC/Texas Red filter, Zeiss \#487924) was found to give a clear color distinction between living and dead cells.

Images are taken in epi-fluorescence mode on the Axiovert 35 microscope, equipped with the Marzhauser scanning stage and a color camera (SONY 3CCD-DXC 930P), the RGB signals of which are digitized by a DASM frame grabber (Analogic Devices, USA). Synchronization of the scanning stage and on-line analysis of the images is performed by a DecStation 5000/200 (DEC, Maynard, USA). The RGB signal, in conjunction with the double line filter assures a net distinction between the calcein signal in the green color channel 
and the propidium iodide signal in the red color channel. On-line analysis is performed by simple thresholding of the images obtained in each channel, counting objects and areas and calculating the fraction of surviving cells.

\section{Morphological evaluation of apoptosis}

At appropriate times, TR14 cells were fixed with $4 \%$ paraformaldehyde and permeabilized with TX100 $0.5 \%$. The cells were then labeled with $10 \mu \mathrm{gr} / \mathrm{ml}$ propidium iodide in PBS for 15 minutes and mounted in gelvatol.

In fluorescence mode typical apoptotic nuclei (fragmented nuclei, chromatin condensation) could be discriminated from healthy or necrotic cells.

\section{Analysis of DNA-fragmentation}

TR 14 cells were lyzed with a buffer containing $1 \%$ sodium dodecy! sulfate, $20 \mu \mathrm{M}$ Tris- $\mathrm{HCl}, 100 \mathrm{mM} \mathrm{KCl}, 10 \mathrm{mM}$ EDTA, $16 \mathrm{mM}$ dithiotreitol at pH 7.4. lysates were centrifuged at $13000 \mathrm{~g}$ for $20 \mathrm{~min}$ at $4^{\circ} \mathrm{C}$. Low and high molecular weight DNA were extracted with sodium perchlorate and chloroform treatment and DNA was recovered after addition of Nucleon suspension (Scotlab, Stratclyde, Scotland). DNA was electrophoresed in 1\% agarose and visualized after ethidium bromide staining. Size of DNA ladder was compared with a standard ladder (Boehringer Mannheim).

\section{Statistics}

Student's t-test was employed for statistical data analysis of cell survival assays.

\section{Results}

\section{A. Dissection of the hyperstimulating cocktail}

In order to find out whether the four original compounds of the hyperstimulating cocktail were all needed, we dissected the effects of the individual contributions. 
Application of $1 \mathrm{mM}$ db-cAMP alone to TR 14 cells induced a marked differentiation (the fraction of positive cells increased from $33.1 \% \pm 9.8 \%$ to $55.5 \% \pm 10.7 \%$, mean $\pm \mathrm{SD}, \mathrm{n}=80$ observations, whereas the neurite length increased from $26.3 \mu \mathrm{m} \pm 5.2 \mu \mathrm{m}$ to $39.3 \mu \mathrm{m} \pm 6.6 \mu \mathrm{m}$, mean $\pm \mathrm{SD}, \mathrm{n}=80$ observations). The compound by itself was not toxic (cell survival $95 \pm 3 \%$ after 48 hours, mean $\pm S D, n=3$ ).

NGF at a relatively high dose of $100 \mathrm{ng} / \mathrm{ml}$ resulted in a survival of $91 \%$ $\pm 6 \%$ mean \pm SD $(n=3)$, whereas $200 \mu M$ gangliosides yielded a survival rate of $89 \% \pm 6 \%$ mean $\pm \mathrm{SD}(\mathrm{n}=3)$.

On the other hand, application of $0.5 \mathrm{mM} \mathrm{NaBut}$ reduced survival to $59 \% \pm 7 \%$ mean $\pm \mathrm{SD}(\mathrm{n}=3)$. These observations lead us to suggest that at least in TR14 cells, of the four compounds making up the hyperstimulating medium, NaBut was the most neurotoxic compound. We therefore studied the effect of NaBut on TR 14 cells in more detail.

\section{B. The effect of NaBut on morphological differentiation}

Exposure of TR14 cells to N2 medium alone induced a slight morphological differentiation, but upon application of $\mathrm{NaBut}$ at a concentration of $0.5 \mathrm{mM}$ (the concentration formerly used in the hyperstimulating cocktail of Ko et al., 1990), a much more enhanced morphological differentiation became apparent

\section{Table 1:}

Condition

Control (N2)

$10 \mu \mathrm{M}$ NaBut

$100 \mu \mathrm{M} \mathrm{NaBut}$

$1 \mathrm{mM} \mathrm{NaBut}$
Neurite Length $(\mu \mathrm{m})$

$25.6 \pm 5.3$

$23.9 \pm 2.4$

$24.6 \pm 2.0$

$25.9 \pm 2.4$
Fraction pos. cells (\%)

$35.7 \pm 3.6$

$35.7 \pm 6.3$

$44.5 \pm 7.3$

$59.6 \pm 4.9^{*}$

Quantitative morphological differentiation induced in human neuroblastoma cells by various doses of $\mathrm{NaBut}$ after 2 days. Displayed are parameters regarding the fraction of positive cells (i.e. cells with at least one neurite longer than twice the cell diameter) and the length of individual neurites. Data are from three independent experiments.

Mean \pm SD $*, P<0.05$ 
within the first hours. A majority of cells displayed nice neuritic extensions and active growth cone movement. Quantitative assessment of morphological differentiation (Table 1) after 24 hours revealed that NaBut dose-dependently increased the fraction of positive cells. Total neurite length, however was not increased by $\mathrm{NaBut}$ treatment.

\section{The effect of NaBut on tau phosphorylation}

When the cells were incubated in N2 medium for 2 days and immunostained with AT8 antibody, a weak immunoreactive signal became apparent in the cell body. However, when cells were treated with NaBut, AT8 immunoreactivity sharply increased and was preferentially localized within the cell body and the proximal part of the neurites (Fig. 1). Quantitative immunocytochemistry
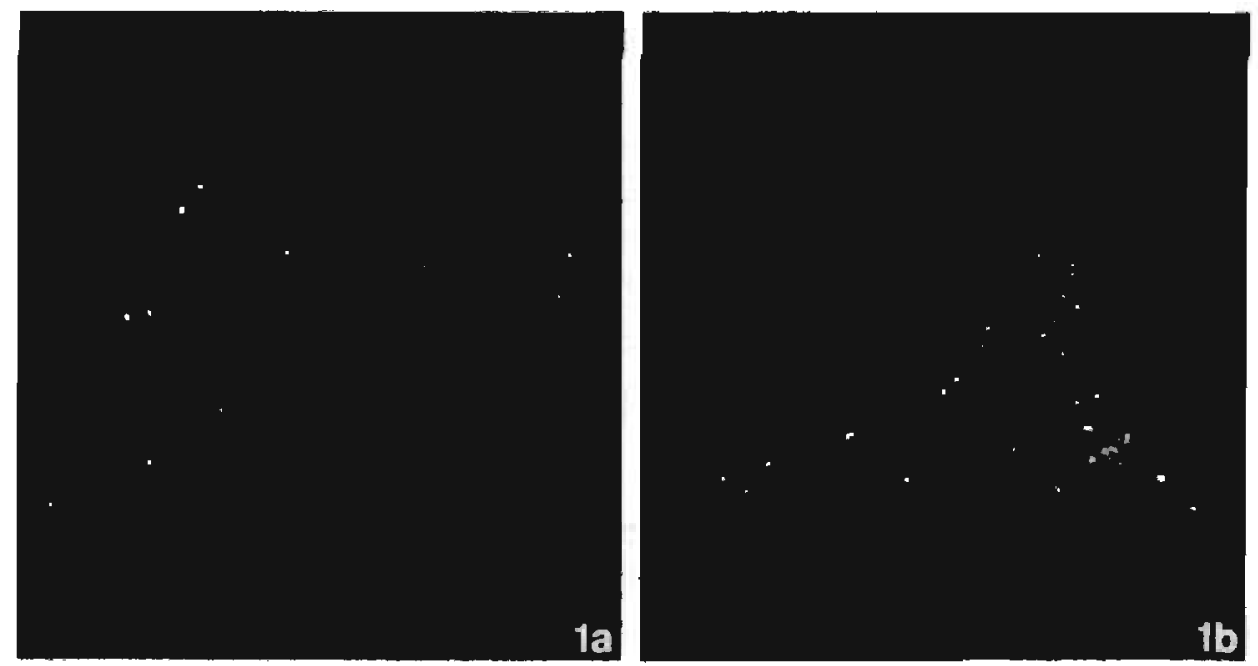

Figure 1: Typical immunocytochemistry of AT8 in unstimulated (a) and NaBut-treated TR14 cells (b) after $48 \mathrm{~h}$ of treatment. Notice the weak AT8-IR in the control situation and the more pronounced appearance of the AT8 epitopes in the proximal part of the cell bodies after NaBut treatment.

indicated that both the degree of Tau- 1 staining and the degree of AT8 staining increased with NaBut (Fig. 2). The ratio of AT8 over Taul however, was significantly increased in the NaBut condition. The slightly lower AT8-IR at 


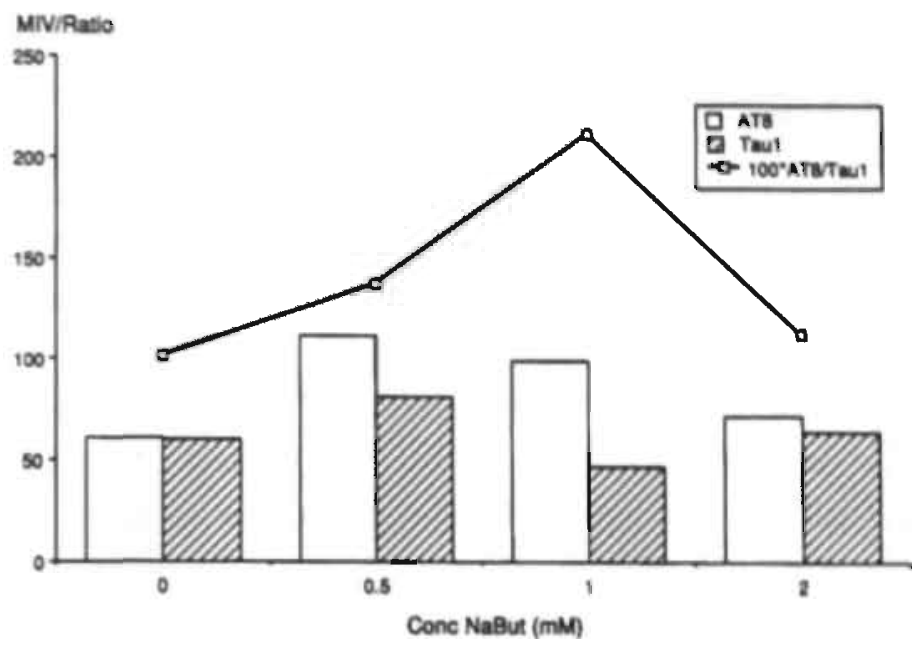

Figure 2: Dose-dependent increase in Tau 1 and AT8 immunoreactivity after 2 days treatment with NaBut. The Mean Intensity Value (MIV) is indicated, calculated over 50-100 cells. The data clearly suggest that NaBut increases the relative fraction of AT8

tau-1

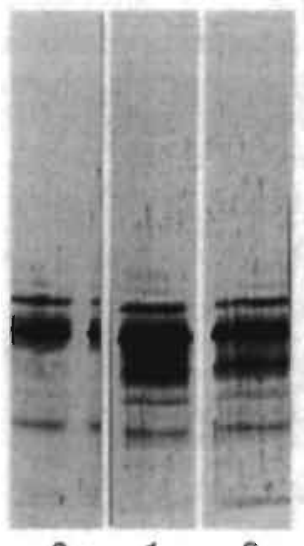

AT8

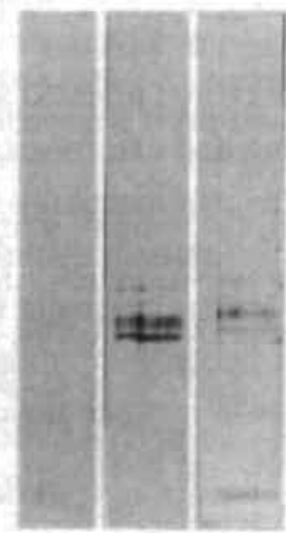

2

$\mathrm{NaBu}$

Figure 3: SDS-PAGE of tau extractedi from TR14 cells grown for $24 \mathrm{~h}$ in N2 medium. Equal amounts of protein were loadeci on each lane. Effect of Na-butyrate treatment on phosphorylation. The first three lanes correspond to antibody tau-1 which recognizes the tau epitope 199/202 in the non-phosphorylated state. Note that the tau-1 signal becomes also more pronounced in the presence of Na-butyrate. The three last lanes correspond to AT-8, a specific antibody for PHF-tau phosphorylated at Ser202. In N2 medium no phosphorylation can be detected, whereas a pronounced signal can be seen at $1 \mathrm{mM} \mathrm{NaBut}$ and (slightly less intense) at $2 \mathrm{mM} \mathrm{NaBut}$. 
the highest $\mathrm{NaBut}$ concentrations, may be due to a greater neurotoxicity (see below) and subsequent detachment of these dead cells during the washing procedures.

Analysis of Western blotting (Fig. 3) shows that after $24 \mathrm{~h}$, a positive AT8 signal became clearly visible in the $1 \mathrm{mN} \mathrm{NaBut}$ condition and less prominent in the $2 \mathrm{mM} \mathrm{NaBut}$ condition. We also observed that the Tau-1 staining slightly increased upon NaBut treatment.

Treatment of TR 14 cells with $1 \mu \mathrm{M}$ okadaic acid for 4 hours induced a more marked elevation of AT8 immunoreactivity on a Western blot (data not shown). However the cells became rapidly detached from their substrate.

Although db-cAMP indeed increased morphological differentiation to a much higher degree (see also table 1), this condition did not induce AT8 immunoreactivity. The degree of AT8-IR was essentially similar to the control condition (data not shown).

\section{The effect of NaBut on neurotoxicity}

After 3 days of exposure, cell death became apparent and a quantitative measure of neurotoxicity indicated a dose-dependent relationship between $\mathrm{NaBut}$ concentration and neurotoxicity (Fig. 4).

In order to study the pharmacology of this neurotoxicity, the effect of the protein synthesis inhibitor cycloheximide was studied. As seen from Fig 4, protection against NaBut treatment starts at around $1 \mu \mathrm{g} / \mathrm{ml}$ or $3.5 \mu \mathrm{M}$ cycloheximide and becomes prominent at 35 and $175 \mu \mathrm{M}$. At $350 \mu \mathrm{M}$, the protective effect of cycloheximide is probably masked by the toxicity of the compound itself.

In order to test the selectivity of the aggression, the effect of Na-propionate on cell survival was investigated (Table 2). It is clear that Na-propionate is much less neurotoxic. In addition, the $\mathrm{Na}^{*} / \mathrm{H}^{+}$exchange blocker EIPA had no effect on the NaBut-induced neurotoxicity (data not shown).

\section{E. NaBut induces programmed cell death}

Because of the observed inhibition of $\mathrm{NaBut}$-induced cell death by the protein synthesis inhibitor cycloheximide, we next studied the question of whether this form of cell death bears any resemblance to programmed cell death. Therefore 


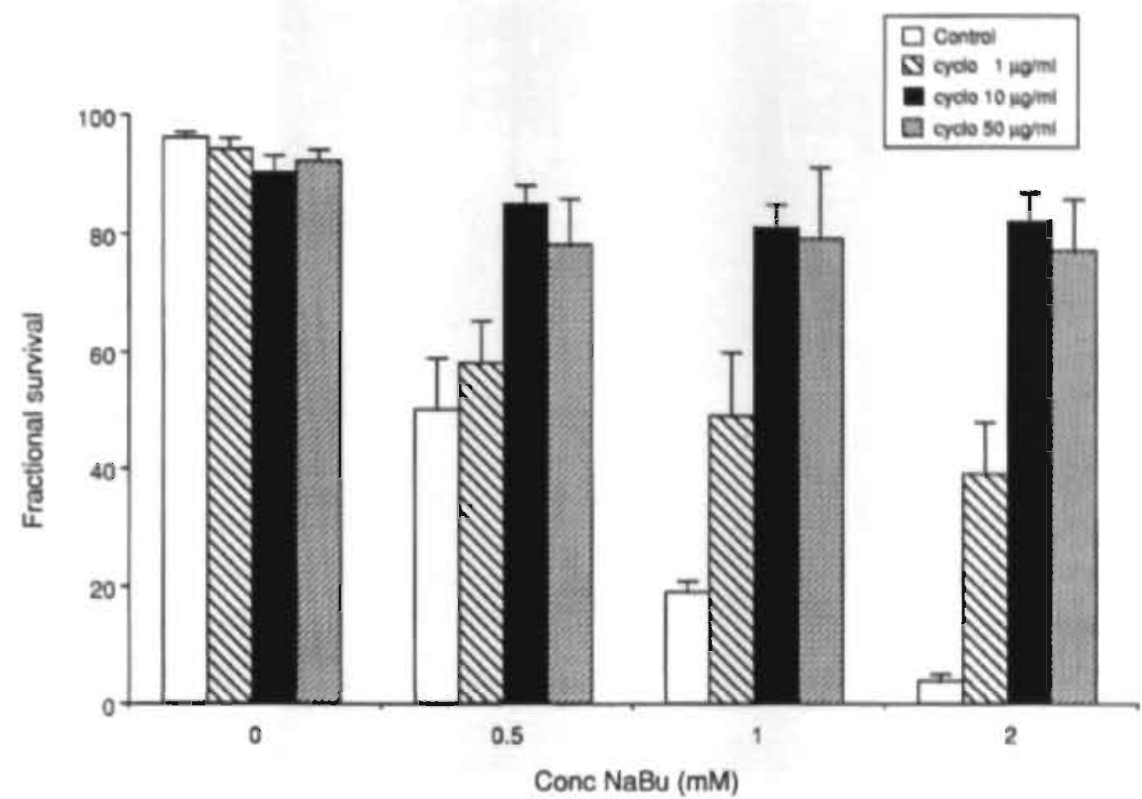

Figure 4: Dose-dependent neurotoxicity in human TR14 neuroblastoma cells after 3 days of treatment with $\mathrm{NaBut}$, as measured with the Live/dead technique. Data are mean $\pm S D$ of 3 independent experiments. It is clear that NaBut dose-dependently induces cell death and that application of cycloheximide is capable of protecting cells from neurotoxicity. ${ }^{*}, \mathrm{P}<0.05$

a DNA agarose gel was performed to look for fragmentation. Fig. 5 indicates that NaBut induced a DNA-laddering pattern, especially at the highest concentration of $2 \mathrm{mM} \mathrm{NaBut}$. This effect was observed after one day of treatment. Furthermore, counting of apoptotic nuclei fragments revealed that the fraction of apoptotic cells increased from $3.8 \%$ to $12.7 \%$ in a typical experiment, upon application of $1 \mathrm{mM} \mathrm{NaBut}$.

Table 2: The effect of NaBut and Na-propionate on neurotoxicity in TR14 cells. The fraction of living cells after 3 days of treatment is listed. Values are calculated over 500-2000 cells. The results are given in mean \pm SD of three independent experiments.

\section{Concentration}

$0.1 \mathrm{mM}$

$0.5 \mathrm{mM}$

$1.0 \mathrm{mM}$

$2.0 \mathrm{mM}$

NaBut
Fraction (\%)
$95.0 \pm 4.2$
$52.1 \pm 7.2$
$24.9 \pm 6.4$
$17.3 \pm 3.8$

Napropionate

Fraction (\%)

$89.7 \pm 4.3$

$84.8 \pm 5.1$

$80.7 \pm 6.9$

$71.2 \pm 4.9$ 


\section{Chapter 3}

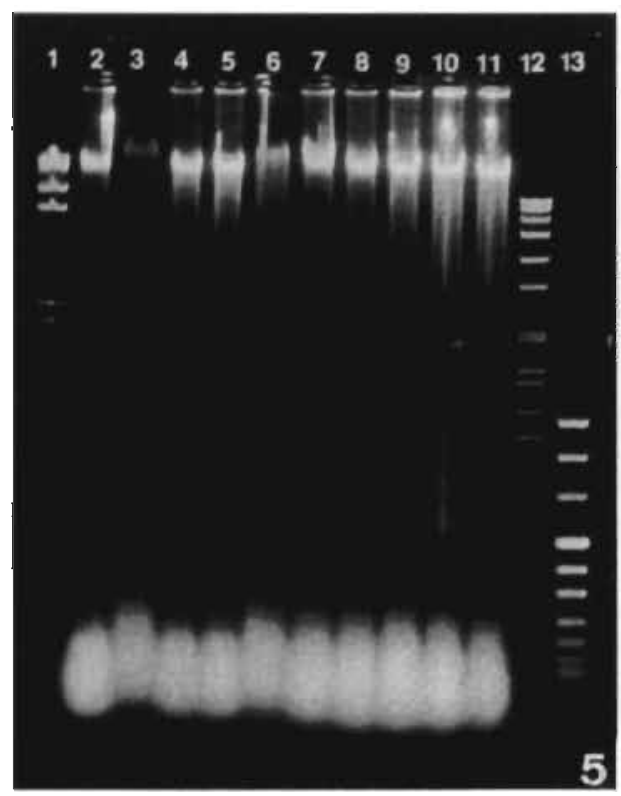

Flgure 5: Agarose gel electrophoresis of the DNA of TR14 cells showing DNA laddering as a function of NaBut concentration and exposure time. Lanes $1,12,13$ are DNA markers, lanes $3 \& 8$ are exposures to $0.1 \mathrm{mM} \mathrm{NaBut}$ for 1 and 2 days respectively, lanes 4 \& 9 to $0.5 \mathrm{mM} \mathrm{NaBut}$, lanes $5 \& 10$ to $1 \mathrm{mM} \mathrm{NaBut}$ and lanes $6 \& 11$ to $2 \mathrm{mlM}$ NaBut. Notice the prominent DNA-laddering in the 1 and $2 \mathrm{mM} \mathrm{NaBut}$ condition after 2 days.

\section{Discussion}

The present study demonstrates that treatment of human neuroblastoma cells with NaBut dose-dependently increases the expression of AT8 epitope as measured by Western blotting and quantitative immunocytochemistry. This epitope has been shown to be an antigenic determinant of PHF in Alzheimer's disease (Mercken et al., 1992). It has been localized to the phosphorylated serine residues at position 202 of the human tau protein (longest isoform) (Goedert et al., 1993). Previous observations have also related NaBut to the expression of Alz-50 epitopes in human IMR32 neuroblastoma cells (Ko et al., 1990) and of AT8 and PHF-1 expression in TR14 cells (Nuydens et al., 1995). In both cases however the compound was part of a hyperstimulating mixture, also including NGF, db-cAMP and gangliosides and aimed at increasing kinase 
activity. However, the increase in AT8 immunoreactivity is moderate, especially when compared to treatment with okadaic acid.

In accordance with the observed effect of $\mathrm{NaBut}$ on neuronal differentiation. immunoblot analysis and quantitative immunocytochemistry both show also that the unphosphorylated Ser202 epitope, as measured by Tau- 1 immunostaining (Binder et al., 1985), slightly increased. In CHO cells transfected with tau and MAP, NaBut has been found to induce leveis of expression significantly (Barlow et al., 1994).

The observations clearly show that of these four components, unexpectedly, $\mathrm{NaBut}$ is the most effective in inducing aberrant tau phosphorylation and neurotoxicity. The membrane permeable analog of cAMP has a prominent differentiation effect, but in the absence of any AT8 immunoreactivity and neurotoxicity. This is in line with previous observations (Yusta et al., 1988). The relation between expression of aberrant tat epitopes and subsequent neurotoxicity has been documented before in TR14 cells as well as in fully differentiated hippocampal cell cultures (Nuydens et al., 1995). This report further shows that NaBut- induced neurotoxicity in TR14 cells can be described as programmed cell death or apoptosis. The degree of fragmentation on a DNA agarose gel is moderate but significant. This is in accord with the relatively small fraction of cells undergoing nuclear fragmentation. Furthermore, the inhibition of neurotoxicity by cycloheximide suggests that newly synthesized proteins actively take part in this neurotoxic process. The failure of Na-propionate to induce neurotoxicity and the lack of effect of EIPA on this neurotoxicity suggest that a $\mathrm{pH}$ change is not involved.

Butyric acid has been shown to induce apoptosis in the human myeloid HL-60 cell line (Calabresse et al., 1993) and in the U-937 leukemic cell line, whereas the myeloblastic KGI and the NB4 promyelocytic leukemic cell lines were resistant to butyric acid (line (Calabresse et al., 1994). Butyric acid in all these cell lines induces arrest in the Gl phase of the cell cycle. The same observations have been found in a rat hepatoma cell line (Gupta et al., 1994). Whether this is the case in the TR14 neuroblastoma cell line is unknown. There is further evidence that NaBut may act at the level of gene transcription by increasing the acetylation of histones, thereby releasing constraints upon 
the DNA template, probably by selective hypermethylation of transcribed nucleosomai DNA (Boffa et al., 1994). In fact, treatment of Friend erythroleukemic cells has been shown to increase new RNA transcripts (Reeves and Cserjesi, 1979).

NaBut induces prominent morphological differentiation in TR 14 neuroblastoma in line with previous observations (Barlow et al., 1994; Prasad, 1980). In this context, it has been shown that sensitivity to apoptosis correlates well with the ability of butyric acid to induce differentiation in 4 leukemic cell lines (Calabresse et al., 1994), suggesting a role for the cytoskeleton in the process of apoptosis. The process of morphological differentiation probably also requires rearrangement of cytoskeletal elements. It is of interest to note that taxol, a microtubule-stabilizing agent, actually induces apoptosis in human myeloid leukemia cells (Bhalla et al., 1993) and that colchicine has a similar effect in differentiating SH-SY5Y neuroblastoma cells (Nakagawa, 1994). Both compounds interfere with normal functioning of the cytoskeleton.

An important observation is that, although NaBut readily increases the fraction of cells with a certain length of neurite extension, its effect on actual neurite length is weak to non-existent. This can be tentatively explained by the following sequence of events. Neurite elongation in TR 14 cells is a dynamic process consisting of rather slow elongations and rapid but less frequent retractions (Nuydens et al., 1995). NaBut induces phosphorylation of tau proteins at Ser202 (as evidenced by AT8 immunoreactivity). This modification is associated with a reduced ability of tau to associate with microtubuli and to enhance microtubule polymerization (Ig̣bal et al., 1994). Therefore, the differentiation tendencies in neurite elongation are balanced by an increased instability in the microtubule network, leading to more frequent retractions of the growing neurite.

Whether aberrant tau phosphorylation is actualiy part of the apoptotic program or actuaily triggers the necessary steps leading to programmed cell death is for the moment unknown. It is known, however that partial phosphorylation of these aberrant sites on the tau protein is observed in fetal conditions (Bramblett et al., 1993; Goedert et al., 1993), during organogenesis of the brain and that 
during that period redundant neurons are eliminated by apoptosis (Oppenheim, 1991). On the other hand, in T cell hybridomas, dephosphorylation has been found to be an essential late step in glucocorticoid-induced apoptosis, as evidenced by the ability of okadaic acid and calyculin A to inhibit this form of apoptosis (Ohoka et al., 1993). It would therefore be of interest to study the effect of other inducers of apoptotic cell death in this system on the expression of aberrant tau phosphorylation.

In summary, this report shows that aberrant tau phosphorylation in the human neuroblastoma TR14 cell line can be induced by NaBut. Furthermore, this treatment leads to neurotoxicity with features of programmed cell death.

\section{Acknowledgments}

We are indebted to Dr. Greet Carmeliet (KU Leuven) for the clone of TR14 cells, to Mr. M. Vandermeeren for the support in tau purification and helpful discussions and Mr. G. Daneels for the help in Western blots. We thank Dr. E. van Mechelen (Innogenetics, Ghent, Belgium) for providing the AT8 antibody. The skillful photographic work of L. Leijssen, G. Verheyen and G. Jacobs is highly appreciated. 


\section{References}

Arias, C., Sharma, N., Davies, P. and Shafit, B. Okadaic acid induces early changes in microtubule-associated protein 2 and tau phosphorylation prior to neurodegeneration in cultured cortical neurons. J. Neurochem. (1993) 61:673-682.

Barlow, S., Gonzales-Garay, M., West, R., Olmsted, J., Cabral, F. Stable expression of heterologous microtubule-associated proteins (MAPS) in Chinese Hamster Ovary cells : Evidence for differing roles of MAPS in microtubule organization.

J. Cell Biol. (1994) 126:1017-1019.

Bhalla, K., Ibrado, A., Tourkina, E., Tang, C., Mahoney, M, Huang, Y.

The chemotherapeutic agent taxol induces apoptotic cell death in human myeloid leukemia. Leukemia (1993) 7:563-568.

Binder, L. , Frankfurther A., Rebhun, L. The distribution of tau in the mammalian nervous system. J. Cell Biol. (1985) 101:1371-1378.

Bofra, L.. Mariani, M. and Parker, I., Selective hypermethylation of transcribed nucleosomal DNA by sodium butyrate. Exp. Cell Res. (1994) 211:420-423.

Bottenstein, and Sato., Growth of rat neuroblastoma cell line in serum-free supplemented medium. Proc. Nat. Acad. Sci. USA (1979) 76:514-517.

Bradford, M. A rapid and sensitive method for the quantitation of microgram quantities of protein utilizing the principle of protein-dye binding. Anal. Biochem. (1976) 72:238-245.

Bramblett, G.T., Goedert, M., Jakes, R., Merrick, S.E., Trojanowski, J.Q. and Lee, V.M., Abnormal tau phosphorylation at $\operatorname{ser}^{396}$ in Alzheimer's disease recapitulates development and contributes to reduced microtubule binding. Neuron (1993) 10:1089-1099.

Brion, J.P., Passareiro, H., Nunez, J. and Flament-Durand, J.. Mise en evidence immunologique au niveau des lesions de degenerescence neurofibrillaire de la maladie d'Alzheimer. Arch. Biol. (Brux) (1985) 95:229-235.

Calabresse, C., Venturinin, L.. Ronco, G., Viulla, P., Chomienne, C., and Belpomme, D., Butyric acid and its monosaccharide ester induce apoptosis in the HL-60 cell line. Bioch. Bioph. Res. Comm (1993) 195:31-39.

Calahresse, C., Venturinin, L., Ronco. G., Villa, P., Degos, L., Chomienne, C. and Belpomme, D. Selective induction of apoptosis in myeloid leukemic cell lines by monoacetone glucose-3 butyrate. Bioch. Bioph. Res. Comm. (1994) 201:226-283. 
Cornelissen, F., Nuyens, R., Nuydens, R., Geerts, H. An automatic image analysis for quantifying morphological differentiation in neuronal cell cultures. submitted

Goedert, M., Jakes R., Expression of separate isoforms of human tau protein : correlation with the tau pattern in brain and effects on tubulin polymerization.

EMBO J. (1990) 9:4225-4230.

Goedert, M., Jakes R., Crowther, R., Six J., Lubke U., Vandermeeren, M., Cras P., Trojanowski, J. and Lee V.s. The abnormal phosphorylation of tau protein at ser202 in Alzheimer's disease recapitulates phosphorylation during development.

P.N.A.S. (1993) 90:5066-5070.

Gong, C., Signh, T., Grundke-Iqbal, I. and Iqbal K., Phosphoprotein phosphatase activities in Alzheimer Disease Brain. J. Neurochem. (1993) 61:921-927.

Greenberg, S., Davies, P., Schein, J., Binder, L. , Hydrofluoric acid-treated tau PHF display. the same biochemical properties as normal tau. J. Biol. Chem. (1992) 267:564-569.

Gupta, S., Alpini, G., Vemuru, R., Hurston, E., Shahfritz, D, Butyrate synchronization of hepatocytes: modulation of cycling and cell cycle regulated gene expression. Growth Factors (1994) 10:171-180.

Haşegawa, M., Atsushi, W., Kojili, T., Masami, S., Takao, A., Koiti, T. and Yashuo, 1., Characterization of two distinct monoclonal antibodies to paired helical filaments : Further evidence for fetal-type phosphorylation of the tau in paired helical filaments. J. Neurochem. (1993) 60:2068-2077.

Iqbal, K., Zaidi, T., Bancher, C., Grundke-Iqbal, L. Restoration of the biological activity by dephosphorylation. FEBS Letters (1994) 349:104-108.

Ko, L., Sheu, K.R., Young, O., Thaler, H. and Blass, J.P., Expression in cultured human neuroblastoma cells of epitopes associared with affected' neurons in Alzheimer's disease. Am. Journ. Path. (1990) 136:867-879.

Mercken, M., Vandermeeren, M., Lübke. U., Six, J., Boons, J., Van de Voorde, A., Martin, J. and Gheuens, J., Monoclonal antibodies with selective specificity for Alzheimer Tau are directed against phosphatase-sensitive epitopes.

Acta Neuropathologica (1992) 84:265-272.

Nakagawa, Y., Induction of apoptotic cell death in differentiating neuroblastoma SH-SY5Y cells by colchicine. Bioch. Bioph. Res. Comm. (1994) 199:807-817. 
Nuydens, R., De Jong, M., Nuyens, R., Cornelissen, F. and Geerts, H., Neuronal kinase stimulation leads to aberrant tau phosphorylation and neurotoxicity.

Neurobiol. of Aging (1995), 16, 3, 465-477.

Ohoks, Y., Nakai, Y., Mukai, M. and Iwata, M., Okadaic acid inhibits glucocorticoid-induced apoptosis in T cell hybridomas at its late stage.

Bioch. Bioph. Res. Comm. (1993) 197:916-921.

Oppenheim, R., Cell death during development of the nervous system. Ann. Rev. Neurosci. (1991) 14:453-501.

Prasad, K., Butyric acid: a small fatty acid with diverse biological functions. Life Sciences (1980) 27:1351-1358.

Reeves, R. and Cserjesi, P., Sodium butyrate induces new gene expression in Friend erythroleukemic cells. J. Biol. Chem. (1979) 254:4283-4290.

Schliwa, M. and Van Blerkom, J. Structural interaction of cytoskeletal elements. J. Cell Biol. (1981) 90:222-235.

Vandermeeren, M., Lubke, U., Six, J. and Cras, P., The phosphatase inhibitor okadaic acid induces a phosphorylated paired helical filament epitope in human LA-N-5 neuroblastoma cells. Neurosc. Letters (1993) 153:57-60.

Verbeek, P., Vrooman, H., van Vliet, L., Low level image processing by max-min filters. Signal processing (1988) 15:249-258.

Yusta, B., Ortiz-Caro, J., Pascual, Angel, Aranda, A., Comparison of the effects of forskolin and diburyryl cyclic AMP in neuroblastoma cells : evidence that some of the actions of dibutyryl cAMP are mediated by butyrate. J. Neurochem. (1988) 51:1808-i818. 




\section{Aberrant tau phosphorylation and}

neurite retraction during NGF deprivation in PC12 cells

Rony Nuydens a, b, Gwenda Dispersyn c, Mirjam de Jong a, Gerd Van Den Kieboom ", Marcel Borgers a and Hugo Geerts".

" Department of Cell Physiology, Life Sciences, Janssen Research Foundation, Beerse, Belgium

'Department of Molecular Cell Biology and Genetics, Maastricht University, the Netherlands

'Department of Biochemistry, University of Antwerp. Antwerp, Belgium

Biochem. Biophys. Res. Commun. 240, 687-691, 1997

\section{Abstract}

Recently apoptotic markers have been found in Alzheimer's Disease (AD) brain. To investigate the relation between tau phosphorylation and apoptosis, immunocytochemistry of AT8 (indicating the degree of phosphorylation at the tau Ser202/Thr205 site) was quantitatively determined during neuronal apoptosis in differentiated PCI 2 cells after nerve growth factor (NGF) deprivation. During this programmed cell death a prominent retraction of neurites took place that was associated with a clear increase in the level of AT8 signal. The broad spectrum 
kinase inhibitor staurosporine anenuated both this increase in tau phosphorylation, neurite retraction and apoptosis. We suggest that at some point during programmed cell death kinases with tau as substrate become activated and that the resulting loss of cytoskeletal integrity leads to neurite' instability.

\section{Introduction}

Apoptosis of neuronal cells plays a major role during development of the mammalian brain. Only those neurons that get sufficient quantities of neurotrophic factors from target tissue, remain alive, whereas the others die by a process called programmed cell death (Raff, 1992).

Recently it has also been argued that in some chronic neuropathological conditions cell death occurs through apoptosis. In Alzheimer's Disease, apoptotic nuclei were identified in the hippocampus and the entorhinal cortex (Su et al., 1994; Smale et al., 1995). In vitro, the neurotoxicity of B-amyloid has been shown to occur through apoptosis (Forloni et al., 1993), an effect which can be attenuated by exogenous supplies of neurotrophic factors (Mattson et al., 1993). This suggests a similarity to NGF-deprivation-induced cell death (Mesner et al., 1992).

Neurofibrillary tangles are a prominent landmark of post-mortem Alzheimer's brain and they are primarily composed of aberrantly phosphorylated tau protein. Tangles preferentially accumulate in the neocortex and hippocampus, regions known to be associated with neurotrophic factor dependent systems. Tau is a member of the family of Microtubule-Associated-Proteins (MAP), 
whose major function is stabilization of the microtubule system. Hyperphosphorylation of tau reduces the affinity for - and hence the stabilization of - the cytoskeleton, thereby seriously compromising the normal functioning of the neuronal cytoskeleton and the cytoarchitecture.

To investigate the relationship between aberrant tau phosphorylation, cell morphology and apoptosis, quantitative immunocytochemistry was used in NGF-deprived PC12 cells. In this system, cell death occurs through an apoptotic pathway as shown by morphological observations and specific TdT-mediated dUTP biotin nick-end labelling (Batistatou and Greene, 1991). We used the well-characterized monoclonal antibody AT8 (Mercken et al., 1992) to investigate tau phosphorylation. This antibody recognizes phosphorylated Ser 202/Thr205, an epitope which is present - although not exclusively - in neurofibrillary tangles in Alzheimer's disease.

In addition we investigated the effect on tau phosphorylation, cytoarchitecture and the subsequent cell death, after NGF-deprivation, of staurosporine a compound which inhibits a broad range of kinases.

\section{Materials and methods}

\section{Cell culture}

PC12 cells were grown in Dulbecco's Minimal Essential Medium (DMEM) supplemented with $7.5 \%$ Fetal Bovine Serum and $7.5 \%$ Horse Serum (HS). For the actual experiments, PC12 cells were plated on poly-L-lysine coated coverslips. After 1 day the cells were placed in DMEM supplemented with 1 $\%$ HS and $50 \mathrm{ng} / \mathrm{ml}$ NGF (Boehringer) for at least 7 days and the medium was changed every 3 or 4 days. For the deprivation experiments medium was changed either to DMEM alone or to DMEM + NGF. Staurosporine was dissolved in DMSO, further dilutions were prepared in the respective media so that the final DMSO concentration did not exceed $0.1 \%$.

\section{Quantitative neuronal morphology}

Morphological changes of neurons were automatically quantified as follows. 
Briefly, at the appropriate times, glutaraldehyde was added directly to the medium and left for 30 minutes at room temperature. This ensured that the morphology of the cells at that time point reflected the real situation. The cells were observed through transmitted light mode in an Axiovert microscope (Zeiss Oberkochen, Germany), equipped with a Marzhauser scanning stage driven by an Indy workstation (Silicon Graphics, Mountain View, USA). Images were captured using a MX5 video camera (HCS). About 3000 cells were evaluated in 64 aligned images, forming a $8 \times 8$ square matrix of images. The exact alignment of the images ensured that neurites could be followed from one image field into the next. The analysis software automatically calculated cell body area and neurite lengths. The neurite length per cell was calculated for free lying cells (not within a cluster). The fraction of positive cells was defined as the fraction of cells having at least one neurite with a length exceeding twice the cell body diameter.

\section{Immunocytochemistry}

At the appropriate time-points, the cells were fixed with $4 \%$ paraformaldehyde for 20 minutes in PHEM buffer followed by a permeabilisation step using Triton X-100 $0.5 \%$ in PHEM buffer for 30 minutes. Free aldehyde groups were reduced with $1 \mathrm{mg} / \mathrm{ml} \mathrm{NaBH} 4$ for 10 minutes, also in PHEM.The tau-epitope was visualised using the phosphorylation-specific antibody AT8 (Innogenetics, Ghent, Belgium) in combination with Immuno Gold Silver Staining. This combination was used to avoid bleaching problems during quantification.

\section{Quantitative immunocytochemistry}

The preparations were observed in brightfield microscopy. Microscope illumination was held constant for all experiments. Image analysis was performed with the image analysis package SCIL (University of Amsterdam. the Netherlands).

In each image the total number of cells and the degree of epitope expression were determined by fully automatic thresholding. Briefly, background variations were eliminated by subtracting a field containing no cells at all. 
The resulting image was then thresholded and the resulting binary image, containing cell bodies and neurites, was labeled. Non-specific small objects, i.e. those below a critical size, were excluded. From this labeled image, the grey value intensity and size of each individual (cellular) object $\mathbf{n}$ was calculated by means of the density routine. At this point three different parameters were calculated.

- Epitope fraction : A histogram of values was also calculated in a sample in which the primary antibody was omitted and replaced by normal goat serum. An "epitope" threshold intensity was calculated as the sum of the mean intensity and one standard deviation. A cell was considered positive for AT8 staining if its intensity exceeded this intensity threshold.

- Epitope area expression: The mean intensity of the reference sample was used to segment the cells and using the "epitope" threshold (as calculated above), the area of positive epitopes was calculated as a fraction.

- Intensity: The mean staining intensity per cell was calculated for each condition.

\section{Viability measurements}

Cell survival was measured using the XTT-method on the basis of the conversion of the substrate to a water soluble formazan product by mitochondrial dehydrogenases from viable cells only. At appropriate times, a prewarmed solution of $1 \mathrm{mg} / \mathrm{ml} \mathrm{XTT} \mathrm{solution} \mathrm{in} \mathrm{the} \mathrm{appropriate} \mathrm{medium} \mathrm{was}$ added to the culture medium and further incubated for $2 \mathrm{~h}$ at $37^{\circ} \mathrm{C}$. After this time the plates were shaken for 10 minutes at $37^{\circ} \mathrm{C}$ and the optical density was read at $450 \mathrm{~nm}$ using $650 \mathrm{~nm}$ as a reference on a Molecular Dynamics plate reader. The data are presented as values relative to the control samples (mean of 3 points).

\section{Statistical analysis}

A statistical analysis was carried out with the JMP package.

\section{Results}


PC12 cells cultured for 7 days in $1 \%$ HS supplemented with $50 \mathrm{ng} / \mathrm{ml} \mathrm{NGF}$ showed a substantial degree of neurite outgrowth. Removal of NGF induced a marked reduction in the number of positive, neurite-bearing ceils (Fig. 1). Using automatic quantitative light microscopy we evaluated the loss of neuronal architecture as a function of time. Table 1 shows that the fraction of positive cells (having neurites at least twice as long as the cell-body diameter) was significantly reduced after $24 \mathrm{~h}$ of NGF deprivation. Interestingly, we observed that the neurite length of individual positive cells per se does not seem to decrease as much. This suggests that neurite retraction is at fast process. Pre-treatment with staurosporine, $4 \mathrm{~h}$ before NGF depletion, dose-dependently attenuated the morphological changes.

As these morphological changes suggested a destabilization of the neuronal cytoskeleton, we investigated the tau Ser202 phosphorylation using the
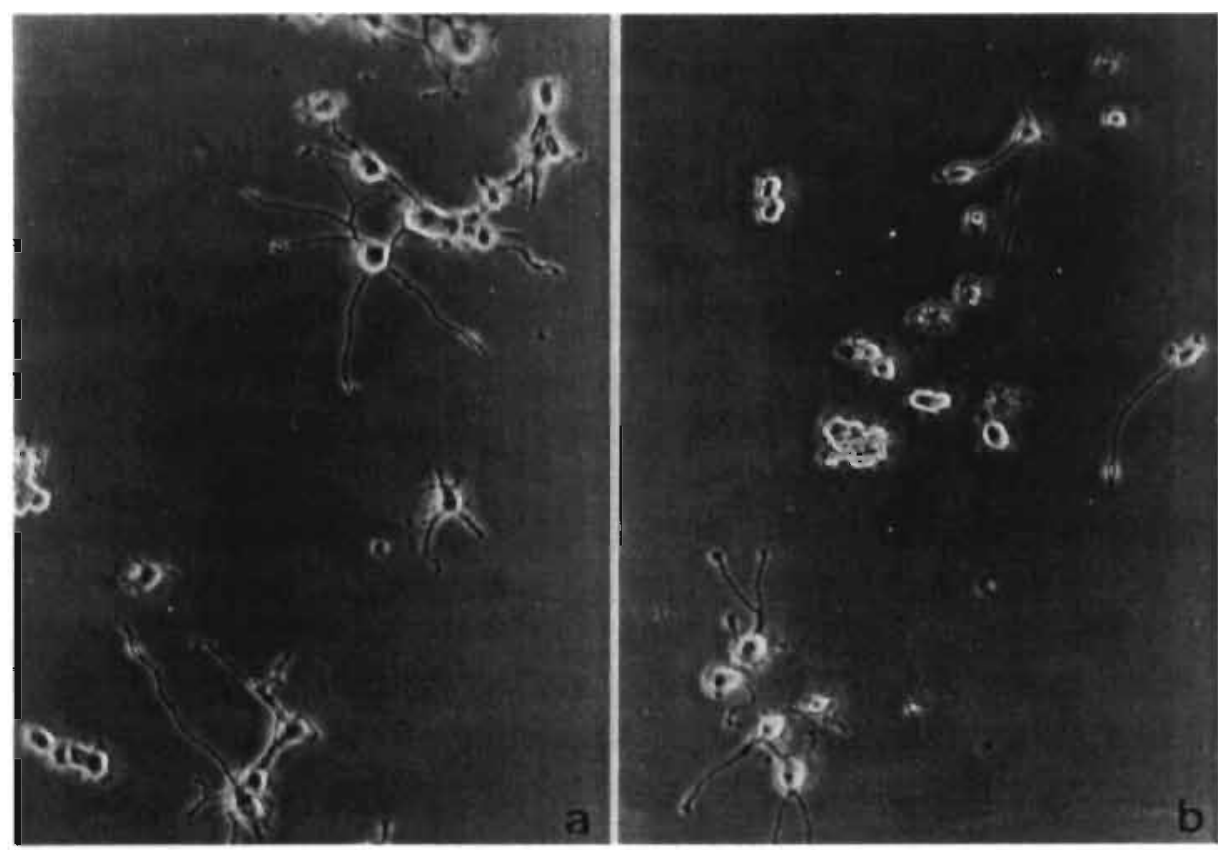

Figure 1: Phase-contrast illustration of the morphological changes upon NGF deprivation. (a) PC12 cells grown in the presence of NGF for 7 days. (b) Identical cuiture $24 \mathrm{~h}$ after removal of neurotrophic supplies. Most cells retracted their neurites and some apoptotic cells are present in the deprived cultures ( $x$ 250). 
Table 1: Effect of staurosporine on the morphological retraction after $48 \mathrm{~h}$ in NGF-deprived PC12 cells. The fraction of positive cells and the mean neurite length of positive cells is given (mean and standard deviation), each normalised to the situation with $50 \mathrm{ng} / \mathrm{ml} \mathrm{NGF}$. (six independent experiments, ${ }^{*} p<0.05$, Dunnet's $t$-test)

\begin{tabular}{l|l|l}
\hline Conc. Staurosporine (nM) & Fraction $(\%)$ & Neurite length \\
\hline 0 & $50.0 \pm 17.4$ & $101.0 \pm 18$ \\
\hline 10 & $81.4 \pm 8.0^{*}$ & $101.1 \pm 15.2$ \\
\hline 50 & $88.6 \pm 24.9^{*}$ & $103.1 \pm 11.4$ \\
\hline 100 & $96.0 \pm 23.1^{*}$ & $95.7 \pm 5.6$ \\
\hline
\end{tabular}

phosphorylation dependent AT8 monoclonal antibody. A moderate AT8 signal was observed in NGF differentiated PC12 cells (Fig. 2a), mostly concentrated in the distal parts of the neurites. Upon NGF-deprivation the AT8 intensity increased, most distinctly towards the more proximal regions of the neurites (Fig. 2b).

Because of the technical problems of adherence with cells dying during apoptosis, we chose to quantify this upregulation of the AT8 signal by the gentler approach of immunocytochemistry rather than by Western blot.

Epitope area expression increased from 0.141 after $4 \mathrm{~h}$ in NGF-containing medium ( $n=187$ cells) to 0.354 after $4 \mathrm{~h}$ of NGF-deprivation ( $n=99$ cells) $(p<0.001$, likelihood chi-square Pearson's test) and from 0.235 after $24 \mathrm{~h}$ in NGF-containing medium ( $n=138$ cells) to 0.65 after $24 \mathrm{~h}$ of NGF-deprivation ( $n=142$ cells) $(p<0.00 \|$, likelihood chi-square Pearson's test). In a second experiment, the level of AT8 expression nearly doubled during NGF deprivation and staurosporine at $100 \mathrm{nM}$ attenuated this increase in AT8 expression (Table 2). In a third experiment, the mean intensity of epitope expression (after subtraction of the mean intensity of the antibody control) was. again increased, from $26.4 \pm 1.0$ (mean grey value \pm SEM, $n=331$ cells) in the situation with $50 \mathrm{ng} / \mathrm{ml} \mathrm{NGF}$ to $35.3 \pm 0.4$ ( $n=880$ cells) with NGF deprivation ( $p<0.001$ Anova student's t-test) and to $31.4 \pm 0.9(n=662$ cells) with NGF deprivation with $100 \mathrm{nM}$ staurosporine ( $p<0.05$ vs. NGF deprivation) . 


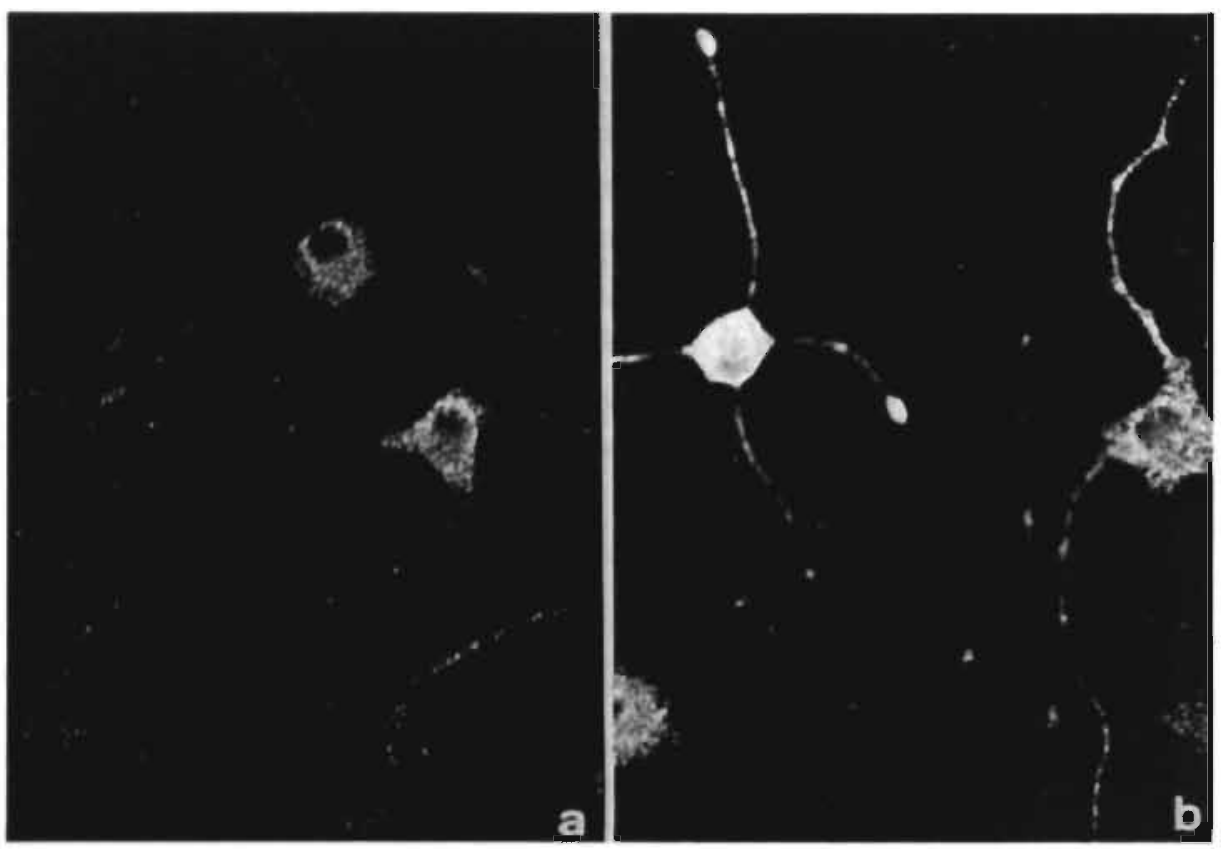

Figure 2: (a) Normal AT8 Iocalization in NGF-control situations. Note the preferentially peripheral (although weak) distribution of AT8 positive epitopes ( $x$ 170). (b) Upon NGF deprivation, ATE immunoreactivity redistributed towards a more proximal localization and the intensity increased as shown by Immuno Gold Silver Staining ( $\times 230$ ). The use of Immuno Gold Silver Staining allows for the observation in either brightfield- or epi-illumination microscopy, both systems give comparable results.

Tabie 2. Fraction of AT8 stained celis after $24 \mathrm{~h}$. A cell was considered positive if its intensity exceeded an "epitope" threshold value, calculated as the mean plus one standard deviation of the intensity found in the antibody control experiment (see text). NGF was used at a concentration of $50 \mathrm{ng} / \mathrm{ml}$, staurosporine at $100 \mathrm{nM}$. The table shows the number of positive cells, the total number of cells and the percentual fraction. (" $p<0.05, " * p<0.001$ vs. DMEM control; likelihood chi-square test)

\begin{tabular}{l|l|l}
\hline Condition & Number of positive cells & Fraction (\%) \\
\hline DMEM & $141 / 285$ & $49.5 \%$ \\
\hline DMEM+Staurosporine & $201 / 498$ & $40.4 \% *$ \\
\hline DMEM+NGF & $105 / 408$ & $25.8 \% * *$ \\
\hline DMEM+NGF+Staurosporine & $81 / 234$ & $34.6 \% * *$ \\
\hline
\end{tabular}


The effect of staurosporine on total cell survival was measured by mitochondrial activity, using conversion of XTT. Staurosporine did not impair cell survival by itself (data not shown), whereas pretreatment, $4 \mathrm{~h}$ before NGF deprivation, yielded a dose-dependent reduction of the number of dying cells (Fig. 3).

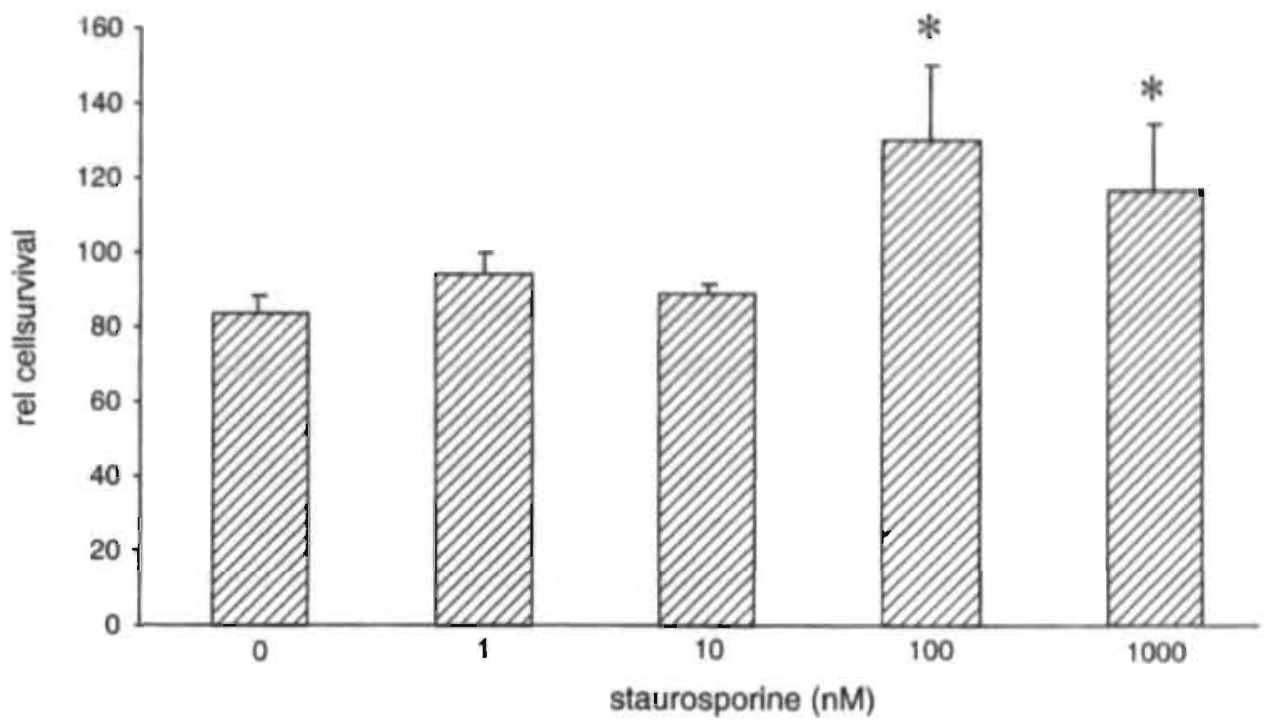

Figure 3: Staurosporine, a broad-spectrum kinase inhibitor, dose-dependently attenuated cell death, which normally occurs $24 \mathrm{~h}$ after NGF deprivation. The mean and standard deviation over six independent experiments is given.

(" $p<0.05$, Dunnet's t-test)

\section{Discussion}


This study shows that in differentiated PC12 cells, the level of tau protein, phosphorylated at Ser202/Thr205 and monitored by the expression of AT8, increased upon removal of neurotrophic factors.

As further evidence of the role of kinase activation during apoptosis, we have also shown that staurosporine, a broad-spectrum kinase inhibitor, attenuates tau phosphorylation and has a dose dependent protective effect on cellular integrity and viability after NGF-deprivation in PCI2 cells. Staurosporine by itself has been reported to induce apoptosis in specific cell types, mostly however in proliferating cells (Hsu and Yeh, 1996). There are more examples of compounds, such as olomoucine and roscovitine (Abraham et al., 1995; Park et al., 1996) which induce apoptosis in proliferating cells and attenuate apoptosis in fully differentiated cells. These compounds presumably act at the level of cell cycle regulators such as cyclin/cdk pairs.

The data suggest that during NGF-deprivation tau may be a substrate for activated kinases. Several kinases have been proposed as possible regulators of tau hyperphosphorylation, among them MAPkinase, GSK3ß, p34cdc2 and cdk5 (Morishima-Kawashima et al., 1995). Interestingly the mitogenic MAPkinase pathway is activated upon growth factor stimulation, p34cdc2 is normally active in proliferative cells while cdk5 is a cdc2-related kinase which is strongly expressed in the brain. Inappropriate activation of these kinases during the initiation of the apoptotic process may lead to aberrant tau phosphorylation which may have far-reaching-effects on cytoskeletal stability. The findings from this study concerning the localization of AT8 positive epitopes are in line with observations on AD brains, in which the appearance of AT8 epitopes in dystrophic neurites precedes their presence in the cell soma (Sherwood et al., 1994). As microtubule-associated-proteins regulate the stability of the microtubule complex, the increased level of hyperphosphorylated tau in the most distal parts of the neurites can locally influence the dynamic instability of the microtubules. A change in microtubule integrity diminishes the axonal flow and impedes the formation of neuronal processes.

The observation that only the fraction of positive cells clearly decreases in this process, suggests that once a neurite starts to retract, it shrinks completely. 
This study reports for the first time an association between apoptosis and aberrant tau phosphorylation and in addition points towards cytoskeletal dysfunction. This is particularly interesting for the study of AD pathology since evidence of apoptosis has been found in post-mortem AD brains (Su et al., 1994; Smale et al., 1995). In addition, the Presenilin-2 (linked to earlyonset Alzheimer's Disease) gene is similar to the apoptosis-linked gene A.LG3 (Vito et al., 1996) and has been reported to increase apoptosis induced by NGF-withdrawal in PC12 cells (Deng et al., 1996). Whether aberrant tau-phosphorylation is a sign of neurons undergoing apoptosis or an obligatory check-point, triggering more downstream events in programmed cell death, needs to be investigated.

\section{Acknowledgements}

The authors are indebted to L. Leijssen, G. Verheyen and G. Jacobs for their skilful photographic work. In addition, the assistance of Mr. Roger Nuyens in the solution of hardware problems and of Mr. Frans Cornelissen in connection with software is much appreciated. 


\section{References}

Abraham, R.T., Acquarone, M., Andersen, A., Asensi, A., Belle, R., Berger, F., Bergounioux, C., Brunn, G., Buquet-Fagot, C., Fagot, D. et al. Cellular effects of olomoucine, an inhibitor of cyclin-dependent kinases. Biol. Cell (1995) 83: 105-120.

Batistatot, A. and Greene, L.A. Aurintricarboxylic acid rescues PCI2 cells and sympathetic neurons from cell death caused by nerve growth factor deprivation: correlation with suppression of endonuclease activity. J. Cell Biol. (1991) 115: 461-471.

Deng, G., Pike, C.J. and Cotman, C.W. Alzheimer-associated presenilin-2 confers increased sensitivity to apoptosis in PC12 cells. FEBS Lett. (1996) 397: 50-54.

Forloni, G., Chiesa, R., Smiroldo, S., Verga, L., Salmona, M., Tagliavini, F. and Angeretti. $\mathbf{N}$. Apoptosis mediated neurotoxicity induced by chronic application of beta amyloid fragment 25-35. Neuroreport (1993) 4: 523-526.

Hsu, H.L. and Yeh, N.H. Dynamic changes of NuMA during the cell cycle and possible appearance of a truncated form of NuMA during apoptosis. J. Cell Sci. (1996) 109: 277-288.

Mattson, M.P., Tomaselli, K.J. and Rydel, R.E. Calcium-destabilizing and neurodegenerative effects of aggregated beta-amyloid peptide are attenuated by basic FGF.

Brain Res. (1993) 621: 35-49.

Mercken, M., Vandermeeren, M., Lubke, U., Six, J., Boons, J., Van de Voorde, A., Martin, J.J. and Gheuens, J. Monoclonal antibodies with selective specificity for Alzheimer Tau are directed against phosphatase-sensitive epitopes. Acta Neuropathol. (1992) 84: 265-272.

Mesner, P.W., WInters, T.R. and Green, S.H. Nerve growth factor withdrawal-induced cell death in neuronal PC12 cells resembles that in sympathetic neurons.

J. Cell Biol. (1992) 119: 1669-1680.

Morishima-Kawashima, M., Hasegawa, M., Takio, K., Suzuki, M., Yoshida, H., Watanabe, A., Tytani, K. and Ihara, Y. Hyperphosphorylation of tau in PHF.

Neurobiol. Aging (1995) 16:365.71.

Park, D.S. Farinelli, S.E. and Greene, L.A. Inhibitors of cyclin-dependent kinases promote survival of posi-mitotic neuronally differentiated $\mathrm{PC} 12$ cells and sympathetic neurons.

J. Biol. Chem. (1996) 271: 8161-8169.

Rair, M.C. Social controls on cell survival and cell death. Nature (1992) 356: 397-400. 
Sherwood, S.W., Sheridan. J.P. and Schimke, R.T. Induction of apoptosis by the anti-tubulin drug colcemid: relationship of mitotic checkpoint control to the induction of apoptosis in HeLa S3 cells. Exp.Cell Res. (1994) 215: 373-379.

Smale, G., Nichols, N.R., Brady, D.R., Finch, C.E. and Horton, W.E., Jr. Evidence for apoptotic cell death in Alzheimer's disease. Exp. Neurol. (1995) 133: 225-230.

Su, J.H., Anderson, A.J., Cummings, B.J. and Cotman, C.W. Immunohistochemical evidence for apoptosis in Alzheimer's disease. Neuroneport (1994) 5: 2529-2533.

Vito, P., Lacana, E. and D'Adamio, L. Interfering with apoptosis: Ca*t-binding protein ALG-2 and Alzheimer's disease gene ALG-3. Science (1996) 271: 521-525. 



\section{Okadaic acid-induced apoptosis in}

\section{neuronal cells:}

\section{Evidence for an abortive mitotic attempt}

Rony Nuydens ${ }^{2 .}$, , Mirjam de Jong a, Gerd Van Den Kieboom ", Cara Heers a, Gwenda Dispersyn ", Frans Cornelissen ", Roger Nuyens a, Marcel Borgers a.b and Hugo Geerts *

- Department of Cell Physiology, Life Sciences, Janssen Research Foundation, Beerse, Belgium

'Department of Molecular Cell Biology and Genetics, Maastricht University, the Netherlands

'Preclinical development, Janssen Research Foundation. Neuss, Germany

${ }^{a}$ Department of Biochemistry, University of Antwerp, Antwerp, Belgium

J. Neurochem. 70, 1124-1133 (1998)

Abstract

There is increasing evidence that apoptosis in postmitotic neurones is associated with a frustrated attempt to reenter the mitotic cycle. Okadaic acid, a specific protein phosphatase inhibitor, is currently used in models of Alzheimer's research to increase the degree of phosphorylation of various proteins, such as the microtubule-associated protein tau. Okadaic acid induces programmed cell death in the human neuroblastoma cell lines TRI 4 and NT2-N, as is evidenced by fragmentation of DNA and 
attenuation of this process by protein synthesis inhibitors.

In differentiated TR14 cells, okadaic acid increases the fraction of cells in the $S$-phase, induces the appearance of cyclin $B_{1}$ and cyclin $D_{1}$ markers of the cell cycle, and triggers a time-dependent increase in DNA fragmentation after release of a thymidine block. Fully differentiated NT2-N cells are forced to enter the mitotic cycle as shown by DNA staining. Chromatin condensation and chromosome formation are initiated but the cells fail to complete their mitotic cycle. These data suggest that okadaic acid forces differentiated neuronal cells into the mitotic cycle. This pattern of cyclin upregulation and cell cycle shift is compared with apoptosis induced by neurotrophic factor deprivation in differentiated rat pheochromocytoma PCI2 cells.

\section{Introduction}

Apoptosis of neuronal cells plays a major role during development and fine-tuning of the nervous system. The amount of neurotrophic factors released by the target tissue regulates the cell survival and the innervation density of this particular tissue. There is, however, increasing evidence that this form of cell death may also contribute to some chronic neurological disease states (for a review see Bredesen, 1995). In these situations of chronic neurodegeneration it may attenuate the inflammatory reaction to the surrounding cells and tissues. As an example it has been shown that during Alzheimer's disease (AD), neurons display the typical characteristics of programmed cell death and as such contribute to the neuronal cell loss observed during progression of the disease (Su et al., 1994: Lassmann et al., 1995).

Recently, it has been argued that apoptosis in differentiated neuronal cells is 
a consequence of the cellular attempts to escape the $\mathrm{G}_{0}$ status and reenter the cell cycle (Park et al.. 1996). Indeed, the programmed cell death in neuronal cells is accompanied by numerous characteristics normally associated with proliferating cells: upregulation of $\mathrm{p} 34^{\mathrm{cok} 2}$ (Brooks et al., 1993), and induction of cyclin B। and cyclin Di (Freeman et al., 1994) to levels normally seen in proliferative cells.

One of the hallmarks in $\mathrm{AD}$ is the appearance of highly phosphorylated tau isoforms (Grundke-Iqbal et al., 1986) in paired helical filaments. This might lead to the dissociation between tau and microtubules and subsequent cytoskeletal instability (A.lonso et al., 1994). Recently, it was shown that in Chinese hamster ovary cells transfected with the neuronal microtubule-associated protein tau, this protein is hyperphosphorylated during mitosis as indicated by the use of phosphorylation sensitive-antibodies and autoradiography (Pope et al., 1994; Preuss et al., 1995). When apoptosis is induced in neuronal cells by sodium butyrate, tau also becomes hyperphosphorylated (Nuydens et al., 1995a).

Aberrant tau phosphorylation can be induced in neuroblastoma cells by treatment with okadaic acid (Vandermeeren et al., 1993; Sautiere et al., 1994; Shea, 1996). At nanomolar concentrations okadaic acid is a specific inhibitor of protein phosphatase 2A activity. The first evidence for an effect of okadaic acid on the cell cycle came from the observation that low concentrations of this inhibitor interfered with the normal progression of LLC-PK cells through mitosis by blocking the cells in a metaphase-like state. After prolonged incubation, multipolar spindles formed, and the metaphase-plate was disrupted (Vandre and Wills, 1992).

In this study we first show that okadaic acid induces apoptosis in human neuroblastoma TR 14 cells, both in proliferative and differentiated states, and in fully differentiated NT2-N neurons, which can serve as a model for human postmitotic neurons. We compared this process with another well-documented example of programmed cell death, such as nerve growth factor (NGF) deprivation in fully differentiated PC12 cells. We further investigate the relation between neuronal apoptosis and the reappearance of mitosis-related events, within the context of the cell cycle/apoptosis model. 


\section{Material and Methods}

\section{Cell culture}

PC.12. cells were grown in Dulbecco's minimal essential medium (DMEM) supplemented with $7.5 \%$ fetal bovine serum and $7.5 \%$ horse serum. For the actual experiments, PCi2 cells were plated on poly-L-lysine-coated coverslips. After I day the cells were placed in DMEM supplemented with I \% horse serum and $50 \mathrm{ng} / \mathrm{ml}$ NGF (Sigma) for at least 7 days, and the medium was changed every 3-4 days. For the deprivation experiments medium was changed either to DMEM alone or to DMEM plus NGF.

TR 14 neuroblastoma cells were a generous gift of Dr. G. Carmeliet (Centre for Human Genetics - KU, Leuven, Belgium) and grown in DMEM/F12 medium supplemented with $10 \%$ fetal calf serum. Differentiation was induced by treating the cells during 4 days with I mM dibutyryl cyclic AMP in serum-free medium.

Synchronised cultures were obtained after a double thymidine block with 2 $\mathrm{mM}$ thymidine, for 16 and 18 hours, respectively, separated by an 8 -h recovery period.

NT2-N human neuroblastomas were differentiated as described (Pleasure et al., 1992). In brief, $2 \times 10^{6} \mathrm{hNT} 2$ cells were treated in T75 flasks with $10 \mu \mathrm{M}$ retinoic acid for 4 weeks. The cells were differentially harvested and replated in DMEM with $10 \%$ fetal calf serum and supplemented with $1 \mu \mathrm{M}$ cytosine arabinoside, $10 \mu \mathrm{M}$ fluorodeoxyuridine and $10 \mu \mathrm{M}$ uridine.

\section{Cell survival}

Cell survival was measured using 3-(4,5-dimethylthiazol-2-yl-2,5-diphenyltetrazolium bromide (MTT: in PCI2 cells) or 2,3-bis(2-methoxy-4-nitro-5sulfopheny!-2H-tetrazolium-5-carboxalilide inner salt (XTT: in TR14 cells). This is based on the conversion of the substrate to a water-solubie formazan. product by mitochondrial dehydrogenases of viable cells only (Mossman, 1983). At appropriate times, prewarmed solution of $0.3 \mathrm{mg} / \mathrm{ml}$ XTT or 0.5 $\mathrm{mg} / \mathrm{ml} \mathrm{MTT}$ in $\mathrm{Ca}^{2+}$-and $\mathrm{Mg}^{2+}$ free phosphate buffered saline was added to the culture medium. The plates were further incubated for $2 \mathrm{~h}$ at $37^{\circ} \mathrm{C}$ and shaken 
for $10 \mathrm{~min}$. Optical density (OD) was read at $450 \mathrm{~nm}$ using $650 \mathrm{~nm}$ as a reference on a plate reader (Molecular Dynamics). In each 96-well plate two determinations of $\mathrm{OD}$ at each concentration were performed.

\section{Time-lapse Video-microscopy}

A MXR (Adimec, Eindhoven, the Netherlands) camera was mounted on top of an Axiovert 35 (Zeiss, Oberkochen, Germany) microscope. The video output was connected to the VINO analogue video input port on an Indy Workstation (Silicon Graphics, USA). Image processing was performed using the SCIL software package (University of Amsterdam, the Netherlands).

A computer-driven motorized stage (Merzhauzer, Germany) was used to record several sets of $(\mathrm{x}, \mathrm{y}, \mathrm{z})$ coordinates corresponding to the fields of interest. Movies were composed by driving the stage to the fields, executing an autofocus routine, grabbing the image, and appending it to the movie-file of the current field in the SGI movie format. The COSMO hardware JPEG-(de)compression board allowed real-time display of the movies ( 25 frames/s). Movies can be analyzed by reading each frame in turn and extracting the desired features with the SCIL-Image software.

\section{Cell staging by flow cytometry}

At the appropriate time-points, cells were mechanically detached from the substrate by scraping, centrifuged, fixed with ethanol $70 \%$ for $1 \mathrm{~h}$ at $4^{\circ} \mathrm{C}$ and rinsed in phosphate-buffered saline. The cells were then pelleted and incubated with RNase and propidium iodide (PI). The stained cells were analyzed on a Cytoron flowcytometer (Ortho Pharmaceuticals, USA). The various fractions of the cell cycle were calculated with the ModFit cell cycle analysis program.

\section{Immunocytochemistry}

At the appropriate time-points, the cells were fixed with paraformaldehyde for $10 \mathrm{~min}$ followed by methanol at $-20^{\circ} \mathrm{C}$ overnight. The following antibodies were used for immunodetection: cyclin $\mathrm{B}_{1}$ (clone2 $\mathrm{H1}-\mathrm{H} 6$; Calbiochem), cyclin D (clone G124-326; Pierce), p34 de2 (Santa Cruz Biotechnology) and AT8 
(Innogenetics). Goat anti-mouse-cyanine 3 (GAM-Cy3)-labeled antibodies were used as secondary antibodies. Double labeling for tubulin was performed using an affinity-purified polyclonal antibody or a monoclonal anti-tubulin (Sigma Biosciences). In that case goat anti-rabbit-fluorescein isothiocyanate (GAR-FITC)-labeled antibodies were used. Nuclei were counterstained using 4,6-diamidino-2-phenylindole, and the preparations were mounted in Gelvatol containing $100 \mathrm{mg} / \mathrm{ml}$ diazabicyclo[2.2.2]octane to avoid bleaching.

\section{Quantitative lightmicroscopy}

The preparations were observed in epifluorescence mode on an Axiovert 35 microscope equipped with a Marzhauser scanning stage and MXRi CCD camera, and digitized by an Indy workstation (Silicon Graphics). Image analysis was performed with the SCIL package on the Silicon Graphics workstation.

In each image the total number of cells and the degree of epitope expression were determined by fully automatic thresholding. In brief, cells and neurites were detected by a Have edge-detection routine followed by a holeclose operation. This ensured correction for the varying background. The resulting binary image, containing only the cell bodies and neurites, was labeled, and nonspecific small objects, i.e., those below a critical size, were excluded. From this labeled image, the fluorescence intensity of each individual (cellular) object $\mathrm{n}$ was reconstructed by ANDING the original image with a binary image, derived from the labeled image containing only pixels belonging to that cell $\mathrm{n}$. From this list of cellular objects, parameters such as mean intensity can be calculated.

\section{Analysis of DNA fragmentation}

DNA labeling was performed on living cells by meañs of the SYTO-9 probe (Molecular Probes, Eugene, Oregon, USA) and the preparations were observed on an Axioplan microscope using classical fluorescein isothiocyanate optics $\left(\lambda_{\text {exc }}<505 \mathrm{~nm}\right.$; band-pass emission $520<\lambda_{\text {em }}<560 \mathrm{~nm}$ ), whereas PI labeling was visualized using rhodamine filters $\left(\lambda_{\text {exc }}<560 \mathrm{~nm}\right.$; emission $\left.590<\lambda_{\mathrm{em}}\right)$. This made it possible to distinguish clearly between intact cell membranes and 
intact nuclei versus mitotic and versus fragmented nuclei (apoptotic cells). At least 300 cells were evaluated for each condition.

\section{Statistical analysis}

Statistical analysis was carried out with the Dunnett's $t$ test and the Pearson chi $^{2}$ test, where appropriate, using the statistical software package JMP.

\section{Results}

\section{Induction of neuronal apoptosis}

In differentiated NT2-N neuroblastoma cells, okadaic acid, at a concentration of $50 \mathrm{nM}$, increases the degree of tau protein phosphorylation as illustrated by AT8 immunocytochemistry (Fig. 1). Similar results have been obtained in
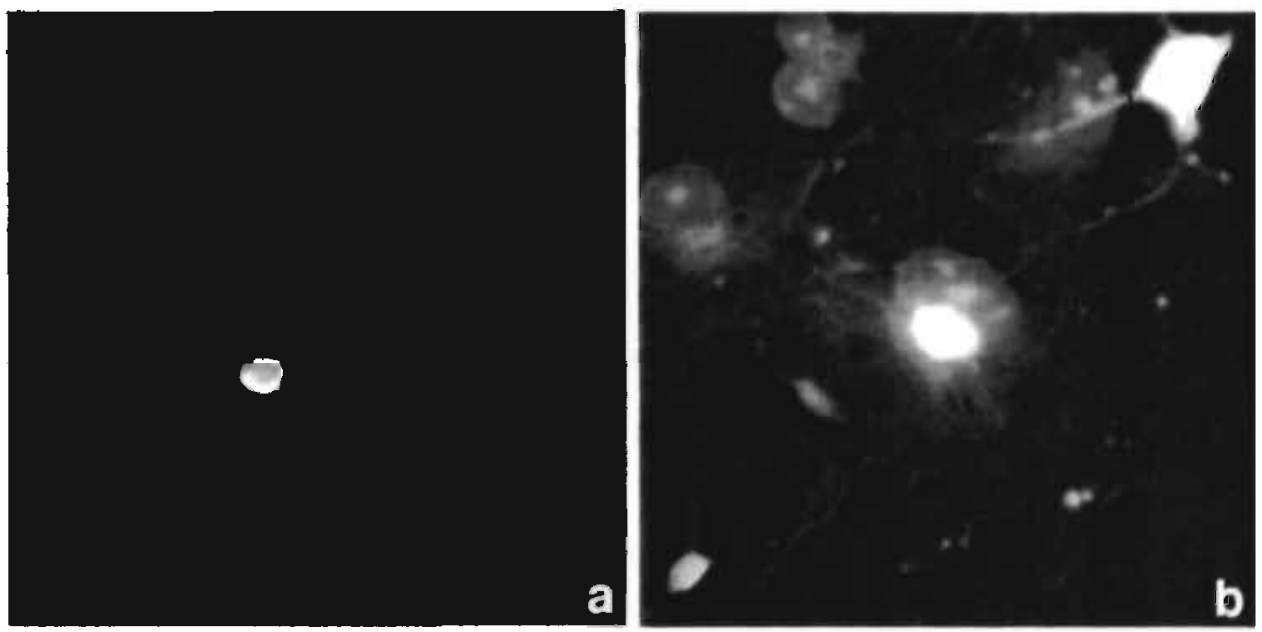

Figure 1. Immunocytochemistry of AT8 in fully differentiated NT2-N cells observed with fluoresceine isothiocyanate microscopy. In control conditions (a), a moderate signal in the cell body is observed. No clear staining of axons is visible. Application of $50 \mathrm{nM}$ okadaic acid for $24 \mathrm{hr}$ (b) increases the AT8 signal, suggesting an increased phosphorylation of tau proteins at Ser ${ }^{202} / \mathrm{Thr}^{205}$. Note the more pronounced increase in the cell body versus the axons and the distal-to-proximal gradient of AT8 label. 
cultures of differentiated TR14 cells. In these cells the phosphatase inhibitor okadaic acid showed a biphasic dose-dependent effect on cell survival as measured by XTT conversion (Fig. 2). At concentrations starting at $50 \mathrm{nM}$ and up, cellular toxicity dose-dependently increased. For instance, at $100 \mathrm{nM}$, cell survival was reduced to $51 \pm 5 \%(n=36)$, whereas application of the protein synthesis inhibitor cycloheximide at $350 \mu \mathrm{M}$ increased cell survival to $69 \pm 7 \%(n=36 ; p<0.01)$. Manual counting showed that treatment of TR 14 cells with $1 \mu \mathrm{M}$ okadaic acid actually increased the fraction of fragmented nuclei from 5 to $27 \%$ in $24 \mathrm{~h}$. However, at subtoxic concentrations (between 1 and $10 \mathrm{nM}$ ), a substantial increase in measured XTT signal was observed, especially in the differentiated cultures. As expected the inactive form of okadaic acid, norokadaic acid, did not show any toxicity at all.

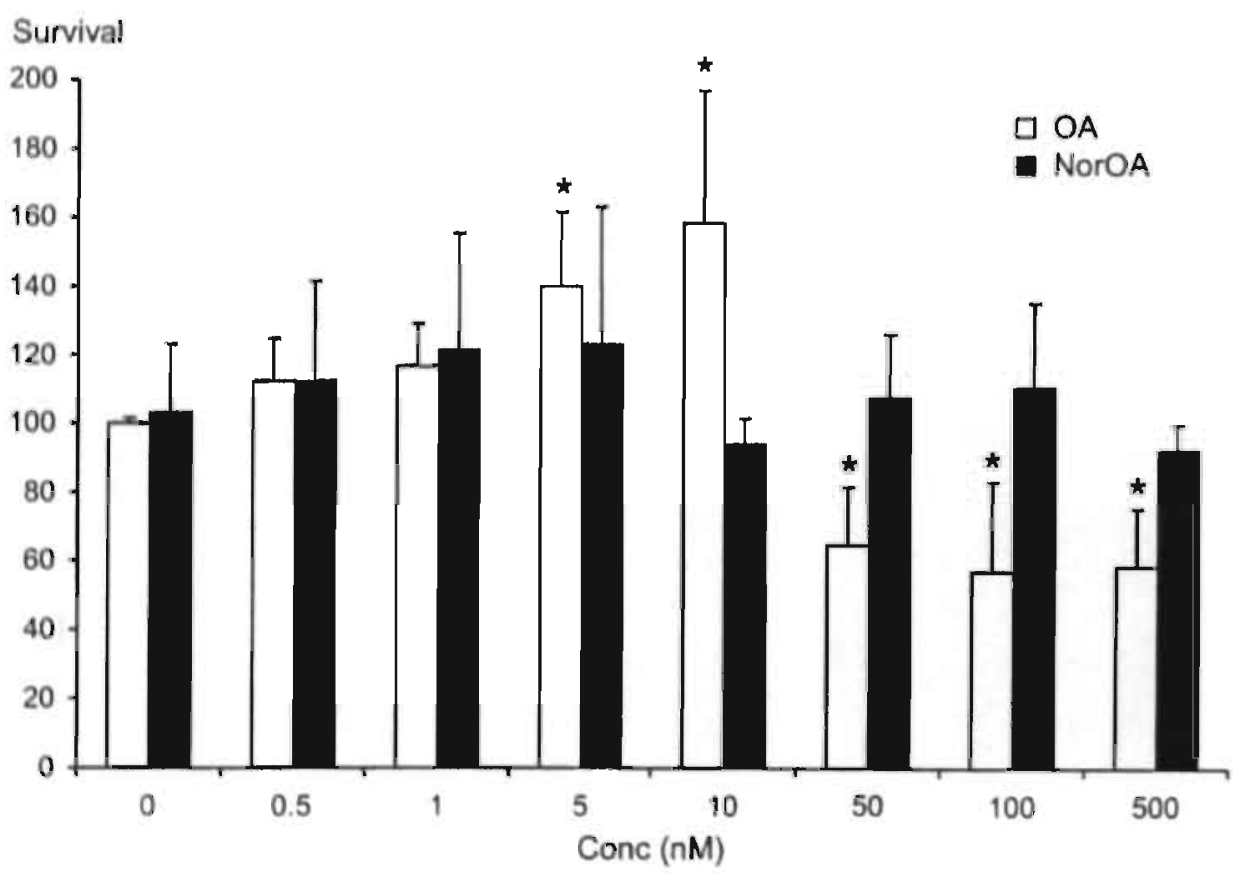

Flgure 2. Dose-dependent effect of okadaic; acid (OA) and its inactive isoform, norokadaic acid (NorOA), on the survival of differentiated TR14 cells after a 24-h exposure (treated with $1 \mathrm{mM}$ dibutyryl cyclicAMP for 3 days prior to treatment). Data are normalized to OD values in the absence of OA. " $p<0.05$ with Dunnett's $t$ test. 
TR 14 cells maintained in the presence of serum and in the absence of any dibutyryl cyclic AMP were slightly less sensitive to the effects of okadaic acid ( Table 1).

Table 1. Effect of okadaic acid treatment for $24 \mathrm{~h}$ on the survival of both nondifferentiated (in serum-containing medium) and differentiated (treated for 3 days with $1 \mathrm{mM}$ dibutyryl cyclicAMP) TR14 cells.

\begin{tabular}{l|l|l}
\hline $\begin{array}{l}\text { Concentration of okadaic acid } \\
(\mathrm{nM})\end{array}$ & Non-differentiated cells & $\begin{array}{l}\text { Differentiated } \\
\text { cells }\end{array}$ \\
\hline 0 & 100 & 100 \\
\hline 0.1 & $101.8 \pm 8.8$ & $103 \pm 8.2$ \\
\hline 0.5 & $100.4 \pm 6.29$ & $112 \pm 11.6$ \\
\hline 1 & $103.8 \pm 7.3$ & $117.2 \pm 12.2$ \\
\hline 5 & $112.7 \pm 12.3^{\circ}$ & $139.3 \pm 21.5^{\circ}$ \\
\hline 10 & $130 \pm 8.5^{\circ}$ & $158.3 \pm 36.8^{\circ}$ \\
\hline 50 & $83.4 \pm 30.3$ & $64.9 \pm 16.1^{\circ}$ \\
\hline 100 & $62.6 \pm 13.7^{\circ}$ & $57.1 \pm 25.9^{\circ}$ \\
\hline 500 & $62.1 \pm 6.5^{\circ}$ & $59.1 \pm 16.4^{\circ}$ \\
\hline
\end{tabular}

Data are mean \pm SEM values form at ieast six experiments for XTT measurements of viabilitty.

$\cdot p<0.05$ by Dunnett's $t$-test versus solvent control.

In $\mathrm{PCl} 2$ cells the removal of NGF caused $30 \%$ cell death within $24 \mathrm{~h}$ (Farinelli and Greene, 1996). In our PC12 system, survival - as measured using the MTT assay - was reduced to $75 \%$ after 24 -h deprivation of NGF. Manual counting of nuclear morphology revealed that the fraction of apoptotic nuclei increased from $0.4 \%$ to $6.5 \%$ after $8 \mathrm{~h}$ of NGF deprivation. 


\section{Apoptosis and mitosis in synchronised TRI4 cells}

If apoptosis and mitosis have some mechanisms in common. then these events should show a temporal correlation. In order to study this hypothesis, we blocked proliferative TR14 cells in S-phase by a 16-h thymidine block, followed by an 8-h recovery period and finally a 18-h thymidine block. One hour after this last thymidine block, okadaic acid $\left(10^{-7} \mathrm{M}\right)$ or solvent was added to the cultures. At different time points the cells were fixed and permeabilized, and the percentages apoptotic or mitotic cells were determined microscopically using PI as DNA label. Cells were considered as mitotic when the chromosome pairs were readily discernible. Apoptotic cells were characterized by means of nuclear fragmentation. In control cultures the percentage mitotic TR 14 cells linearly increased starting $2 \mathrm{~h}$ after removal of the last thymidine block. In cultures treated with okadaic acid the fraction of apoptotic cells time-dependently increased as well, with a similar linear relationship as in the control conditions. A typical example is given in Fig. 3.

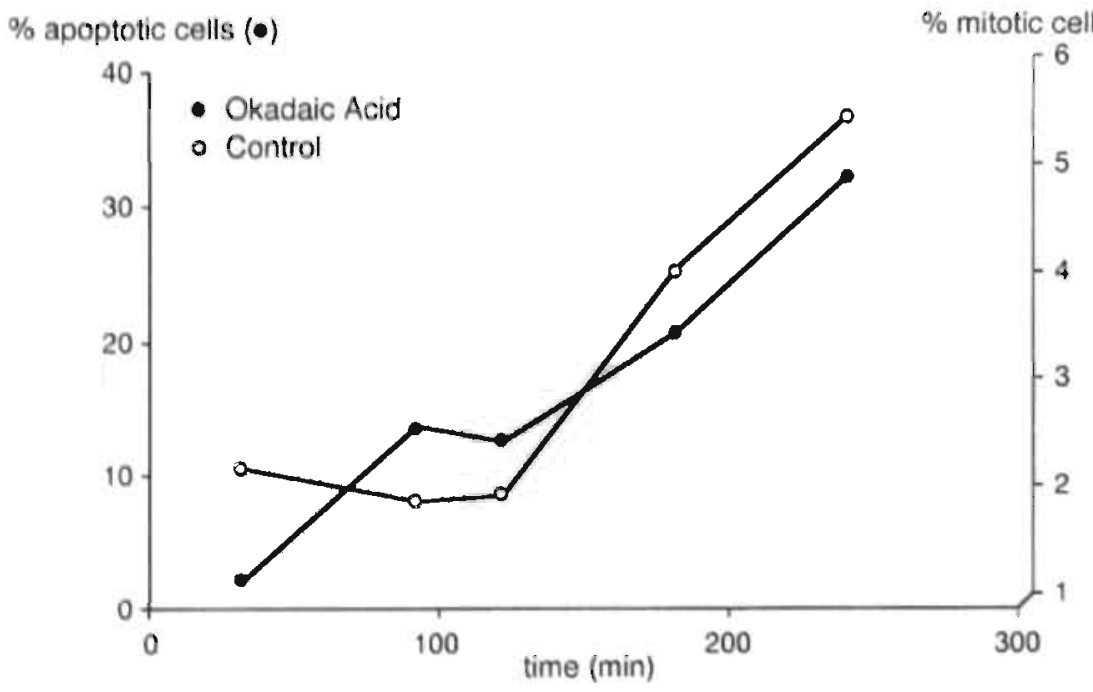

Figure 3. Time-dependent increase in apoptotic DNA fragmentation in synchronized TR14 cells treated with $1 \mu \mathrm{M}$ okadaic acid (left axis; closed symbols) and mitotic figures in untreated synchronised TR14 cells (right axis; open symbols), both after release of the blocking agent thymidine at $t=0$. Both the percent cells with mitotic figures and with DNA fragmentation follow a linear time course, with the latter being five times as fast. 


\section{Altered chromatid separation during meta- and anaphase}

To investigate further the spatial and temporal organization in TR14 cells during progression through apoptosis, we followed these cells with time-lapse phase-contrast video microscopy. Addition of a toxic okadaic acid concentration to TR 14 cells induced an activation of the overall cellular activity when compared to control cultures: ruffling activity, increased mobility and growth cone activity. Another striking phenomenon observed in the time-lapse experiments on TR14 cells was the high number of cells unsuccessfully entering the mitotic cycle (Fig. 4). Sometimes this resulted in the formation of multipolar spindles and subsequently the formation of multinucleated cells. Higher concentrations of okadaic acid induced a rapid rounding of the cells and this was accompanied by the formation of pro- and prometaphase cells. The chromosomes did not, however, align to form a proper metaphase plate. These cells quite often assumed anaphase-like configurations but without chromatid separation. Finally the chromatin recondensed, and fragmented nuclei typical for apoptotic cells were formed. In some cells the irregular spindle formation lead to the formation of multinucleated cells. 


\section{Chapter 5}

a
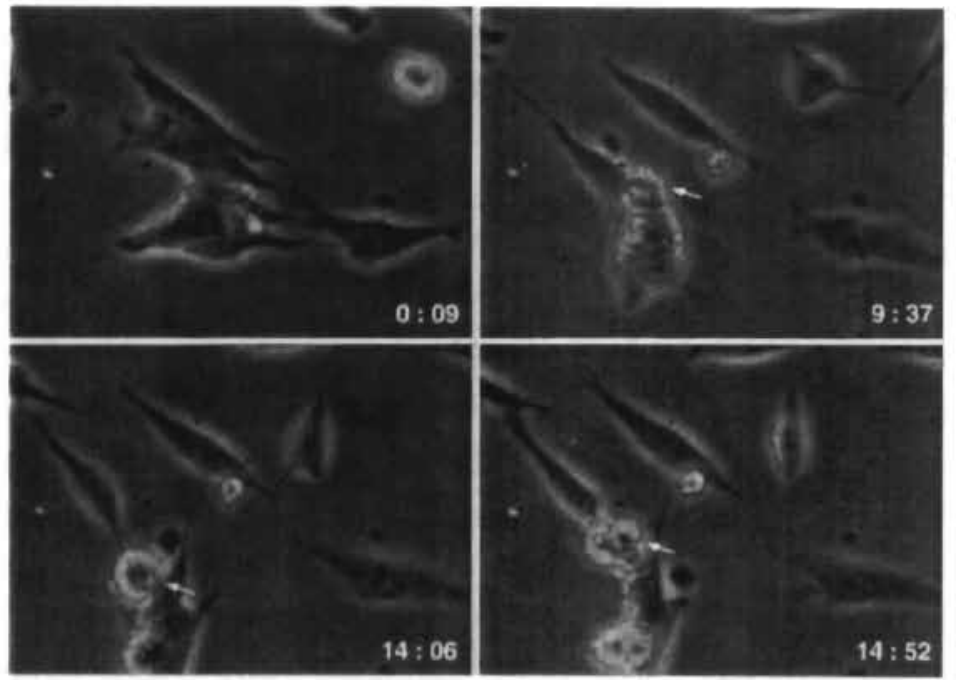

b
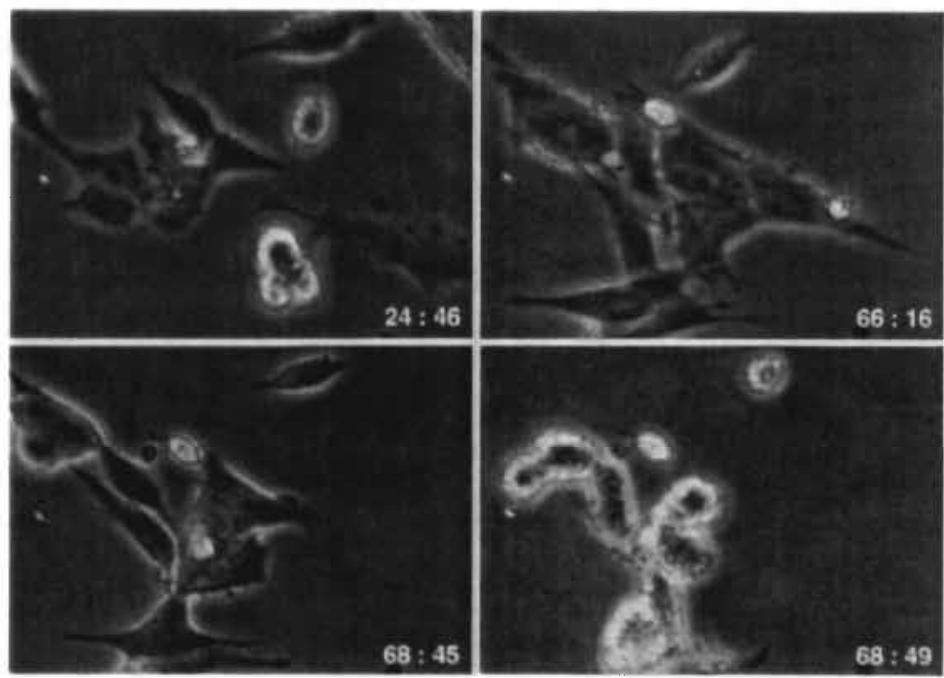

Figure 4. a: Time-lapse sequence on the effects of okadaic acid on fully differentiated TR14 cells. Time is indicated in the lower right comer (h:min). Application of low doses okadaic acid ( $10 \mathrm{nM}$ ) induces abnormal cell division. A cell is shown (arrow) entering the mitotic phase at 09:37 what finally results in a multipolar division some $5 \mathrm{~h}$ later. b: When the concentration of okadaic acid is increased up to $100 \mathrm{nM}$ (after $60: 00 \mathrm{~h}$ ) the cells first become very active, increase their cell volume and finally round up and die through apoptosis, a process completed in a few minutes. (from 68:45 to 68:49). 
Sequence of events during apoptosis in NT2- $N$ cells

In fully differentiated NT2-N cells treated with $0.1 \mu \mathrm{M}$ okadaic acid, similar events occurred as observed in TR 14 cells. Table 2 shows the effect of $10^{-7} \mathrm{M}$ okadaic acid on the nuclear morphology of fully differentiated NT2-N neurons. In this experiment, living cells with intact nuclei are PI-negative and have a uniform SYTO-staining of the cell nuclei. Apoptotic nuclei showed a fragmented nuclear SYTO-staining and were PI-negative (because they have still an intact plasma membrane), whereas necrotic cells were Pí-positive (suggesting that their plasma membrane is deficient). Okadaic acid increased the fraction of apoptotic cells from $2 \%$ to $18 \%$, an increase which was partially attenuated by the broad-spectrum kinase inhibitor staurosporine (Table 2).

Table 2. Effect of $0.1 \mu \mathrm{M}$ okadaic acid on the nuclear morphology of fully differentiated NT2-N cells.

\begin{tabular}{|c|c|c|c|}
\hline Condition & Intact nuclei & Apoptotic & Necrotic \\
\hline Control & $97.8 \%$ & $2.15 \%$ & $0 \%$ \\
\hline Staurosporine & $94.8 \%$ & $3.8 \%$ & $1.2 \%$ \\
\hline Okadaic acid & $74.4 \%$ & $18.2 \%$ & $7.4 \%$ \\
\hline $\begin{array}{l}\text { Okadaic acid and } \\
\text { staurosporine }\end{array}$ & $89 \%$ & $8.8 \%$ & $2.1 \%$ \\
\hline
\end{tabular}

The fraction of cells (measured on at least 200 cells) in each of three categories. Intact nuclei are considered to be those that are PI-negative and that have, at uniform SYTO-staining, apoptotic nuclei show a fragmented nuclear SYTO signal and are PI-negative, whereas necrotic cells are PI-positive.

$p<0.05$ versus control by chi ${ }^{2}$ test.

$\cdots p<0.05$ versus okadaic acid by chi $^{2}$ test.

In another series of experiments we treated cells with $0.1 \mu \mathrm{M}$ okadaic acid, fixed them at different times and stained the DNA with 4,6-diamidino-2-phenylindole. In these preparations we counted the number of cells that assumed mitosis-like configurations. During the first $8 \mathrm{~h}$ there was 


\section{Chapter 5}

a small increase, from $0 \%$ in control cultures to $5 \%$ in okadaic acid treated cultures; after $24 \mathrm{~h}$, however, the number of "mitotic cells" increased up to $25 \%$. Figure 5 illustrates the different stages of chromosome distribution during the apoptotic process up to the formation of the fragmented nuclei.
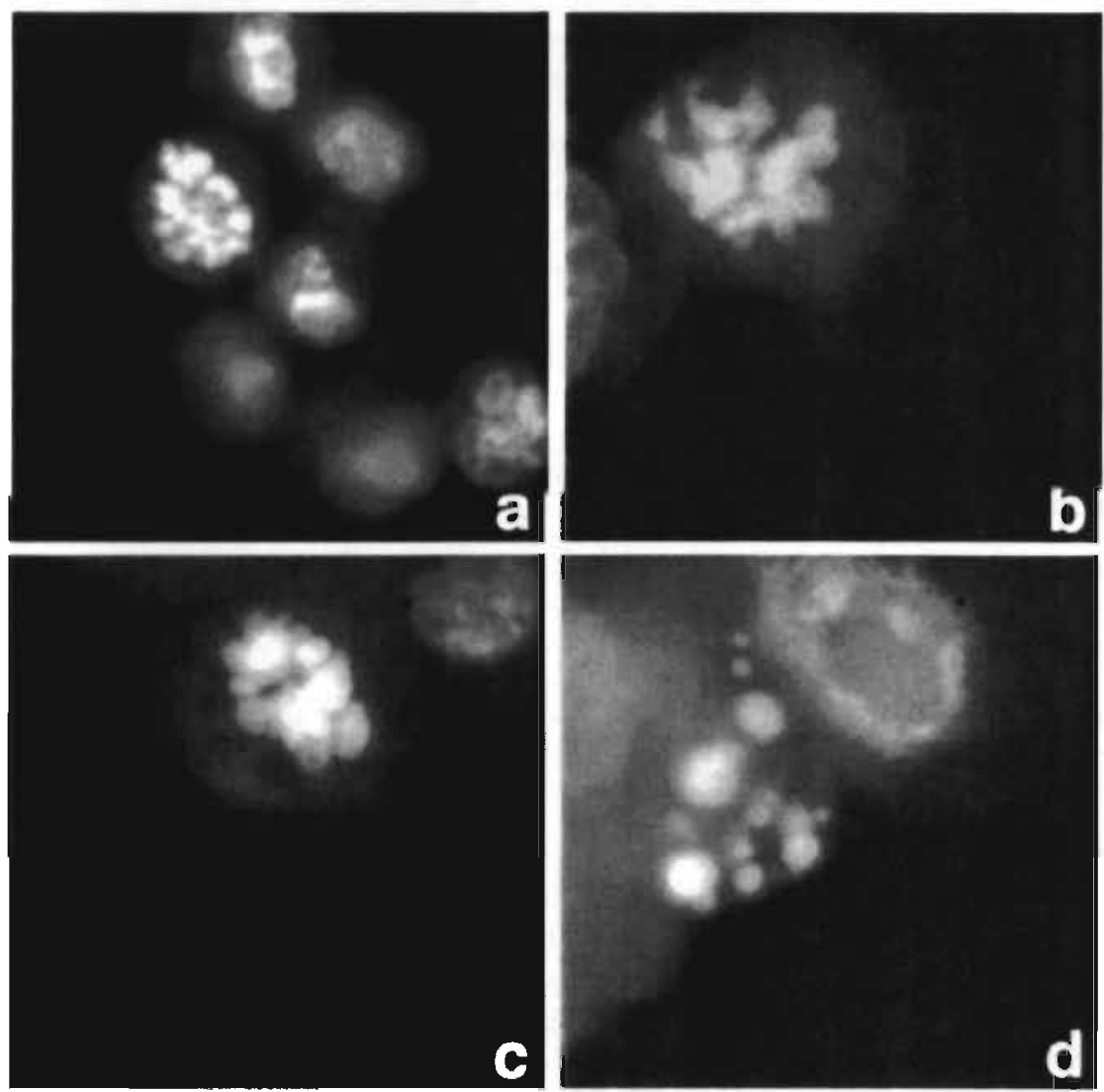

Figure 5. Illustration of the different stages of chromatin distribution and DNA mor phology monitored with the membrane-permeable DNA probe SYTO-9 in fully differentiated NT2-N cells treated for $24 \mathrm{~h}$ with $100 \mathrm{nM}$ okadaic acid. Fluorescence images show that chromosomes are actually formed (a), but they fail to separate (b), leading to reaggregation (c) and the formation of fragmented nuclei (d). 


\section{Cell cycle distribution during apoptosis}

In the next series of experiments, using DNA analysis, we compared the relative fraction of cells in different stages of the cell cycle in okadaic acid-treated TR14 cells with that in PCI2 cells after NGF deprivation (Fig. 6). Flow cytometry data clearly showed that upon removal of NGF a substantial number of PC12 cells leave $\mathrm{G}_{0} / \mathrm{G}_{1}$ and reinitiate DNA synthesis. Within $8 \mathrm{~h}$ after deprivation the percentage of cells in $\mathrm{G}_{0} / \mathrm{G}_{1}$ was decreased from 78 to 67 $\%$, with compensatory increase in the S-phase from $10 \%$ to $22 \%$. After $24 \mathrm{~h}$ the fraction of cells in $\mathrm{G}_{0} / \mathrm{G}_{1}$ phase decreased to $58 \%$, with a concomitant further increase in S-phase to $29 \%$. Similarly, analysis of the fraction of TR 14 cells in different stages of the cell cycle revealed that okadaic acid treatment increased the fraction of cells in the S-phase from 36 to $52.4 \%$ and reduced the fraction of cells in the $\mathrm{G}_{0} / \mathrm{G}_{1}$ phase from $50.6 \%$ to $35.4 \%$ (Fig. 6).

\section{Expression of cell cycle related epitopes}

If the onset of the apoptotic process is related to initiation of mitosis then this should also be reflected in the expression levels of certain $\mathrm{G}_{2} / \mathrm{M}$ phase-associated proteins. Using quantitative fluorescence microscopy we investigated the effect of okadaic acid in TR 14 neuroblastoma cells and NGF deprivation in PC12 cells on the levels of cyclin $B_{1}, p 34^{\text {cde } 2}$ and cyclin $D_{1}$. Visual scoring of $>250 \mathrm{PC} 12$ cells in each condition revealed that the fraction of p34 cde2 -positive cells increased from 2.5 to $6 \%$ at $8 \mathrm{~h}$ of deprivation and to $6.2 \%$ at $24 \mathrm{~h}$ of NGF deprivation. In the case of okadaic acid-treated TR 14 cells $(0.05 \mu \mathrm{M})$, the fraction of cyclin $\mathrm{B}_{\mathrm{i}}$-positive cells increased from $2.2 \%$ to $5.2 \%$ at $24 \mathrm{~h}$, and p $34^{\text {cde } 2}$-positive cells from $1.8 \%$ to $7.3 \%$ at $24 \mathrm{~h}$.

Moreover, automatic image analysis showed that the levels of cell cycle marker proteins, such as cyclin $B_{1}$, cyclin $D_{1}$ and $p 34^{\text {cdc } 2}$ were not affected after $8 \mathrm{hr}$ of okadaic acid treatment, but especially cyclin $D_{1}$ levels and to a lesser extent cyclin $\mathrm{B}_{1}$ and $\mathrm{p} 34^{\mathrm{cdc} 2}$ levels increased after $24 \mathrm{~h}$ treatment (Table 3). For instance, cyclin $D_{1}$ levels increased by $30 \%$, similar to the $35 \%$ increase in fraction of cells in the S-phase as assessed by DNA flow cytometry.

The comparison between manual scoring and automatic image analysis is illustrated by the following example, based on the expression levels of 

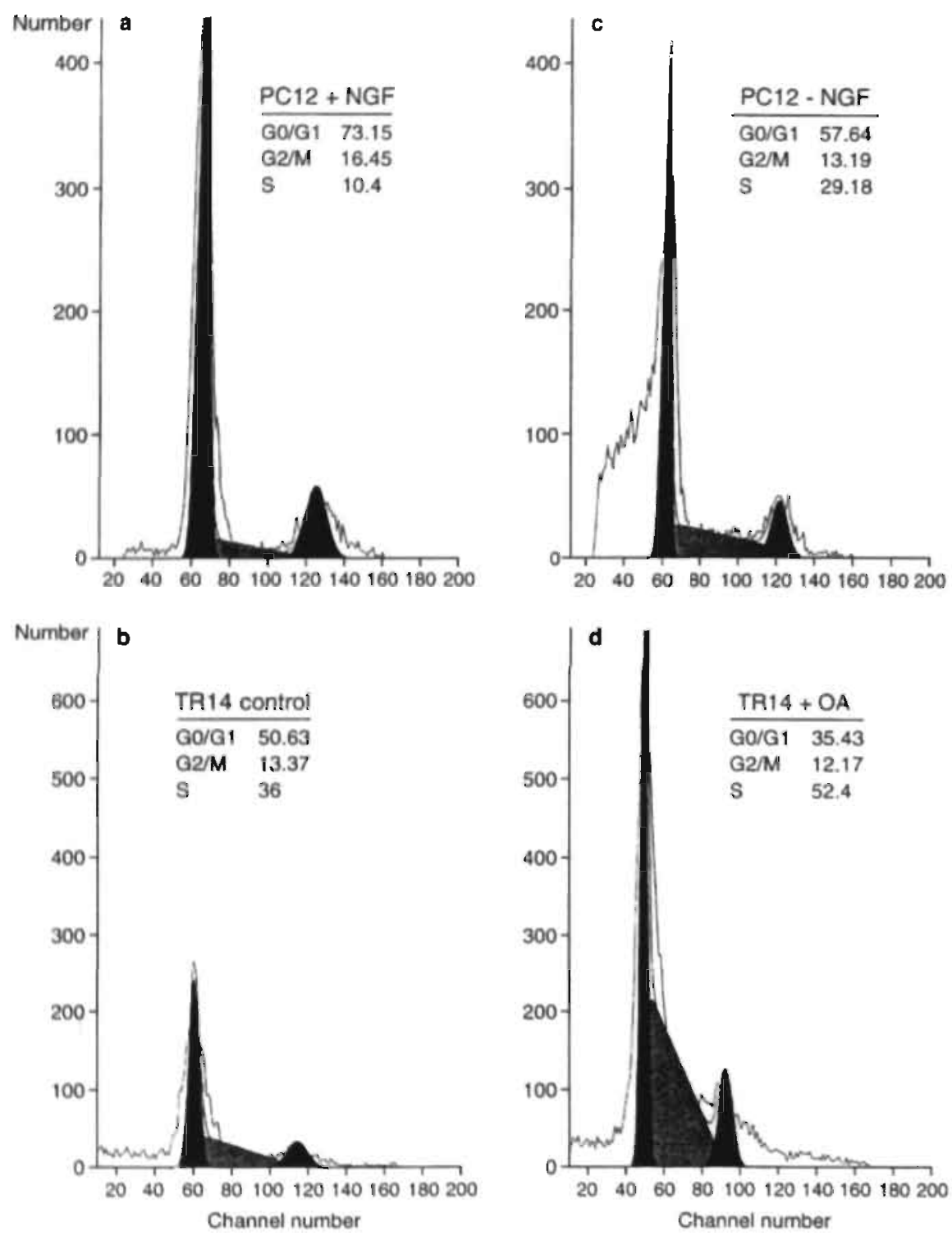

Figure 6. Fraction of cells, in different phases of the cell cycle as measured by flow cytometry: PC12 cells (a) in the presence of NGF and (c) after NGF deprivation; TR14 cells (b) in control conditions and (d) in the presence of $100 \mathrm{nM}$ okadaic acid. Note that with both NGF deprivation and okadaic acid treatment conditions a shift from cells in $G_{0} / G_{1}$, phase to $S$ phase takes place, whereas the fraction of cells in the $G_{2} / M$ phase essentially remains unchanged. Both experiments were sampled after $24 \mathrm{~h}$. 
cyclin $B_{1}$ in control versus okadaic acid-treated cells (mean intensity, 123.7 vs. 143.0). Based on the cumulative histogram of the intensities of the individual cells and defining an intensity threshold for a positive cell as mean intensity plus $2 \mathrm{SD}(143.0+2 \times 28.1=199)$, we find $2.7 \%$ positive cells in control situations and $5.7 \%$ positive cells in okadaic acid conditions. This compares favourably with the $2.2 \%$ and $5.2 \%$, obtained by manual counting.

Table 3. The effect of okadaic acid (OA) treatment $(50 \mathrm{nM})$ on the induction of cell cycle-related proteins cyclin $B_{1}, p 34^{\text {cdc2 }}$ and cyclin $D_{1}$, by means of quantitative immunocytochemistry.

\begin{tabular}{l|l|l|l}
\hline Condition in Tr14 cells & Cyclin $\mathrm{B}_{1}$ & ${\mathrm{p} 34^{\text {ede2 }}}$ & Cyclin $\mathrm{D}_{1}$ \\
\hline Control 24 h & $\begin{array}{l}123.7 \pm 1.42 \\
(\mathrm{n}=301)\end{array}$ & $\begin{array}{l}156.9 \pm 2.15 \\
(\mathrm{n}=181)\end{array}$ & $\begin{array}{l}101.6 \pm 1.85 \\
(\mathrm{n}=107)\end{array}$ \\
\hline OA 24 h & $\begin{array}{l}143.0 \pm 2.01 \\
(\mathrm{n}=193)\end{array}$ & $\begin{array}{l}165.4 \pm 2.72^{*} \\
(\mathrm{n}=111)\end{array}$ & $\begin{array}{l}132.8 \pm 2.13 * \\
(\mathrm{n}=185)\end{array}$ \\
\hline
\end{tabular}

Data are mean \pm SEM fluorescence intensities per cell after background correction (no. of cells). $p<0.01,{ }^{\prime} p<0.05$ by Student's $t$-test versus control at $24 \mathrm{~h}$. 


\section{Discussion}

This report shows that in human neuroblastoma cells, aberrant phosphorylation of tau can be induced by application of the phosphatase inhibitor okadaic acid, and is associated with a form of programmed cell death. In addition, it is shown that this form of neuronal cell death is accompanied by a frustrated attempt to enter mitosis. The effect is observed both in proliferative and in fully differentiated neuronal cells.

In differentiated $\mathrm{PC1} 2$ cells the process of programmed cell death is initiated when differentiated cells are deprived of NGF (Park et al., 1996), whereas in human TR 14 and fully differentiated NT2-N cells this can be initiated by application of okadaic acid. Using these three different cell systems allowed us to compare species, human versus rat, but more important the differences between proliferative and differentiated cells. It also showed that the artificial okadaic acid model does share some features with the more physiological model of NGF deprivation. In both NGF deprivation and okadaic acid treatment there is a substantial dose-dependent loss of cellular viability over $24 \mathrm{~h}$. Furthermore, the attenuation of cytotoxicity by the protein synthesis inhibitor cycloheximide and the appearance of DNA fragmentation and membrane blebs, suggest that okadaic acid-induced cytotoxicity is apoptosis. Similar results have been found in a variety of cultured retinoblastoma cells (Inomata et al., 1996).

It is intriguing that okadaic acid at subtoxic concentrations induces a dose-dependent increase of the biochemical parameters indicative of cell viability, which might be explained by an increasing number of cells forced to enter the cell cycle. This is corroborated by the observation in our time-lapse experiments that some cells actually were able to escape the mitotic block and went on to form multinucleated cells. In addition, the effect is less pronounced on nondifferentiated TR 14 cells than in their more differentiated counterpart. This could be partly explained by the consideration that the effect of the forced mitosis induced by okadaic acid is masked by the higher normal basal proliferative rate in the nondifferentiated condition. Alternatively, cells in the proliferative phase may have their machinery for cell cycle-related events more 
ready. A similar observation has been reported in proliferating LLC-PK cells where okadaic acid was documented to induce a mitotic block in a metaphase-like state within $6 \mathrm{~h}$ after the initial treatment (Vandre and Wills, 1992). Differentiated neuroblastoma cells, such as the dibutyryl cyclic AMP-treated TR 14 cells (Rupniak et al., 1984) or the retinoic acid-treated NT2-N cells (Pleasure et al., 1992), can be considered almost synchronized as they either are mostly in $\mathrm{G}_{0}$ or $\mathrm{G}_{1}$ phase. However, it is not excluded that they maintain some proliferative capacities and that this system might be reactivated by okadaic acid. This question was addressed by synchronizing proliferating TR 14 cells in S phase through the addition of excess thymidine. Removal of the thymidine block allowed the cells to proceed through the cell cycle, and addition of okadaic acid at the time of thymidine removal induced a linear increase in the number of apoptotic cells. A time-dependent increase in the number of fragmented nuclei paralleled the appearance of mitotic cells in control conditions. This indicated that inhibition of phosphatase activity actually seems to enhance steadily the progression of the cell through the mitotic cycle, a progression which eventually ended up in an apoptotic process. Again, this observation suggests that mitosis and apoptosis may use similar processes.

This report also documents that both in NGF-deprived PCI 2 cells and in okadaic acid-treated TR 14 cells, the induction of apoptosis is accompanied by the expression of specific $M$ phase-related epitopes and cyclin $D_{1}$, suggesting again that cells seemed to be forced into a mitotic cycle. The induction of cyclin $D_{1}$ is prominent at subtoxic concentrations of okadaic acid. Similar celi cycle arrest induced by okadaic acid has been documented in human myeloid leukemic cell lines HL-60 and U937 (Ishida et al., 1995). This extends earlier observations of Gao and Zelenka (1995), who showed that cyclin $D_{1}$ and cyciin B are up-regulated after NGF deprivation. Brooks et al. (1993) showed that under these conditions p34 ${ }^{\text {cdc2 }}$ levels also were increased. In lymphocytes it was shown that the activation of $\mathrm{p} 34^{\text {cde } 2}$ was necessary for the progression of apoptosis after exposure to a lymphocyte granule protease (Shi et al., 1994). Flow cytometric analysis of the cell stages in PCI2 cells indicated that induction of apoptosis was preceded by re-initiation of the cell 
cycle in these cells normally considered as blocked in $G_{0}-G_{1}$ phase.

The induction of programmed cell death apparentiy forces the cells to enter $S$ phase and start DNA synthesis, as evidenced by the decreased cell number in $\mathrm{G}_{0}-\mathrm{G}_{1}$. This result is in line with the observation that blocking the cell cycle before $G_{1} / S$ phase prevents the death of trophic-factor deprived PC12 cells, whereas agents that act at different points during the cell cycle did not show any long-term protective effects (Farinelli and Greene, 1996). Induction of cyclin $D_{1}$ has been documented to be a hallmark of mitogenic cells entering the mitotic cell cycle, where it has been implicated in the $\mathrm{G}_{1}$ checkpoint (for review, see Darzynkiewicz et al., 1996). It is interesting that both the morphological observations of chromosome formation in okadaic acid-treated NT2-N cells and the appearance of cyclin $B_{1}$ marker suggest that some cells at least are able to pass this $\mathrm{G}_{1}$ checkpoint. Therefore, the data imply that nontoxic concentrations of okadaic acid actually force differentiated neuroblastoma cells into mitosis and that bifurcation into an apoptotic pathway actually may take place after the $\mathrm{G}_{1}$ checkpoint.

We documented earlier that features typical of cytokinesis were observed in TR 14 cells when these cells were exposed to hyperstimulating medium. leading ultimately to apoptosis (Nuydens et al., 1995 a,b).

Taken together with previous results, this report shows that on induction of apoptosis neuronal cells resume DNA synthesis and attempt to enter the cell cycle. During $M$ phase, synchronization is lost, and chromosome separation is not completed. At this point the metaphase checkpoint is probably overridden, and fragmented nuclei are formed.

One of the key players in this process is the microtubular cytoskeleton. An important regulatory mechanism for the meta- to anaphase transition is the chemical and mechanical interaction between microtubules and the kinetochores (Gorbsky, 1995). If the stability of the microtubules is in anyway impaired, proper chromosome alignment is prohibited, and consequently metaphase to anaphase transition is delayed. One of the factors influencing microtubule stability is the phosphorylation state of microtubule-associated proteins. It has been shown that aberrant phosphorylation of tau diminished its stabilizing effect on microtubules 
(Alonso et al., 1994; Shea, 1996). In human platelets, application of okadaic acid induces a dramatic fragmentation of microtubuli (Yano et al., 1995). The application of okadaic acid to microtubules changes the dynamic instability of microtubules from an interphase to a mitosis-like state by reducing the rescue frequency (Gliksman et al., 1992). In Chinese hamster ovary cells, okadaic acid reduces the number of microtubules, whereas the remaining microtubules have a tendency to rearrange into an aster-like pattern (Thyberg and Moskalewski, 1992). A particularly interesting role, especially during mitosis is attributed to cyclin $\mathrm{B}_{1} / \mathrm{p} 34^{\mathrm{cd} 2}$ complex. This $\mathrm{M}$ phase-promoting factor mediates chromatin condensation and breakdown of the nuclear envelope, and it is targeted to microtubules through the interaction with microtubule-associated protein 4 (Ookata et al., 1995). This suggests that proper microtubule functioning is essential for progression through mitosis. Diminished stability of spindle microtubules through aberrant phosphorylation of microtubule-associated proteins might in turn disturb the mitotic forces that control a cell division checkpoint ( $\mathrm{Li}$ and Nicklas, 1995). For example, it is documented that in HeLa cells the activity of a kinesin related protein is regulated through p34 $4^{\text {cde2 }}$-mediated phosphorylation (Blangy et al., 1995) and as such is required for the formation of normal bipolar spindles. Alternatively, disturbing the phosphorylation-dephosphorylation equilibrium influences the degradation of the cyclin $\mathrm{B}_{1} / \mathrm{p} 34^{\text {edc2 }}$ complex, necessary to proceed properly through the mitotic cycle (Yamashita et al., 1990). Especially in chronic neurodegenerative disease evidence has been provided that neurones die through an apoptotic pathway (Su et al., 1994). In this regard it is important to note that apoptosis-linked gene- 3 is quite homologous to the familial Alzheimer's disease gene presenilin-2 (Vito et al., 1996). In addition, the Alzheimer-specific antibody TG-3, directed against a modified form of tau, actually stains a nuclear protein only in mitotic cells (Vincent et al., 1996). The mechanisms that trigger these postmitotic neuronal cells to undergo apoptosis are not fully understood. It has been argued that the apoptotic process in several cell types shares some features with the normal mitotic cycle. The identification of the trigger that initiates $\mathrm{G}_{\mathrm{I}} / \mathrm{S}$ transition may therefore be useful for developing therapeutics which inhibit apoptosis in neuronal cells. 


\section{Acknowledgements}

We gratefully acknowledge the expertise and help of Dr. Marina Cools in the experiments with the flow cytometer. The discussions with Dr. Bert Schutte (Maastricht University) together with his critical suggestions are highly appreciated. 


\section{References}

Alonso, A.C., Zaidl, T., Grundke-Iqbal, I. and Iq̨al, K. Role of abnormally phosphorylated tau in the breakdown of microtubules in Alzheimer disease.

Proc. Natl. Acad. Sci. USA (1994) 9I: 5562-5566.

Blangy, A., Lane, H.A., d'Herin, P., Harper, M., Kress, M., and Nigg, E.A. Phosphorylation by p34 ${ }^{\text {cat2 }}$ regulates spindle association of human Eg5, a kinesin-related motor essential for bipolar spindle formation in vivo. Cell (1995) 83: 1159-1169.

Bredesen, D.E. Neural apoptosis. Ann. Neurol. (1995) 38: 839-851.

Brooks, S.F., Gibson, A., and Rubin, L.L. Apoptosis induced by NGF-withdrawal form differentiated PC12 cells involves activation of $\mathrm{p} 34^{\text {ede }}$ kinase.

Soc. Neurosci. Abstr. (1993) 19: 885.

Darzynkiewicz, Z., Gong, J., Juan, G., Ardelt, B., and Traganos, F. Cytometry of cyclin proteins. Cytometry (1996) 25: 1-13.

Farinelli, S.E. and Greene, L.A. Cell cycle blockers mimosine, ciclopirox, and deferoxamine prevent the death of $\mathrm{PCl} 2$ cells and postmitotic sympathetic neurons after removal of trophic support. J. Neurosci. (1996) 16: 1150-1162.

Freeman, R.S., Estus, S., and Johnson, E.M., Jr. Analysis of cell cycle-related gene expression in postmitotic neurons: selective induction of Cyclin DI during programmed cell death. Neuron (1994) 12: 343-355.

Gao, C.Y. and Zelenka, P. Induction of cyclin B and $\mathrm{HI}$ kinase activity in apoptotic PC12 cells. Exp. Cell Res. (1995) 219: 612-618.

Gliksman, N.R., Parsons, S.F., and Salmon, E.D. Okadaic acid induces interphase to mitoticlike microtubule dynamic instability by inactivating rescue.

J. Cell Biol. (1992) 119: 1271-1276.

Gorbsky, G. Kinetochores, microtububes and the metaphase checkpoint.

Trends Biol. Sci. (1995) 5: 143-147.

Grundke-Iqbal, I., Iqbal, K., Tung, Y.C., Quinlan, M., Wisniewski, H.M., and Binder, L.I. Abnormal phosphorylation of the microtubule-associated protein tau in Alzheimer cytoskeletal pathology. Proc. Natl. Acad. Sci. USA (1986) 83:4913-4917. 
Inomata, M., Saijo, N., Kawashima, K., Kaneko, A., Fujiwara, Y., Kunikane, H., and Tanaka, Y. Induction of apoptosis in cultured retinoblastoma cells by the protein phosphatase inhibitor, okadaic acid. J. Cancer Res. Clin. Oncol. (1995) 121: 729-738.

Ishida, Y., Furukawa, Y., Decaprio, J.A., Saito, M., and Griffin, J.D. Treatment of myeloid leukernic cells with the phosphatase inhibitor okadaic acid induces cell cycle arrest at either $\mathrm{G}_{1} / \mathrm{S}$ or $\mathrm{G}_{2} / \mathrm{M}$ depending on dose. J. Cell Physiol. (1992) 150: 484-492.

Lassmann, H., Bancher, C., Breitschopf, H., Wegiel, J., Bobinski, M., Jellinger, K., and Wisniewski, H.M. Cell death in Alzheimer's disease evaluated by DNA fragmentation in situ. Acta Neuropathol. (Berl) (1995) 89: 35-41.

Li, X., and Nicklas, R.B. Mitotic forces control a cell-cycle checkpoint. Nature (1995) 373: 630-632.

Mosmann, T. Rapid colorimetric assay for cellular growth and survival: application to proliferation and cytotoxicity assays. J. Immunol. Methods (1983) 65: 55-63.

Nuydens, R., De Jong, M., Nuyens, R., Cornelissen, F., and Geerts, H. Neuronal kinase stim. ulation leads to aberrant tau phosphorylation and neurotoxicity.

Neurobiol. Aging (1995a) 16: 465-77.

Nuydens, R., Heers, C., Chadarevian, A., De Jong, M., Nuyens, R., Cornelissen, F., and Geerts, H. Sodium butyrate induces aberrant tau phosphorylation and programmed cell death in human neuroblastoma cells. Brain Res. (1995b) 688: 86-94.

Ookata, K., Hisanaga, S., Bulinski, J.C., Murofushi, H., Aizawa, H., Itoh, T.J., Hotani, H., Okumura, E., Tachibana, K., and Kishimoto, T. Cyclin B interaction with microtubuleassociated protein 4 (MAP4) targets $\mathrm{p} 34^{\text {ade } 2}$ kinase to microtubules and is a potential regulator of M-phase microtubule dynamics. J. Cell Biol. (1995) 128: 849-862.

Park, D.S., Stefanis, L., Yan, C.Y.I., Farinelli, S.E., and Greene, L.A. Ordering the cell death parhway. Differential effects of BCL2, an interleukin-1-converting enzyme family protease inhibitor, and other survival agents on JNK activation in serum/nerve growth factor-deprived PC12 cells. J. Biol. Chem. (1996) 271: 21898-21905.

Pleasure, S.J., Page, C., and Lee, V.M. Pure, postmitotic, polarized human neurons derived from. NTera 2 ceils provide a system for expressing exogenous proteins in terminally differentiated neurons. J. Neurosci. (1992) 12: 1802-1815.

Pope, W.B., Lambert, M.P., Leypold, B., Seupaul, R., Sletten, L., Kraft, G., and Klein, W.L. Microtubule-associated protein tau is hyperphosphorylated during mitosis in the human neuroblastoma cell line SH-SY5Y. Exp. Neurol. (1994) 126: 185-194. 
Preuss, U., Doring, F., Illenberger, S., and Mandelkow, E.M. Cell cycle-dependent phosphorylation and microtubule binding of tau protein stably transfected into Chinese hamster ovary cells. Mol. Biol. Cell (1995) 6: 1397-1410.

Rupniak, H.T., Rein, G. Powell, J.F., Ryder, T.A., Carson, S., Povey, S., and Hill, B.T. Characteristics of a new human neuroblastoma cell line which differentiates in response to cyclic adenosine $3^{\prime}: 5^{\prime}$-monophosphate. Cancer Res. (1984) 44: 2600-2607.

Sautiere, P.E., Caillet, M.L., Wattew, A., and Delacourte, A. Detection of Alzheimer-type tau proteins in okadaic acid-treated SKNSH-SY 5 Y neuroblastoma cells. Neurodegeneration (1994) 3: 53-60.

Shea, T.B. Induction of abnormal phosphorylation and tau hyperphosphorylation in human neuroblastoma cells by colchicine and okadaic acid: evidence that microtubule disruption contributes to Alzheimer's disease. Neurosci. Res. Commun. (1996) 19: 27-36.

Shi, L., Nishioka, W.K., Th'ng, J., Bradbury, E.M., Litehfield, D.W., and Greenberg, A.H. Premature p34 ack activation required for apoptosis. Science (1994) 263: 1143-1145.

Su, J.H., Anderson, A.J., Cummings, B.J., and Cotman, C.W. Immunohistochemical evidence for apoptosis in Alzheimer's disease. Neuroreport. (1994) 5: 2529-2533.

Thyberg, J., and Moskalewski, S. Disorganization of the Golgi complex and the cytoplasmic microtubule system in $\mathrm{CHO}$ cells exposed to okadaic acid.

J. Cell Sci. (1992) 103: 1167-1175.

Vandermeeren, M., Lubke. U., Six, J., and Cras, P. The phosphatase inhibitor okadaic acid induces a phosphorylated paired helical filament tau epitope in human LA-N-5 neuroblastoma cells. Neurosci. Lett. (1993) 153: 57-60.

Vandre, D.D., and Wills, V.L. Inhibition of mitosis by okadaic acid: possible involvement of a protein phosphatase $2 \mathrm{~A}$ in the transition from metaphase to anaphase.

J. Cell Sci. (1992) 101: 79-91.

Vincent, I., Rosado, M., and Davies, P. Mitotic mechanisms in Alzheimer's disease? J. Cell Biol. (1996) 132: 413-425.

Vito, P. Lacana, E., and D'Adamio, L. Interfering with apoptosis: Ca ${ }^{2+}$-binding protein ALG-2 and Alzheimer's disease gene ALG-3. Science (1996) 271: 521-525.

Yamashita, K., Yasuda, H., Pines, J., Yasumoto, K., Nishifani, H., Ohtsubo, M., Hunter, T., Sugimura, T., and Nishimoto, T. Okadaic acid, a potent inhibitor of type 1 and type $2 \mathrm{~A}$ protein phosphatases, activates cdc $2 / \mathrm{HI}$ kinase and transiently induces a premature mitosis-like state in BHK2l cells. EMBO J. (1990) 9: 4331-4338. 
Yano, H., Agatsuma, T., Nakanishi, S., Saitoh, Y., Fukui, Y., Nonomura, Y., and Matsuda, Y. Biochemical and pharmacological studies with KT7692 and LY294002 on the role of phosphatidylinositol 3-kinase in Fc epsilon RI-mediated signal transduction. Biochem. J. (1995) 312: 145-150. 




\title{
Bcl-2 protects neuronal cells against taxol-induced apoptosis by inducing multi-nucleation
}

\author{
Rony Nuydens ${ }^{a . b}$, Gwenda Dispersyn ", Gerd Van Den Kieboom ", \\ Mirjam de Jong a , Rich Connors ${ }^{4}$, Frans Ramaekers ${ }^{b}$, Marcel Borgers a and \\ Hugo Geerts a \\ - Department of Cell Physiology, Life Sciences, Janssen Research Foundation, Beerse, Belgium \\ - Department of Molecular Cell Biology and Genetics, Maastricht University. \\ Maastricht, the Netherlands \\ c Department of Biochemistry, University of Antwerp, Antwerp, Belgium \\ Ancology Group, Janssen Research Foundation, Spring House, Pennsylvania, USA
}

Exp. Neurol., under review

Abstract

Taxol-induced peripheral neuropathy is a commonly-occurring side-effect in the treatment of cancer patients with taxoteres or taxanes. Taxol is known to induce apoptosis in a number of tumor cells. This report documents that, as with the effects in proliferating cells, taxol induces apoptosis in NGF-differentiated PCI2 cells, as assessed by exogenous FITC-annexin-V binding and nuclear fragmentation. It is shown that PCI2 cells that stably overexpress Bcl-2 are protected 
against the toxic effect of taxol, as evidenced by the Live/Death assay and by a decreased fraction of annexin-V positive cells and by the number of fragmented nuclei. The effect is similar to the protective effect of Bcl-2 against NGF-deprivation in differentiated PCI2 cells.

Although taxol forced both wild-type and $\mathrm{Bcl}$-2-overexpressing cells into a mitotic state, only in Bcl-2-overexpressing cells did this lead to the appearance of metabolically active, multi-nucleated cells. This suggests that Bcl-2 is able to induce an alternative escape pathway, downstream of the $G / M$ block, in taxol-treated differentiated PCI 2 cells.

\section{Introduction}

Taxol is a cytostatic compound that is becoming increasingly popular in the treatment of solid tumors such as breast cancer. In proliferating cells taxol interferes with normal mitotic spindle formation, thereby causing the cells to halt at the $\mathrm{G}_{2} / \mathrm{M}$ transition phase of the cell cycle. This mitotic block eventually leads to cell death through activation of an apoptotic pathway (Shu et al., 1997) initiated by cell-cycle checkpoint controls.

The anti-microtubule effects of taxol presumably cause the appearance of peripheral neuropathies frequently encountered in patients receiving taxol-based chemotherapy.

It has been shown that induction of apoptosis in neuronal cells is accompanied by a number of events normally observed in cycling cells during the $G_{2} / \mathrm{M}$ phase (Freeman et al., 1994; Nuydens et al., 1998). These phenomena have been described during neuronal apoptosis using a number of different triggers like NGF-deprivation and modulation of the kinase/phosphatase balance (Nuydens et al., 1998). Evidence is accumulating that the cell then progresses into an apoptotic pathway (Nuydens et al., 1998). 
Direct disruption of microtubules by application of colchicine has been shown to induce apoptosis in cerebellar granule cells (Bonfoco et al., 1995). However, little is known about the effects of excessive microtubule stabilization, as induced by taxol, on neuronal functioning and eventually on cell survival. $\mathrm{Bcl}-2$, an anti-apoptotic oncogene, has been documented to confer protection in a number of assays using a diverse range of apoptotic triggers in both proliferating and differentiated cells. Bcl-2 has been shown to protect against neuronal cell death in a variety of in vitro (Kroemer, 1997) and in vivo (Tanabe et al., 1997) systems.

The present study documents the induction of apoptosis by taxol in PC12 cells, which were studied in both a proliferative and a differentiated state. We evaluated the effects on total cell survival, confirmed the apoptotic nature by an annexin-V label and DNA analysis. We provide further support for the hypothesis that neuronal apoptosis occurs consequent to the attempt of a differentiated cell to re-enter the cell cycle. By using Bcl-2-overexpressing cells we also gained insight into a possible escape pathway created by this anti-apoptotic protein with reference to taxol.

\section{Materials and methods}

\section{Cell culture}

Bcl-2 (CL-7) and vector- (pcDA) transfected PC12 cells were maintained in Dulbecco's modified Eagle's medium (DMEM. GIBCO BRL) supplemented with $7.5 \%$ horse serum (HS, GIBCO BRL), $7.5 \%$ fetal calf serum (FCS,

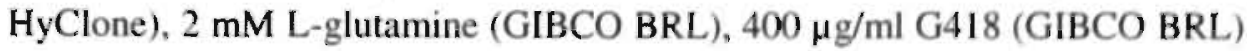
and $0.5 \mu \mathrm{g} / \mathrm{ml}$ gentamycine in a humicifited incubator aerated with $95 \%$ air and $5 \% \mathrm{CO}_{2}$ at $37^{\circ} \mathrm{C}$. The cells were used in either the proliferative state (cultured in serum-containing medium) or the differentiated state. In the latter case, they were pre-differentiated for 3 days by changing the medium of the culture flask to DMEM supplemented with $1 \% \mathrm{HS}, 2 \mathrm{mM} \mathrm{L}$-glutamine and $50 \mathrm{ng} / \mathrm{ml}$ nerve growth factor (NGF, Alomone Labs). 


\section{Stable cellular transfection}

The Human Bcl-2 gene was cloned from normal primary foreskin fibroblasts (ATCC-CCD-27SK) via RT/PCR (Stratagene) using the following oligonucleotide primers:

\section{5'CTGGGAAATATGGCGCACGCTGGGAGAA-3' and}

5' AGGCATGTTGACTTCACTTGTGGC 3'. The 750 bp. cDNA fragment was directly cloned into pCR2.1 (Invitrogen) and subjected to DNA sequencing. Only 'wobble' differences were noted in comparison with Genbank human $\mathrm{Bcl}-2$ sequences. So that the $\mathrm{Bcl}-2$ protein could be expressed in mammalian cells, a EcoRI fragment containing the entire Bcl-2 coding region was excised from the pCR2.1Bcl plasmid and subcloned into pCDNA3 (Invitrogen).

PC- 12 cells (a gift from R. Slemmon) were transfected with pCD.Bcl-2 DNA using lipofectamine under conditions recommended by the manufacturer (GIBCO). Briefly, $4 \mu \mathrm{gs}$ of pCD.Bcl-2 or pCDNA3 was mixed with $20 \mu \mathrm{l}$ of lipofectamine in $200 \mu \mathrm{I}$ serum free media and incubated at room temperature for 45 minutes. $800 \mu \mathrm{l}$ of serum free media was added and the DNA/liposome solution was applied to a monolayer of $10^{6} \mathrm{PC} 12$ cells in a $35 \mathrm{~mm}$ dish. After 6 hours of incubation the DNA solution was rernoved and the cells were fed growth media (RPMI with 10\% FCS, 10\% HS, 100 units penicillin/ml, $100 \mu \mathrm{g}$ streptomycin/ml and $2 \mathrm{mM}$ glutamine). The next day the cells were distributed over 5 dishes $(100 \mathrm{~mm}$ ) and fed growth media with $400 \mu \mathrm{g} / \mathrm{ml} \mathrm{G} 418$ for selection of transfected cells. Clones developed after 4 to 6 weeks in selective media and were isolated with cloning cylinders and expanded in selective media.

\section{Viability measurements}

For the viability measurements in 96 -well plates, $2 \times 10^{4}$ cells per poly-L-lysine-coated well (Biocoat. Falcon) were plated in $200 \mu \mathrm{I}$ DMEM supplemented with $7.5 \%$ HS, $7.5 \%$ FCS and $2 \mathrm{mM} \mathrm{L-glutamine.} \mathrm{Four} \mathrm{hours}$ after plating, the medium was replaced with DMEM supplemented with $1 \%$ HS, $2 \mathrm{mM}$ L-glutamine, $400 \mu \mathrm{g} / \mathrm{ml} \mathrm{G418}$ and $50 \mathrm{ng} / \mathrm{ml} \mathrm{NGF.}$

After 4 days the experiment was started by switching the medium to a medium 
supplemented with different concentrations of taxol and $25 \mathrm{ng} / \mathrm{ml} \mathrm{NGF}$. Cell viability was determined 48 hours later by adding $0.1 \mu \mathrm{M}$ calcein-acetoxymethylester and $0.1 \mu \mathrm{g} / \mathrm{ml}$ propidium iodide. Fluorescence intensity was then measured in a Cytofluor II (Perkin-Elmer) plate reader, which allows the sequential measurement of each well at the respective wavelengths. The ratio of the intensities is an indication of viability.

\section{Annexin V labeling by flow cytometry}

For the quantification of apoptotic cells, phosphatidylserine (PS) exposure was monitored by an annexin-V label (Schutte et al., 1998). This was performed simply by adding annexin-V-FITC to the cells cultured in the various experimental conditions. After 10 minutes the supernatant was collected and the floating cells were rinsed twice with Phosphate Buffered Saline. The adherent cells were scraped of the substrate with a rubber policeman. Both cell suspensions were pooled and incubated with propidium iodide $0.1 \mu \mathrm{g} / \mathrm{ml}$ for 10 minutes. The cells were then kept on ice and analyzed with a Calibur flow cytometer (Becton-Dickinson, San Josee, California).

An argon laser was used for excitation of the fluorescent probes. Intensities were analyzed using two PMTs with the following spectral windows: $530 \pm 30 \mathrm{~nm}$ (FLl), $650 \mathrm{~nm}$ and above (FL3). Analysis was performed by calculating the fraction of cells in each of the four gating windows.

\section{Nuclear morphology}

Cells were plated on poly-L-lysine-coated coverslips in DMEM supplemented with $1 \%$ HS, $2 \mathrm{mM}$ L-glutamine, $400 \mu \mathrm{g} / \mathrm{ml} \mathrm{G} 418$ and $50 \mathrm{ng} / \mathrm{ml}$ NGF. After 4 days of differentiation the cells were treated with taxol. At the appropriate time points the cells were fixed with $4 \%$ paraformaldehyde and stained with Hoechst 33342 (Molecular Probes, Eugene, OR), $1 \mu \mathrm{g} / \mathrm{ml}$ for 10 minutes. With a fluorescence microscope (Axioplan, Zeiss) the nuclei were counted and classified as discussed below.

\section{Western blotting}

Cell lysates were prepared in $50 \mathrm{mM}$ Tris, $2 \mathrm{mM}$ EDTA, and 1\% SDS. Before 
loading, samples were heated for 10 minutes at $100^{\circ} \mathrm{C}$. Proteins were separated in $10 \%$ SDS-PAGE and transferred to nitrocellulose membranes. Membranes were blocked by $10 \%$ non-fat dry milk in PBS containing $0.1 \%$ Tween 20. Primary antibody (anti-Bcl-2 monoclonal antibody, Santa Cruz Biotechnology, California) was diluted in 5\% non-fat dry milk in PBS with $0.05 \%$ Tween 20 and incubated overnight at $4{ }^{\circ} \mathrm{C}$. Antibodies were detected with peroxidase-conjugated secondary antibody and peroxidase with ECL (Amersham).

\section{Statistical analysis}

The statistical analyses were carried out with the JMP package version 3.3.2.

\section{Results}

\section{Bcl-2 expression protects against taxol toxicity}

PC12/PCDA, PC12/CL-6 and PC12/CL-7 cells were created by stable transfection of PC12 cells with expression plasmid containing the cDNA for the human Bcl-2 protein. Western blot (Fig. 1) analysis disclosed that in

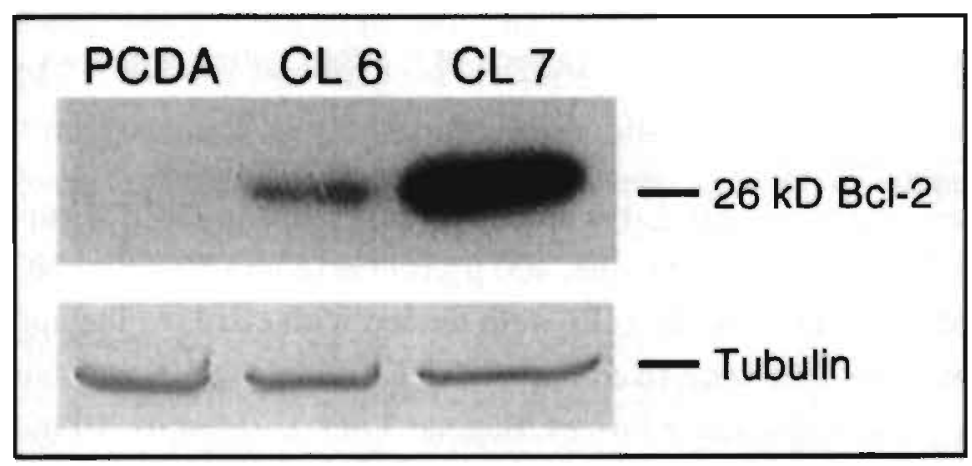

Figure 1. Western blot showing expression of Bcl-2 in two stably transfected cell lines. Total protein was separated on a SDS-polyacrylamide gel and blots were developed with a monoclonal Bcl-2 antibody in combination with an enhanced chemiluminescence detection kit from Amersham. Lane 1, vector transfected PC12 cell (pcDA), this cell line is called PC12/PCDA; lane 2, clone 6, stable transfection with human bcl-2, this cell line is called PC12/CL6; lane 3, clone 7, stable transfection with human bcl-2, this cell line is called $\mathrm{PC} 12 / \mathrm{CL} 7$. 
$\mathrm{PC} 12 / \mathrm{CL}-7$ cells the expression levels of $\mathrm{Bcl}-2$ were significantly higher than in their vector-transfected counterparts. Immunodetection showed a band at 26 $\mathrm{kD}$, the presumed molecular weight of $\mathrm{Bcl}-2$. All subsequent experiments were performed with the PC12/CL-7 line, the cell line with the highest $\mathrm{Bcl}-2$ expression.

Exposure of differentiated PC12 cells to different concentrations of taxol induced a decrease in cell survival as measured with the Live/Death assay (Fig. 2). PC12/PCDA cells showed a decrease in viability after 72 hours' treatment with taxol (dose-dependent between 1 and $50 \mu \mathrm{M}$ ). As a positive control we used $100 \mathrm{ng} / \mathrm{ml} \mathrm{NGF}$ in combination with taxol, which rescued a large fraction of cells (data not shown).

$\mathrm{PC} 12 / \mathrm{CL}-7$ cells with high $\mathrm{Bcl}-2$ levels clearly showed an increased resistance to taxol-induced cell death. At concentrations below $10 \mu \mathrm{M}$ the survival was

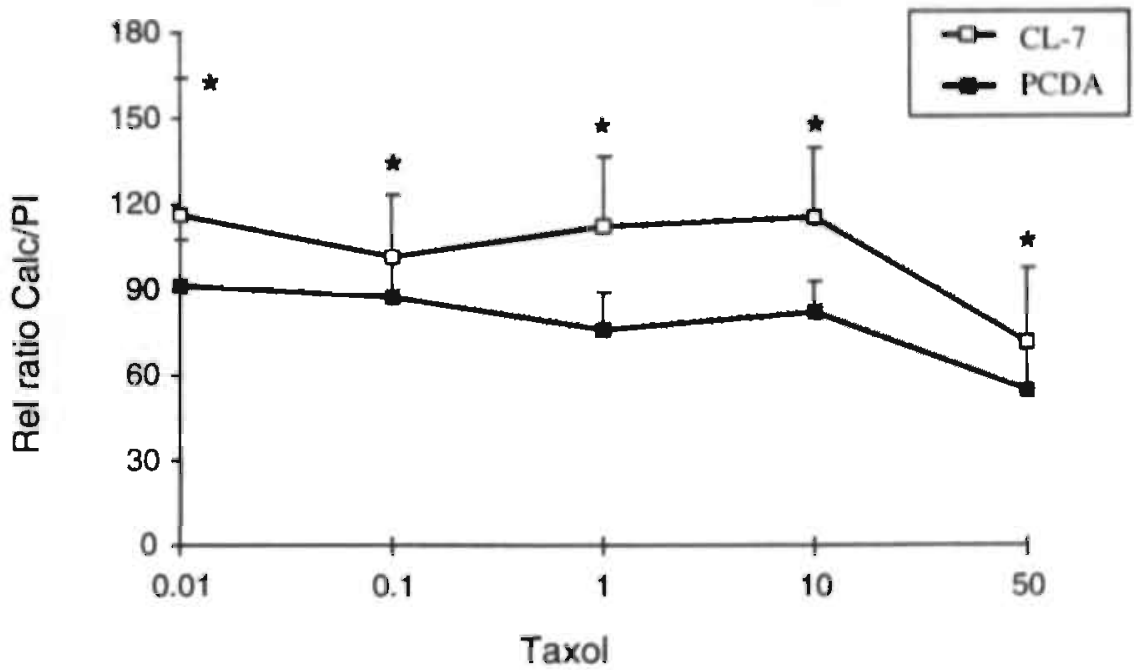

Figure 2. Dose-dependent effect of taxol on the survival of differentiated PC12 cells after $72 \mathrm{~h}$ exposure. The ratio of calcein AMl fluorescence (living cells) over propidium iodide fluorescence (dead cells) as measured in a 96-well plate reader in PC12/PCDA (vector transfected) and PC12/CL-7 (bcl-2 overexpressing) exposed to different concentrations of taxol is documented. Data are from two independent experiments in triplicate. The protective effect of bcl-2 transgene on this viability parameter is clear. Data are normalized to control values in the absence of taxol.

(" $p<0.05$ by Student's t-test) 
essentially unaffected. At all taxol concentrations, the protective effect of the $\mathrm{Bcl}-2$ transgene was statistically significant.

\section{Interference of Bcl-2 with taxol-mediated cytostatic effects}

To determine if the cytoprotective effect of $\mathrm{Bcl}-2$ occurs through inhibition of the cytostatic effects of taxol, we performed a series of experiments on

Table 1: Dose and time-dependent effect of taxol on cell cycle progression in proliferating and differentiated PC12/PCDA and PC12/CL-7. The cells were either used in the proliferative state (cultured in serum-containing medium) or in the differentiated state. In the latter case, they were differentiated for 7 days in DMEM supplemented with $1 \% \mathrm{HS}, 2 \mathrm{mMl} \mathrm{L}$-glutamine and $50 \mathrm{ng} / \mathrm{ml} \mathrm{NGF}$. They were then treated with the appropriate taxol concentrations, and stained with the nucleic acid probe Hoechst 33342 after the indicated time duration. The nuclear morphology is quantified by assessing at least 200 cells per preparation using a DAPI fluorescence filter combination.

The presence of the transgene bcl-2 does not influence the fraction of cells blocked in mitosis. Data show 1 representative example out of 3 independent experiments. (statistical analysis done by Fisher's exact test)

\begin{tabular}{|c|c|c|c|c|}
\hline$\%$ mitosis & $24 \mathrm{~h}$ & $48 \mathrm{~h}$ & $72 \mathrm{~h}$ & p \\
\hline PCDA proliferating: & & & & \\
\hline control & 2 & 2 & 1 & \\
\hline $\operatorname{taxol} 10^{-5} \mathrm{M}$ & 8 & 1 & 4 & \\
\hline taxol $10^{-6} \mathrm{M}$ & 25 & 3 & 3 & \\
\hline \multirow[t]{2}{*}{$\operatorname{taxol} 10^{-7} \mathrm{M}$} & 22 & 5 & 3 & \\
\hline & $24 \mathrm{~h}$ & $48 \mathrm{~h}$ & $72 \mathrm{~h}$ & \\
\hline $\begin{array}{l}\text { CL-7 proliferating: } \\
\text { control }\end{array}$ & & & & \\
\hline $\begin{array}{l}\text { control } \\
\text { taxol } 10^{-5} \mathrm{M}\end{array}$ & 2 & 1 & 1 & ns \\
\hline $\begin{array}{l}\text { taxol } 10^{-5} \mathrm{M} \\
\text { taxol } 10^{-6} \mathrm{M}\end{array}$ & 10 & 1 & 2 & ns \\
\hline $\begin{array}{l}\text { taxol } 10^{-6} \mathrm{M} \\
\text { taxol } 10^{-7} \mathrm{M}\end{array}$ & 26 & 4 & 3 & ns \\
\hline taxol $10^{-7} \mathrm{M}$ & 23 & 7 & 2. & ns \\
\hline$\%$ mitosis & $24 \mathrm{~h}$ & $48 \mathrm{~h}$ & $72 \mathrm{~h}$ & \\
\hline \multicolumn{5}{|l|}{ PCDA differentiated: } \\
\hline control & 0 & 1 & 2 & \\
\hline taxol $10^{-5} \mathrm{M}$ & 5 & 6 & 3 & \\
\hline taxol $10^{-6} \mathrm{M}$ & 15 & 13 & 1 & \\
\hline taxol $10^{-7} \mathrm{M}$ & 9 & 11 & 1 & \\
\hline & $24 \mathrm{~h}$ & $48 \mathrm{~h}$ & $72 \mathrm{~h}$ & \\
\hline $\begin{array}{l}\text { CL-7 difterentiated: } \\
\text { control }\end{array}$ & \multicolumn{4}{|c|}{ CL-7 differentiated: } \\
\hline taxol $10^{-5} \mathrm{M}$ & 1 & 3 & 2 & ns \\
\hline $\operatorname{taxol} 10^{-6} \mathrm{M}$ & 4 & 14 & 1 & 0.02 at $24 \mathrm{~h}, \mathrm{~ns}$ at other times \\
\hline taxol $10^{-7} \mathbf{M}$ & 8 & 10 & 3 & ns \\
\hline
\end{tabular}


proliferating PC12/PCDA and PC12/CL-7 cells and counted the number of mitotic cells at various time points after application of taxol (Table 1). in PC12/PCDA cells, taxol induced a mitotic block, which was most obvious after 24 hours of treatment. This reflects the presence of cells halted in the $\mathrm{G}_{2} / \mathrm{M}$ cell cycle phase. At later time points the percentage of mitotic cells decreased, probably as a result of cell death. PC12/CL-7 cells showed a response almost identical to that of their control counterparts. This is a clear indication that the anti-proliferative effect of taxol is not affected by the high expression levels of $\mathrm{Bcl}-2$.

The same type of experiment was performed in NGF-differentiated $\mathrm{PC} 12$ cells. As expected, in the vehicle-treated cultures the number of mitotic cells was very sparse, almost zero. Upon taxol application, however, their number significantly increased, albeit substantially less then the corresponding proliferating cultures. Comparison between the PC12/PCDA and the PC12/CL-7 differentiated cells indicated that the appearance of a mitotic block by taxol is somewhat delayed in the Bcl-2-overexpressing cells, but with regard to dose-responses, the trend was the same in the two conditions.

\section{Differentiated PCI2 cells initiate apoptosis upon taxol application} To establish the nature of the observed cell death we first quantified phosphatidylserine (PS) exposure at the outer surface of the membrane by applying annexin-V-FITC conjugate. This PS flip-flop is one of the recently discovered and early markers of apoptosis. In combination with the membrane-impermeable DNA stain propidium iodide (PI), with a flow cytometer one can distinguish four different cell types during apoptosis: healthy cells (annexin-V and PI-negative), apoptotic cells (annexin-V-positive but PI-negative), apoptotic cells after membrane breakdown (annexin-V'-positive and PI-positive cells) and necrotic cells (annexin-V-negative and PI-positive). The intensity values for classification of the objects into positive and negative classes (thresholding) were determined from histogram analyses of signals from PI only and annexin-V only. Table 2 illustrates the fraction of cells in the two populations (annexin-V-positive vs. annexin-V-negative) after 
Table 2: Annexin- $V$ positive cells as a fraction of the total cell population in cultures exposed to different taxol concentrations for $24 \mathrm{~h}$ and measured by flow cytometry. All cells are differentiated for 7 days by changing the medium of the culture flask to DMEM supplemented with $1 \%$. HS, $2 \mathrm{mM}$ L-glutamine and $50 \mathrm{ng} / \mathrm{ml} \mathrm{NGF}$. In each case 5000 cells were analyzed and gated within pre-defined thresholds for annexin- $V$ fluorescence. The transgene bcl-2 clearly decreases annexin- $V$ expression induced by taxol. ( $p$-values are calculated using Fisher's Exact test)

$\begin{array}{ccc}\text { condition } & \text { \% annexin-pos. cells } & \text { p-value } \\ \text { pCDA: } & 5.5 & \\ \text { control } & 13.41 & \\ \text { taxol } 10^{-5} \mathrm{M} & 18.33 & \\ \text { taxol } 10^{-6} \mathrm{M} & 7.67 & \\ \text { taxol } 10^{-7} \mathrm{M} & & \\ & & \mathrm{ns} \\ \mathrm{CL}-7: & 6.40 & 0.08 \\ \text { control } & 6.97 & 0.012 \\ \text { taxol } 10^{-5} \mathrm{M} & 3.70 & 0.0502 \\ \text { taxol } 10^{-6} \mathrm{M} & 2.021 & \\ \text { taxol } 10^{-7} \mathrm{M} & & \end{array}$

24 hours of taxol exposure for a typical experiment. It can be seen that the presence of the $\mathrm{Bcl}-2$ transgene significantly reduced the fraction of annexin$\mathrm{V}$-positive cells.

In the same set of experiments we quantified the percentage of apoptotic cells on the basis of nuclear morphology after staining with Hoechst 33342 (Table 3 ). In the proliferating PC12/PCDA cells the majority of the apoptotic nuclei $(25 \%)$ were detected after 48 hours' treatment with $1 \mu \mathrm{M}$ and $0.1 \mu \mathrm{M}$ taxol. This maximal effect coincided with the wave of mitotic cells seen at the same concentrations 24 hours earlier. At $10 \mu \mathrm{M}$ the apoptosis-inducing effect of taxol was unexpectedly lower. When the same parametric values were determined in the PC12/CL-7 cells, there was a substantially lower percentage of apoptotic cells at all taxol concentrations. In these cultures the number of apoptotic cells rarely exceeded $5 \%$ of the total cell population. When the same analysis was performed on the PC12/PCDA differentiated cells, there was a clear increase in apoptotic cells at all taxol concentrations used (Table 3). In this instance as well, this coincided with the wave of mitotic cells observed 24 hours earlier. Again, the PC12/CL-7 cells conferred at considerable degree of protection against apoptosis. 
Table 3: Dose and time-dependent induction by taxol of apoptotic nuclei in proliferating and differentiated PC12/PCDA and PC12/CL-7. The cells were either used in the proliferative state (cultured in serum-containing medium) or in the differentiated state. In the latter case, they were differentiated for 7 days in DMEM supplemented with $1 \% \mathrm{HS}$, $2 \mathrm{mM} \mathrm{L}$-glutamine and $50 \mathrm{ng} / \mathrm{ml} \mathrm{NGF}$. They were then treated with the appropriate taxol concentrations, and stained with the nucleic acid probe Hoechst 33342 after the indicated time duration. The nuclear morphology is quantified by assessing at leas! 200 cells in each preparation using DAPI filter combination.

The transgene bcl-2 clearly protects against the induction of apoptotic nuclei by taxol. Data are obtained from the same preparations as used in table 1. ( $p$-value calculated by statistical analysis done by Fisher's exact test)

$\%$ apoptosis

PCDA proliferating: control taxol $10^{-3} \mathrm{M}$

taxol $10^{-6} \mathrm{M}$

taxol $10^{-7} \mathrm{M}$

CL-7 proliferating: control

taxol $10^{-5} \mathrm{M}$

taxol $10^{-6} \mathrm{M}$

taxol $10^{-7} \mathbf{M}$

$\%$ apoptosis

PCDA differentiated:

$$
\text { control }
$$

taxol $10^{-5} \mathrm{M}$

taxol $10^{-6} \mathrm{M}$

taxol $10^{-7} \mathrm{M}$
$24 \mathrm{~h}$

0

4

13

14
$48 \mathrm{~h}$

1

6

21

23
72 h

I

12

15

22

p

0

6

3

5

$24 \mathrm{~h}$.

0

6

5

5
0

6

5

3

$48 \mathrm{~h}$.

$72 \mathrm{~h}$

6

18

$18 \quad 21$

CL-7 differentiated:

control

taxol $10^{-5} \mathrm{M}$

taxol $10^{-6} \mathrm{M}$

taxol $10^{-7} \mathrm{M}$
0

5

4

4 ns

ns

0.016

0.01

16 


\section{Bcl-2 facilitates the formation of multinucleated cells}

One of the features frequently observed in cells treated with taxol is the formation of so-called multi-nucleated cells (Fig. 3). This occurs secondary to the formation of non-functional multi-polar spindles. As a consequence, chromosomal segregation is hampered. At this point, many cells are driven into a suicide program and enter apoptosis. Some cells are able to escape this checkpoint by forming these multi-nucleated cells. We further investigated the role of $\mathrm{Bcl}-2$ in this possible escape pathway by counting the number of cells with single (non-apoptotic) nuclei and multi-nucleated cells (and also non-apoptotic nuclei). Quantification of the vector-transfected cells yielded comparable numbers ranging from 0 in the non-treated samples to $25 \%$ in the 72-hour taxol-treated cells (Table 4). This effect was present at all the taxol concentrations used, there was no difference between proliferating or differentiated cells.

In the PC12/CL-7 cultures there was a dramatic increase (up to $70 \%$ ) in the number of multi-nucleated cells after 72 hours' taxol treatment, in both the proliferating and the differentiated condition. 

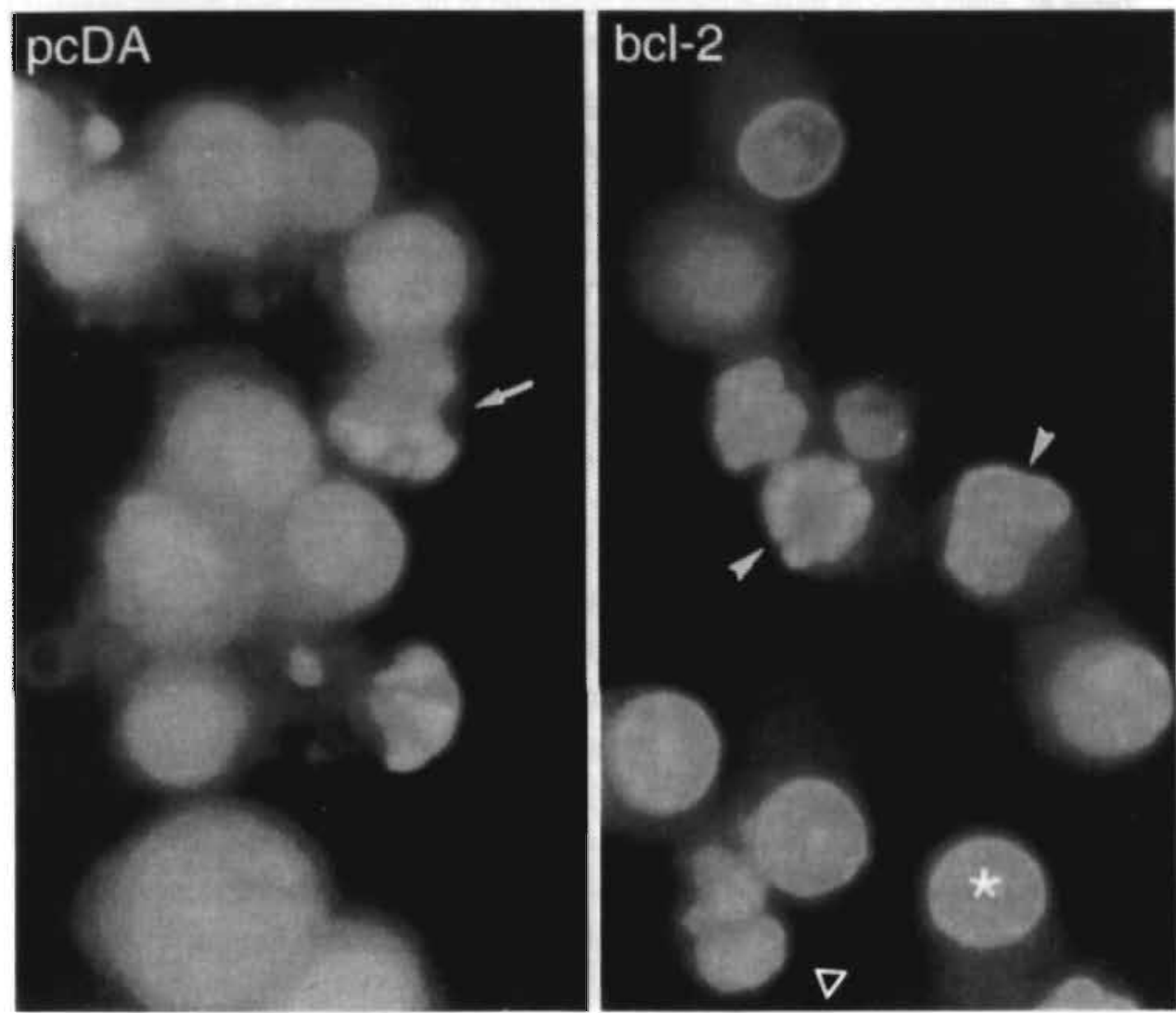

Figure 3. Illustration of the different morphological phenotypes encountered in taxol treated cells. The example is from PC12/pcDA and PC12/CL-7 cells after $72 \mathrm{~h}$ of $10^{-6} \mathrm{M}$ taxol treatment. Cells are stained with Hoechst 33342 probe, which binds to nucleic acids. The fluorescence image is taken on an Axioplan microscope using a DAPI filter combination, i.e. $380 \mathrm{~nm}$ excitation and $450 \mathrm{~nm}$ emission filters. This preparation shows normal nuclei (asterisks), mitotic cells (arrowhead), apoptotic nuclei (arrow) and multi-nucleated cells (open arrowhead). 
Table 4: Frequency of multi-nucleation observed in proliferating and differentiated PC12/PCDA and PC12/CL-7. The cells were either used in the proliferative state (cultured in serum-containing medium) or in the differentiated state. In the latter case, they were differentiated for 7 days in DMEM supplemented with $1 \% \mathrm{HS}, 2 \mathrm{mM}$ L-glutamine and $50 \mathrm{ng} / \mathrm{ml}$ NGF. They were then treated with the appropriate taxol concentrations, and stained with the nucleic acid probe Hoechst 33342 after $72 \mathrm{~h}$. The nuclear morphology is quantified by assessing at least 200 cells in each preparation using DAPI filter combination. Only cells with normal nuclei are considered here, i.e. cells with apoptotic and mitotic nuclei are excluded.

Cells overexpressing the bcl-2 transgene display a much larger fraction of multinucleated cells. Data are obtained from the same preparations as used in table 1. ( $p$-value calculated by statistical analysis done by Fisher's exact test).

$\begin{array}{ccc}\text { PCDA proliferating: } & & \\ \text { control } & 100 & 0 \\ \text { taxol } 10^{-5} \mathrm{M} & 80 & 20 \\ \text { taxol } 10^{-6} \mathrm{M} & 78 & 22 \\ \text { taxol } 10^{-7} \mathrm{M} & 83 & 17\end{array}$

CL-7 proliferating:

conirol

taxol $10^{-5} \mathrm{M}$

$\operatorname{tax} 0110^{-6} \mathrm{M}$

taxol $10^{-7} \mathrm{M}$

PCDA differentiated:

control

taxol $10^{-5} \mathrm{M}$

taxol $10^{-6} \mathrm{M}$

taxol $10^{-7} \mathrm{M}$

CL-7 differentiated:

control

100

taxol $10^{-5} \mathrm{M}$

taxol $10^{-6} \mathrm{M}$

taxol $10^{-7} \mathrm{M}$
100

60

58

37

normal

100

75

77

71

multi-nucleated

$\begin{array}{ll}00 & 0 \\ 5 & 25 \\ 7 & 23 \\ 1 & 29\end{array}$

p 


\section{Discussion}

This study documents the effect of taxol on PC12 cells, which, upon differentiation in low serum containing medium and NGF, acquire a neuronal phenotype with the extension of long cellular processes. NGF-differentiated PC1 2 cells have been used in a large number of studies on programmed cell death as induced either by growth factor or serum deprivation and DNA. damage (Park et al., 1998). We showed that taxol induces cell death through apoptosis as indicated by the phosphatidy!serine flip-flop, measured by the binding of exogenously applied FITC-annexin-V (Schutte et al., 1998) and nuclear fragmentation. Interestingly, the effect faded away at the higher taxol concentration of $10 \mu \mathrm{M}$. This result may reflect the differences in microtubule stabilization, which is dependent on the stochiometry of the binding of taxol to microtubules. At low doses, taxol suppresses shortening at microtubule plus ends, while at high concentrations it completely blocks micrombule dynamics (Derry et al., 1995), and therefore may attenuate effects on total cell survival. This investigation also shows that Bcl-2-overexpression protects differentiated PC12 cells from taxol-induced apoptotic cell death. Bcl-2 is a member of a family of oncogenes with presumed anti-apoptotic activity during programmed cell death. Along these lines, we provided evidence that Bcl-2 overexpression protects NGF-differentiated PC12 cells from this apoptotic cell death with reference to both the course of metabolic activity and the unfolding of two of the typical apoptotic features: phosphatidylserine flip-flop and nuclear fragmentation.

A variety of functions have been attributed to Bcl-2 (Bergeron and Yuan, 1998). In a number of cases, $\mathrm{Bcl}-2$ has been documented to reduce the oxidative stress induced, for instance, by UV irradiation. Another mechanism of action is based upon the regulation of calcium homeostasis in the endoplasmic reticulum (Lam et al., 1994). It has also been suggested that Bcl-2 and its regulatory function in the formation of the mitochondrial megapore are crucially important for the initiation of the apoptotic cascade (Zamzami et al., 1996).

Recently, a study disclosed that Bcl-2 accelerates neuronal differentiation in 
PC12 celis by enhancing the neurofilament polymerization (Suzuki and Tsutomi, 1998). Evidence for this phenomenon came from experiments in which Bcl-2 inhibited taxol-related effects on neurite elongation and the polymerization of NF-L and NF-H. In the above-mentioned study there was no indication of cell death either in vector or Bcl-2 transfected PC 12 cells. Various reasons may account for the discrepancy between these findings and our own. We monitored the appearance of apoptotic features only from $24 \mathrm{~h}$ and not after short $(2 \mathrm{~h})$ incubation periods. Another important factor is the protection against taxol toxicity by high concentrations $(100 \mathrm{ng} / \mathrm{ml})$ of $\mathrm{NGF}$. It has indeed been shown that neurotrophic factors can protect neurons from the deleterious effects exerted by cytostatics (Malgrange et al., 1994).

The sensitivity range among $\mathrm{PC} 12$ cells of different origins is also a possible cause of the various manifestations observed.

In addition to its effects in vitro, $\mathrm{Bcl}-2$ confers protection in an in vivo model of cerebral ischemia (Martinou et al., 1994) and in a genetic mouse model of motor neuron disease (Sagot et al., 1995). Intriguingly, in these mice Bcl-2 overexpression only rescued the affected neurons but did not influence axonal degeneration and hence the animal's life span.

In proliferating cells, taxol induces a $\mathrm{G}_{2} / \mathrm{M}$ block, presumably through its interference with the mitotic spindle. Recent findings suggest that a persistent or transient arrest in $G_{2} / M$ is an important step in taxol-induced apoptosis (Shu et al., 1997). Activation of cyclin B1-cdc2 is required for the completion of this process. The same phenomena have been reported to occur during apoptosis in neuronal cells (Nuydens et al., 1998), including PC12 cells. The increased kinase activities may also explain the phosphorylation of $\mathrm{Bcl}-2$ during the $\mathrm{G}_{2} / \mathrm{M}$ phase in cancer cells treated with microtubule poisons but not in cultures treated with DNA-damaging or topoisomerase-inhibiting compounds (Haldar et al., 1997).

This report (Haldar et al., 1997) also shows that in NGF-differentiated neuron-like PC12 cells, taxol-induced apoptosis is preceded by a form of mitotic wave consisting of cells with abnormal spindle figures. This suggests that alterations in microtubule dynamics as triggered by taxol treatment forces the differentiated cell to exit the $\mathrm{G}_{0}$-phase and re-initiate the cell cycle. 
Interestingly, $\mathrm{Bcl}-2$ overexpression does not seem to inhibit this transition. Rather the Bcl-2-overexpressing cells arrested in the $\mathrm{G}_{2} / \mathrm{M}$ phase form multi-nucleated cells as an escape pathway from apoptosis. These cells are still viable, as suggested by calcein conversion. The same phenomena are documented in $\mathrm{Bcl}-\mathrm{X}_{\mathrm{L}}$-overexpressing, cycling cells when they are treated with microtubule poisons (Minn et al., 1996). The molecular mechanisms responsible for the formation of these multinucleated cells are still unknown. This observation may well point to the role of a proper centriolar separation as a spindle checkpoint for cell cycle progression. Similarly, it has been documented that loss of P53 function reduces sensitivity to taxol treatment with reference to tumors, but allows the formation of polyploid cells after mitotic spindle damage (Minn et al., 1996). This process is even more pronounced in cells which show higher expression levels of anti-apoptotic genes (Ibrado et al., 1996).

In conclusion, we have shown that taxol induces Bcl-2-sensitive apoptosis in both differentiated and proliferating PC12 cells. The initiation of programmed cell death by taxol is preceded by re-initiation of the cell cycle irrespective of the differentiation state. Bcl-2-overexpressing cells create an escape pathway from apoptosis by the formation of multi-nucleated cells. Deregulation of microtubule dynamics may therefore play an important role during the initiation of these apoptotic processes. 


\section{References}

Bergeron, L. and Yuan, J. Sealing one's fate: control of cell death in neurons. Curr, Opin. Neurobiol. (1998) 8: 55-63.

Bonfoco, E., Ceccatelli, S., Manzo, L. and Nicotera, P. Colchicine induces apoptosis in cerebellar granule cells. Exp. Cell Res. (1995) 218: 189-200.

Derry, W.B., Wilson, L. and Jordan, M.A. Substoichiometric binding of taxol suppresses microtubule dynamics. Biochemistry (1995) 34: 2203-2211.

Freeman, R.S., Estus, S. and Johnson, E.M., Jr. Analysis of cell cycle-related gene expression in postmitotic neurons: selective induction of Cyclin D1 during programmed cell death. Neuron (1994) 12: 343-355.

Haldar, S., Basu, A. and Croce, C.M. Bcl2 is the guardian of microtubule integrity. Cancer Res. (1997) 57: 229-233.

Ibrado, A.M., Huang, Y., Fang, G. and Bhalla, K. Bcl- $X_{L}$ overexpression inhibits taxol-induced Yama protease activity and apoptosis.

Cell Growth Differ: (1996) 7: 1087-1094.

Kroemer, G. The proto-oncogene Bel-2 and its role in regulating apoptosis Nat. Med. (1997) 3: 614-620.

Lam, M., Dubyak, G., Chen, L., Nunez, G., Miesfeld, R.L. and Distelhorst, C.W. Evidence that $\mathrm{BCL}-2$ represses apoptosis by regulating endoplasmic reticulum-associated $\mathrm{Ca}^{2 \text { to }}$ fluxes. Proc. Natl. Acad. Sci. USA (1994) 91: 6569-6573.

Malgrange, B., Delree, P., Rigo, J.M., Baron, H. and Moonen, G. Image analysis of neuritic regeneration by adult rat dorsal root ganglion neurons in culture: quantification of the neurotoxicity of anticancer agents and of its prevention by nerve growth factor or basic fibroblast growth factor but not brain-derived neurotrophic factor or neurotrophin-3, J. Neurosci. Methods (1994) 53: 111-122.

Martinou, J.C., Dubois-Dauphin, M., Staple, J.K., Rodriguez. I., Frankowski, H., Missotten, M.. Albertini, P., Talabot, D., Catsicas, S., Pietra, C. et al. Overexpression of BCL-2 in transgenic mice protects neurons from naturally occurring cell death and experimental ischemia. Neuron (1994) 13: 1017-1030.

Minn, A.J., Boise, L.H. and Thompson, C.B. Expression of $\mathrm{Bcl}-\mathrm{X}_{\mathrm{L}}$ and loss of $\mathrm{p} 53$ can cooperate to overcome a cell cycle checkpoint induced by mitotic spindle damage. Genes Dev. (1996) 10: 2621-2631. 
Nuydens, R., de Jong, M., Van Den Kieboom, G., Heers, C., Dispersyn, G., Cornelissen, F., Nuyens, R., Borgers, M. and Geerts, H. Okadaic acid-induced apoptosis in neuronal cells: evidence for an abortive mitotic attempt. J. Neurochem. (1998) 70: 1124-1133.

Park, D.S., Morris, E.J., Stefanis, L., Troy, C.M., Shelanski, M.L., Geller, H.M. and Greene, L.A. Multiple pathways of neuronal death induced by DNA-damaging agents, NGF deprivation, and oxidative stress. J. Neurosci. (1998) 18: 830-840.

Sagot, Y., Dubois-Dauphin, M., Tan, S.A., de Bilbao, F., Aebischer, P., Martinou, J.C. and Kato, A.C. Bcl-2 overexpression prevents motoneuron cell body loss but not axonal degeneration in a mouse model of a neurodegenerative disease.

J. Neurosci. (1995) 15: 7727-7733.

Schutte, B., Nuydens, R., Geerts, H. and Ramaekers, F. Annexin V binding assay as a tools to measure apoptosis in differentiated neuronal cells.

J. Neurosci. Methods (1998) 86: 63-69.

Shu, C., Yang, W., Kuo, M.-L. and Huang. T.-S. Cell cycle G,/M arrest and activation of cyclin-dependent kinases associated with low-dose paclitaxel-induced sub-GI apoptosis. Apoptosis (1997) 2: 463-470.

Suzuki, A. and Tsutomi, Y. Bcl-2 accelerates the neuronal differentiation: new evidence approaching to the biofunction of $\mathrm{Bcl}-2$ in the neuronal system.

Brain Res. (1998) 801: 59-66.

Tanabe, H., Eguchi, Y., Kamada, S., Martinou, J.C. and Tsujimoto, Y. Susceptibility of cerebellar granule neurons derived from Bcl-2-deficient and transgenic mice to cell death. Eur. J. Neurosci. (1997) 9: 848-856.

Zamzami, N., Susin, S.A., Marchetti, P., Hirsch, T., Gomez-Monterrey, I., Castedo, M. and Kroemer, G. Mitochondrial control of nuclear apoptosis.

J. Exp. Med. (1996) 183: 1533-1544. 



\section{Bcl-2 protects against}

\section{apoptosis-related microtubule alterations}

Rony Nuydens ${ }^{a, b}$, Gwenda Dispersyn ${ }^{c}$, Gerd Van Den Kieboom a , Mirjam de Jong ${ }^{a}$, Rich Connors ${ }^{d}$, Frans Ramaekers ${ }^{b}$, Marcel Borgers ${ }^{a}$ and Hugo Geerts $\sqrt{1}$

- Department of Cell Physiology, Life Sciences, Janssen Research Foundation, Beerse, Belgium

'Department of Molecular Cell Biology and Genetics, Maastricht University, Maastricht, the Netherlands

${ }^{c}$ Department of Biochemistry, University of Antwerp, Antwerp, Belgium

`Oncology Group, Janssen Research Foundation, Spring House, Pennsylvania, USA

submitted for publication

Abstract

Bcl-2 is a gene with clear anti-apoptotic properties in neurodegenerative conditions. One of the earliest hallmarks of degeneration in neuronal cell cultures is the loss of neurite morphology. Therefore the effect of Bcl-2 on neuronal morphology and microtubule stability was studied in nerve growth factor differentiated PCI2 cells. Microtubule dynamics were modulated using the microtubule stabilizer taxol and the microtubule destabilizer, okadaic acid, a protein phosphatase inhibitor. It was 
shown that Bcl-2 protects against both taxol-and okadaic acid induced neurite retraction. Bcl-2 overexpression also significantly reduced the increased ratio of acetylated tubulin over total tubulin induced by taxol treatment. Interestingly, Bcl-2 attenuates the decrease of the same ratio after exposure to okadaic acid, suggesting that Bcl-2 is able to normalize the level of acetylated tubulin. In addition, cell death and nuclear fragmentation, induced by okadaic acid, were reduced in Bcl-2 overexpressing cells. This protection is either downstream or independent of tau phosphorylation as quantitative immunocytochemistry with AT8 showed that Bcl-2 did not modify the level of tau phosphorylation. The data suggest that the protective effect of Bcl-2 on the neuronal cytoskeleton is probably linked to changes in the post-translational modification of tubulin. 


\section{Introduction}

Microtubules play a prominent role in the maintenance of the highly polarized cyto-architecture in neurons. Dynamic instability endows microtubules with the ability to switch between growing and shrinking phases. Stability of the microtubular system is tightly regulated by the concerted action of microtubule-associated proteins (MAPs) and post-translational tubulin modifications.

In axons, microtubules are composed of domains that differ in their tyrosinated and acetylated tubulin content. The proportion of the less stable tyrosinated tubulin is higher in the distally oriented plus-end of the individual microtubule near the growth-cone, while acetylated microtubules are primarily found in the axonal shaft (Brown et al., 1993). These subpopulations show different sensitivities towards microtubule disruptions (Audebert et al., 1993) with the acetylated subtypes being the more stable population while the tyrosinated ones are more dynamic.

Tau, a neuronal MAP, has long been postulated a phosphorylation dependent regulator of microtubule stability. Paired helical filaments, a hallmark of Alzheimer's disease, are mainly composed of hyperphosphorylated tau (Grundke-Iqbal et al., 1986), the result of a change in the kinase/phosphatase balance (Nuydens et al., 1995). Xie et al., (1998) demonstrated in SH-SY5Y cells that the phosphorylation of tau is regulated by microtubule dynamics and that only phosphorylation at Ser262/356 by protein kinase A prevented the association with microtubules.

In NT2N cells, the polymerization state of the microtubule cytoskeleton modulated the phosphorylation of tau at specific sites due to changed phosphatase 2A (PP2A) activity (Merrick et al., 1996). It has been shown that altering microtubule kinetics pharmacologically induces apoptosis not only in cycling cells but also in differentiated cells of neuronal origin (Bonfoco et al., 1996; Nuydens et al., 1998). Recently, it was also documented that, in PC12 cells, microtubule disassembly might be an early step during the execution phase of programmed cell death and this process might be related to PP2A activity (Mills et al., 1998). 


\section{Chapter 7}

In PC1 2 cells, it was established that during differentiation tau mRNA levels increased and the degree of tau phosphorylation decreased (Sadot et al., 1995), possibly leading to a more tight tau-microtubule association and microtubule stability. Similarly, we showed that, upon removal of nerve growth factor in differentiated PC12 cells, tau phosphorylation increased while the morphological differentiation decreased (Nuydens et al., 1997).

Inhibition of PP2A by okadaic acid has been associated with the induction of apoptosis in a number of cell types including neurons (Nuydens et al., 1998). The loss of the neuronal cytoarchitecture is an early event during apoptosis. By modulating microtubule stability either positively or negatively we further investigated the role of the cytoskeleton during programmed cell death. Bcl-2, an apoptosis-inhibiting protein, has been shown to protect against neuronal cell death in a variety of in vitro (Kroerner, 1997) and in vivo (Tanabe et al., 1997) systems.

Using $\mathrm{Bcl}-2$ overexpressing $\mathrm{PC} 12$ cells we also gained insight into the role of this anti-apoptotic protein during the sequence of events associated with programmed cell death.

\section{Materials and methods}

\section{Cell culture}

Bcl-2 (cl7) and vector (pCDA) transfected PC12 cells (Nuydens et al., unpublished observations) were maintained in Dulbecco's modified Eagle's medium (DMEM, GIBCO BRL) supplemented with $7.5 \%$ horse serum (HS, GIBCO BRL), $7.5 \%$ fetal calf serum (FCS, HyClone), $2 \mathrm{mM}$ L-glutamine

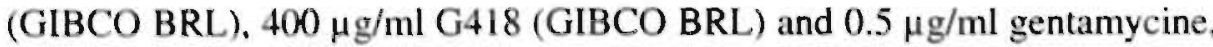
in a humidified incubator aerated with $95 \%$ air and $5 \% \mathrm{CO}_{2}$ at $37^{\circ} \mathrm{C}$.

\section{Stable transfection}

The human bcl-2 gene was cloned from normal primary foreskin fibroblasts (ATCC-CCD-27SK) via RT/PCR (Stratagene). PC- 12 cells (a gift from $R$. Slemmon) were transfected with pCD.Bcl-2 DNA by means of lipofectamine 
under conditions recommended by the manufacturer (GIBCO BRL). Briefly, 4 $\mu \mathrm{g}$ of pCD.Bcl-2 or pCDNA3 was mixed with $20 \mu \mathrm{l}$ of lipofectamine in $200 \mu \mathrm{l}$ serum free media and incubated at room temperature for 45 minutes.

Eight hundred $\mu \mathrm{l}$ of serum free media was added and the DNA/liposome solution was applied to a monolayer of $10^{6} \mathrm{PC}-12$ cells in a $35 \mathrm{~mm}$ dish.

After $6 \mathrm{~h}$ of incubation the DNA solution was removed and the cells were fed growth media (RPMI with $10 \%$ fetal calf serum, $10 \%$ horse serum,

100 units $/ \mathrm{ml}$ penicillin, $100 \mu \mathrm{g} / \mathrm{ml}$ streptomycin and $2 \mathrm{mM}$ glutamine).

The next day the cells were split into five $100 \mathrm{~mm}$ dishes and fed growth media with $400 \mu \mathrm{g} / \mathrm{ml} \mathrm{G} 418$ for selection of transfected cells. Clones were isolated with cloning cylinders and expanded in selective media. Bcl-2 expression was assessed by comparison of equal quantities of Triton X-100 solubilized proteins from several expanded pCDBcl-2 or pCDNA3 transfected cloned lines. PCDBcl-2 Clone 7 was found to have 6 fold more Bcl-2 protein compared to pCDNA.

\section{Quantitative neuronal morphology}

Morphological changes in neurons were automatically quantified as described (Nuydens et al. 1995). In short, at the appropriate times, $4 \%$ giutaraidehyde was added directly to the medium and left for 10 minutes at room temperature. The cells were observed by transmitted light mode in an Axiovert microscope (Zeiss Oberkochen, Germany), equipped with a Marzhauser scanning stage driven by an Indy workstation (Silicon Graphics, Mountain View, USA). Images were captured with a MX5 video camera (HCS). About 3000 cells were evaluated in 64 aligned images, forming a $8 \times 8$ square matrix of images. The exact alignment of the images ensured that neurites could be followed from one image field into the next. Automatic detection of the neurite extensions, labeled by polyclonal tau antibody was performed using an unbiased detector of curvilinear structures (Steger, 1998). The analysis software automatically calculated cell body area and total neurite length. 


\section{Viability measurements}

Cell survival was measured by means of the XTT-method which is based upon the conversion of the substrate to a water-soluble formazan product by mitochondrial dehydrogenases from viable cells only. At the appropriate times, a prewarmed solution of $1 \mathrm{mg} / \mathrm{ml} \mathrm{XTT} \mathrm{solution} \mathrm{in} \mathrm{the} \mathrm{appropriate}$ medium was added to the culture medium and further incubated for $2 \mathrm{~h}$ at $37^{\circ} \mathrm{C}$. After these times the plates were shaken and the optical density was read at $450 \mathrm{~nm}$ with $650 \mathrm{~nm}$ as a reference on a Molecular Dynamics plate reader. The data are presented as values relative to the control samples (mean of 3 points).

\section{Immunocytochemistry}

At the appropriate time-points the cells were fixed for 10 minutes with a mixture of $0.5 \%$ glutaraldehyde and $0.5 \%$ Triton-X100 in PHEM buffer (Schliwa and Van Blerkom, 1981). After a rapid wash the cells were further permeabilized with $0.5 \%$ Triton $\mathrm{X}-100$ for 30 minutes. The remaining aldehyde groups were reduced during a 20 -minutes incubation with $1 \mathrm{mg} / \mathrm{ml}$ $\mathrm{NaBH}_{4}$ in PHEM. The subsequent incubations were all done in TBS containing $0.1 \% \mathrm{BSA}$. The following antibodies were used: monoclonal anti-acetylated tubulin (clone6-11 B-1, Sigma) and monoclonal anti-B-tubulin (Sigma) in combination with GAM-Cy-3 (Jackson ImmunoResearch Labs, Pennsylvania).

The preparations were mounted in gelvatol containing $100 \mu \mathrm{g} / \mathrm{ml} \quad \overline{D A B C O}$ and viewed on a Zeiss Axioplan.

For quantitative immuno-gold silver staining, the cells were fixed for 20 minutes with 4\% paraformaldehyde in PHEM buffer (Schliwa and Van Blerkom, 1981). After a rapid wash the cells were further permeabilized with $0.5 \%$ Triton $\mathrm{X}-100$ for 30 minutes, followed by a 20 -minutes incubation with $1 \mathrm{mg} / \mathrm{ml} \mathrm{NaBH}_{4}$ in PHEM. The subsequent incubations were all done in TBS containing $0.1 \%$ BSA. The AT- 8 antibody (Innogenetics, Belgium) against phosphorylated tau was used at 1:100 dilution in combination with GAM-Ultra Small Conjugates (Aurion, the Netherlands) followed by silver enhancement with Aurion R-Gent (Aurion, the Netherlands). 
The preparations were mounted in gelvatol and viewed on a Zeiss Axiovert microscope. Quantification was done according to methods described previously (Nuydens et al., 1997). Briefly, in each image the number of cells and the degree of epitope expression were determined on background corrected images by means of fully automatic tresholding. In this way, the mean intensity of individual cells after background correction was calculated over 300 to 700 cells in each condition.

Elisa

For the quantitation of the microtubule content, the cells were plated in poly-L-lysine coated 96-well plates (Biocoat, Falcon, Massachusetts), differentiated for 7 days and treated with the compounds or solvent for the indicated periods. The cells were then fixed and processed by a method virtually identical to immunofluorescence except for peroxidase-linked secondary antibodies which were then developed with TMB as a substrate. The antibodies used were monoclonal anti-acetylated tubulin (clone6-11 B-1, Sigma) and monoclonal anti-B-tubulin (Sigma). A Triton X-100 glutaraldehyde mixed lysis fixation was used to remove all non-polymerized tubulin and by determining the ratio of acetylated to total tubulin we obtained an indication of the post-translational modifications in the various experimental conditions.

\section{Statistical analysis}

A statistical analysis was carried out with the JMP package. A. Dunnet t-test was used. P values smaller then 0.05 were considered significant.

\section{Results}

Cell survival during okadaic acid treatment

$\mathrm{PC} 12 / \mathrm{PCDA}$ (expressing the empty vector) and PC12/CL-7 (expressing the bcl-2 transgen) cells were created by stable transfection of $\mathrm{PC} 12$ cells.

Previous studies had already documented the effect of different concentrations 
of taxol on differentiated PC12 cells with regard to cell survival (Nuydens et al., unpublished observations) and the protection by $\mathrm{Bcl}-2$ overexpression in this system. In the same cells we evaluated the effects of okadaic acid on total cell survival after 24 -and 48 hours exposure. As described for other cell types (Nuydens et al., 1998), in this case too, application of okadaic acid induced apoptosis. In PC12/PCDA cells a time and dose-dependent response towards phosphatase inhibition was seen (fig 1). At $10^{-6} \mathrm{M}$ okadaic acid cell viability had decreased by about $20 \%$ after 24 hours (data not shown) while at 48 hours there was a significant reduction of $50 \%$ with respect to total cell survival. At the latter time-point $10^{-7} \mathrm{M}$ okadaic acid also induced a clear toxic effect. At concentrations below $10^{-7} \mathrm{M}$ no cell death was observed. In the $\mathrm{PC1} 2 / \mathrm{CL}-7$ cells no toxicity was seen even after 48 hours at $10^{-6} \mathrm{M}$. However, a striking observation in these cells was the increase in XTT conversion at $10^{-7} \mathrm{M}$

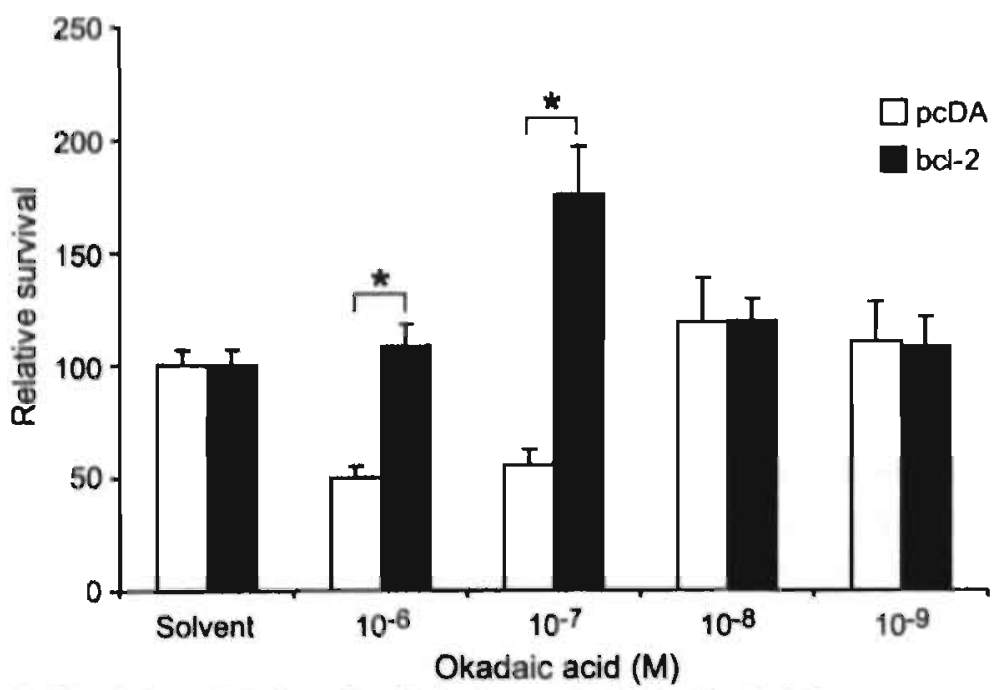

Figure 1: Okadaic acid induced cell death was inhibited by bcl-2.

The effect of okadaic acid on cell metabolism as measured by conversion of XTT. PC12 cells were differentiated for 7 days with $50 \mathrm{ng} / \mathrm{ml} \mathrm{NGF}$. Okadaic acici or vehicle was added and XTT conversion was measured after 48 hours. The data show that okadaic acid dose-dependently reduces cell viability in PC12/PCDA cells and overexpression of $\mathrm{Bcl}-2$ clearly provides protection against cell death. Interestingly, the signal was increased by okadaic acid in Bcl.2 overexpressing cells. The data are expressed as the mean $\pm S D$., from six independent experiments, each in triplicate. Statistical analysis was done with ANOVA Dunnett's t-test. (" $p<0.001$ ) 
okadaic acid after 48 hours. Also with reference to nuclear fragmentation, another hallmark of the apoptotic nature of the observed cell death, $\mathrm{PC1} 2 / \mathrm{Cl} 7$ cells showed a high degree of protection against okadaic acid. In a typical experiment, quantitative analysis of DAPI-stained preparations revealed that $10^{-7} \mathrm{M}$ okadaic acid treatment induced DNA fragmentation in $22 \%$ of $\mathrm{PC} 12 / \mathrm{PCDA}$ cells, whereas in $\mathrm{PC} 12 / \mathrm{Cl} 7$ cells this was reduced to $1 \%$ (data not shown),

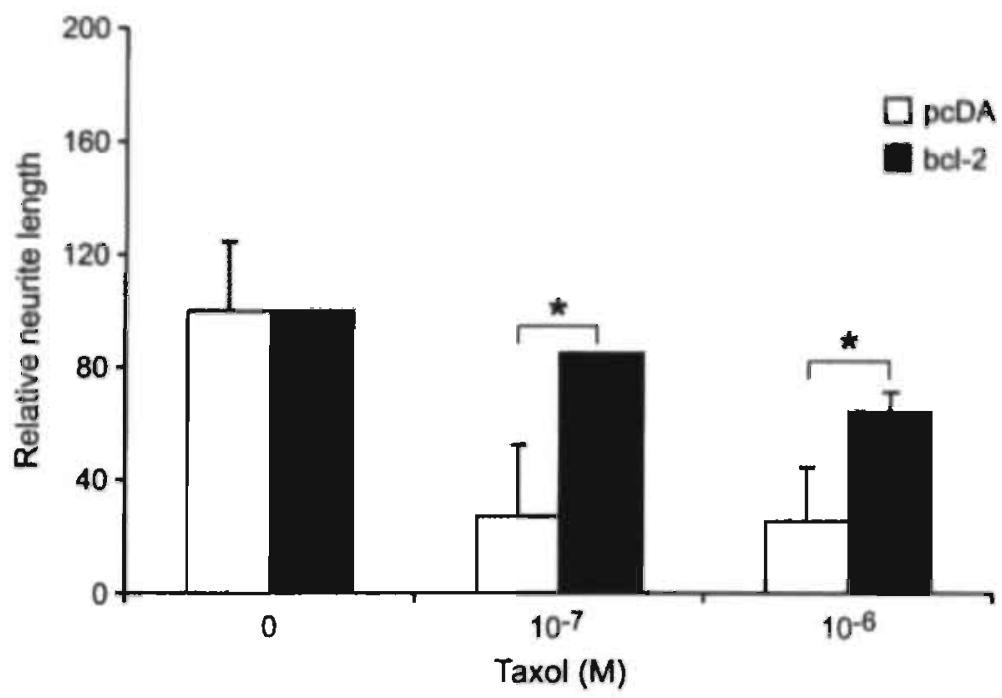

Figure 2: Taxol induced neurite retraction is inhibited by bcl-2.

Total neurite length in PC12/PCDA and PC12/c17 cells after 48 hours treatment with different concentrations of taxol. The cells were differentiated for 4 days with $50 \mathrm{ng} / \mathrm{ml}$ NGF before plating. After $\mathbf{4 8}$ hours treatment with taxol they were fixed with glutaraldehyde and visualized in brightfield on an Axiovert microscope. Neatly aligned fields were digitized by a video camera and neurite length was automatically quantified over more than 5000 cells using image analysis. The total neurite length was taken over an $8 \times 8$ field and normalized to the neurite length of the PC12/PCDA condition without taxol. Overexpression of the Bcl-2 transgene clearly protected against neurite retraction induced by treatment with taxol. The data are from three independent experiments, each in duplicate. Statistical analysis was done with ANOVA Dunnett's t-test. (" $p<0.05)$ 


\section{Neurite length after okadaic acid or taxol treatment}

Cytoskeletal alterations are likely to be reflected in changes in the highly polarized morphology of neuronal cells. By using quantitative light microscopy, we evaluated the effect of taxol and okadaic acid on neuronal morphology. In PC12/PCDA cells taxol induced a significant retraction of the neuronal processes over 48 hours (fig.2). At $10^{-7}$ and $10^{-6} \mathrm{M}$ there was an $80 \%$ reduction in overall length. In $\mathrm{PCl} / 2 / \mathrm{CL}-7$ cells this reduction was inhibited and even at $10^{-6} \mathrm{M}$ the protection was significant when compared to PC12/PCDA cells.

Application of okadaic acid induced a dose- and time-dependent retraction of neurites (table 1) in PC12/PCDA cells, which was already present after 8 hours. In PC12/CL-7 cultures there was no effect at the early time-points.

Table 1: Okadaic acid-induced neurite retraction is inhibited by $\mathrm{Bcl}-2$.

NGF differentiated PC12/PCDA and PC12/Ci7 cells were treated for 8 and 24 h with two different okadaic acid concentrations. At the appropriate time-points the cells were fixed and the neurite length ( $\mathrm{n}>50$ cells for each condition) was determined interactively. The data are normalized to the solvent control for each cell type. One out of 3 independent experiments is shown.

Application of okadaic induced a dose- and time-dependent retraction of neuronal processes as measured by quantitative light microscopy. Neurites were preserved in the Bcl-2 overexpressing cells.

$\begin{array}{llllll}\text { Mean neurite length } & \text { PCDA } & \text { SEM } & \text { CL-7 } & \text { SEM } & \text { P } \\ \text { control 8h } & 100.00 & 6.35 & 100.00 & 3.61 & \\ \text { okadaic acid 10.7 M } & 63.70 & 3.94 & 98.40 & 5.07 & <0.05 \\ \text { okadaic acid 10-8 M } & 89.03 & 3.87 & 96.66 & 3.36 & \\ & & & & & \\ \text { control 24h } & 100.00 & 4.04 & 100.00 & 2.36 & \\ \text { okadaic acid 10.7 } \mathrm{M} & 0.00 & 0.00 & 70.58 & 3.54 & <0.05 \\ \text { okadaic acid 10-8 M } & 125.27 & 10.33 & 97.88 & 2.43 & \end{array}$

Figure 3 illustrates the morphological changes associated with okadaic acid application. After 24 hours at $10^{-7} \mathrm{M}$ okadaic acid, in the PC12/PCDA cells, all neurites were retracted while in the Bcl-2 overexpressing cell line there was still a considerable degree of differentiation. Identical data were obtained from analyzing the fixed preparations stained for tau. In the PC12/PCDA cells the 

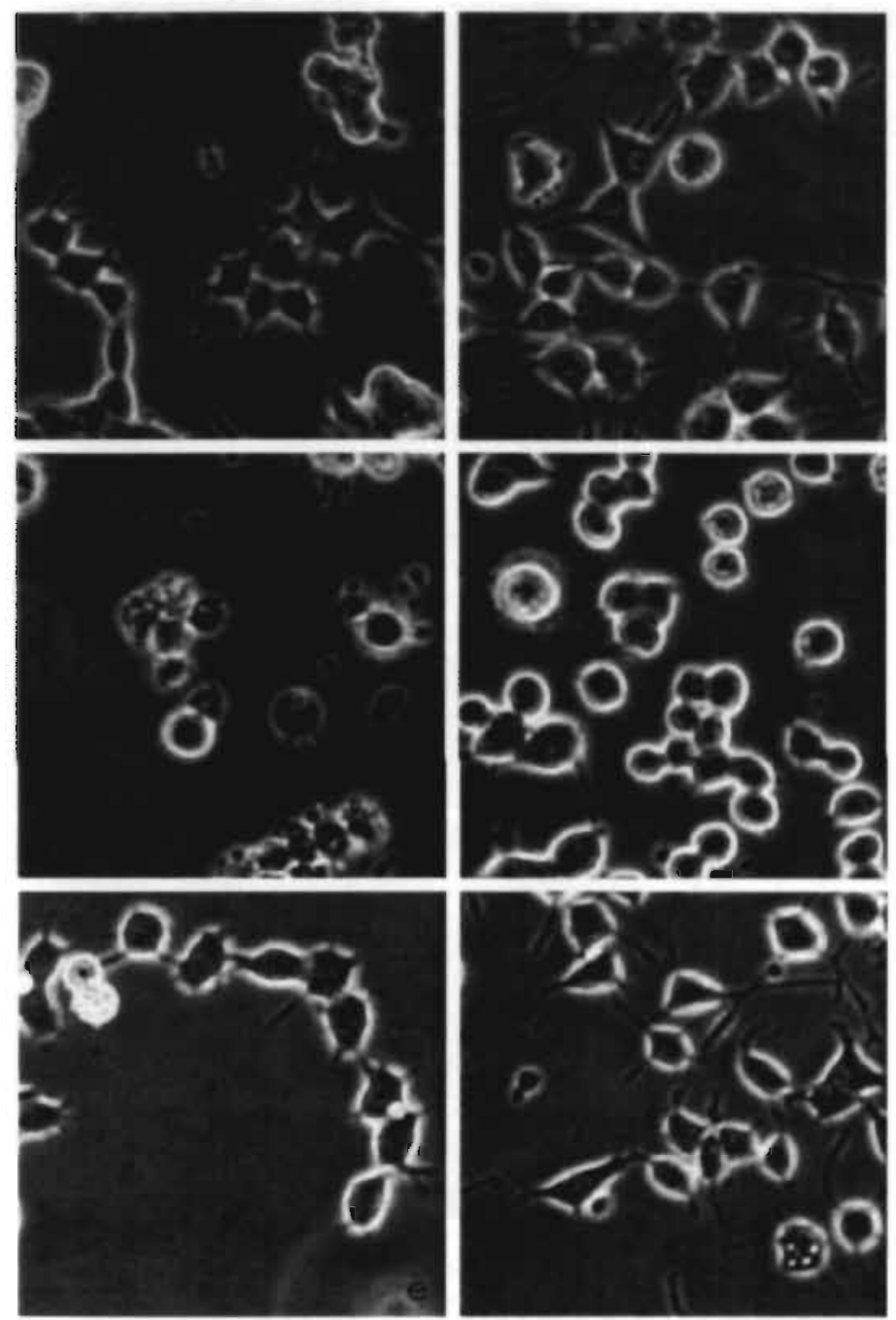

Figure 3: Okadaic acid induced morphological changes.

Phase contrast illustrations of the changes observed in NGF differentiated PCDA (a) and $\mathrm{CL}-7 / \mathrm{PC} 12$ (b) cells 24 hours after solvent (a-b) or okadaic acid addition (c- $\mathrm{f}$ ). At $10^{-7} \mathrm{M}$ a pronounced cellular degeneration is seen in the PCDA/PC12 (c) cells.

Neurites are completely absent but note also the presence of a large number of apoptotic cells while in the CL-7/PC12 (d) cells a substantial amount of processes are still present and no evidence of cell death is seen. At $10^{-6} \mathrm{M}$ the morphological changes are less dramatic but the retraction of processes is substantial in the PCDA/PC12 (e) cells when compared with CL7/PC12 (f) cells. 


\section{Chapter 7}

neurite length per cell decreased to 23 and $77 \%$ of the control values with respectively okadaic acid $10^{-7}$ and $10^{-8} \mathrm{M}$. PC12/CL7 cells did not show any major alterations in neurite length after 12 hours, 98 and $102 \%$ at $10^{-7}$ and $10^{-8} \mathrm{M}$.

\section{Distribution of acetylated microtubules}

In differentiated $\mathrm{PC} 12$ cells, both vector and $\mathrm{Bcl}-2$ transfected lines, the main location of the more stable, acetylated microtubules is the axonal shaft. In the cell body acetylated microtubules are very sparse and mainly concentrated around the cyto-center which presumably corresponds with the centrosomal area. In the more distal parts, individual and nicely curved microtubules can be discerned which protrude into the leading edge of the growth-cone (fig. 4). After 48 hours of taxol treatment, the overall density of acetylated microtubules in PC12/PCDA cells increased, most prominently in the cell body, with the occurrence of very dense bundles, which also appeared in the apparently shorter but thicker processes. In the distal parts, individual curved microtubules were replaced by dense parallel arrays of acetylated microtubules and the most active part of the growth-cone disappeared. In PC12/CL-7 cells however the effect of taxol on the cytoskeleton was much less pronounced. The caliber of the dense acetylated microtubule bundles was smaller and there was hardly any effect on the cell body. The neurites seemed to be less rigid in comparison with PC12/PCDA cells. The lamellopodia which form the active part of the growth-cone were also largely diminished in the PC12/CL-7 cells (fig.4).

Application of okadaic acid had the opposite effect to that of taxol (fig. 4). The overall density of acetylated microtubules in PC12/PCDA cells decreased. The continuity of the acetylated microtubules in the neurite shaft was lower after 24 hours treatment with $10^{-8} \mathrm{M}$ okadaic acid, especially towards the distal parts. In PC12/CL-7 cells the effects of okadaic acid were almost completely abolished by the overexpression of $\mathrm{Bcl}-2$. 

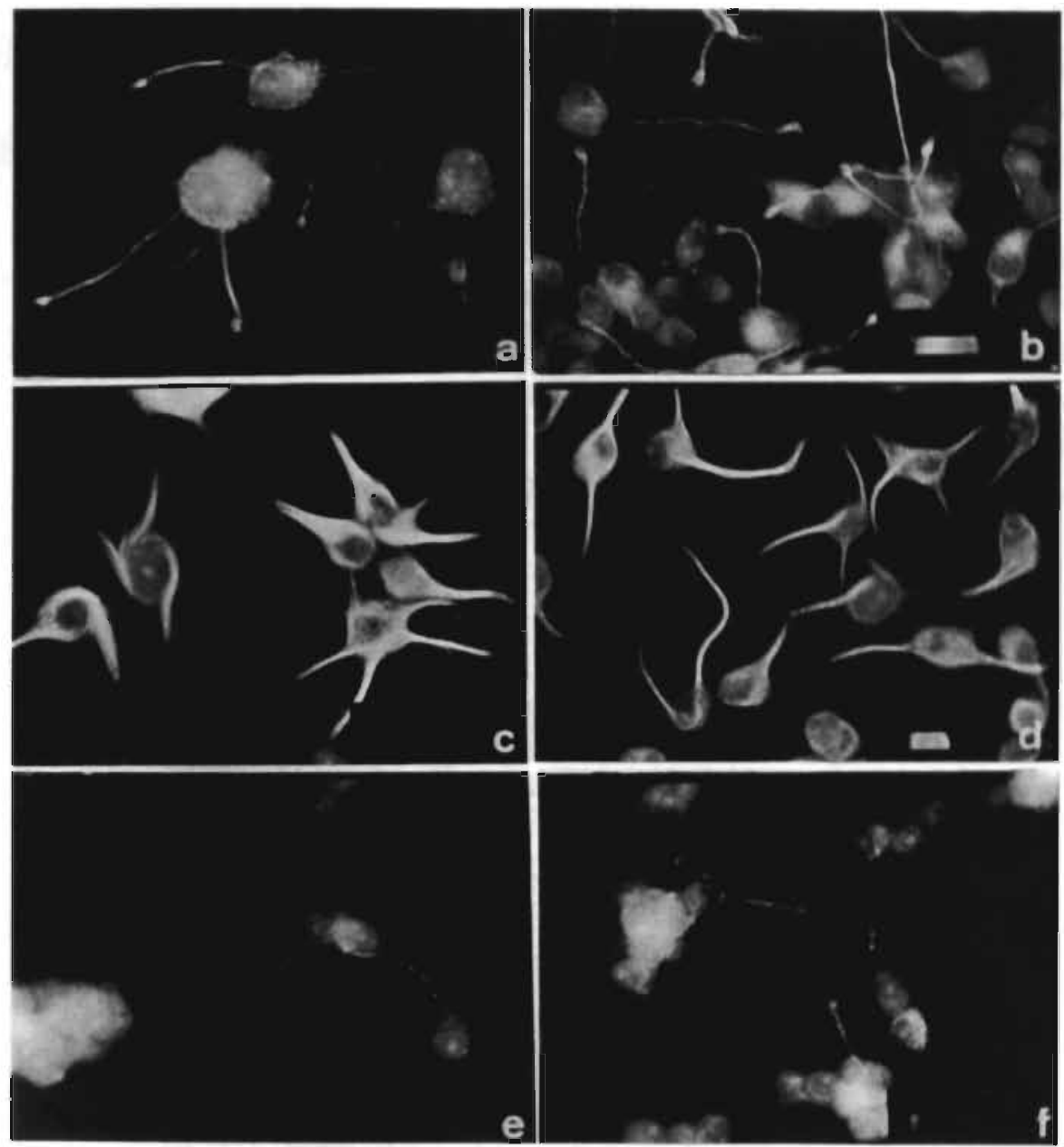

Figure 4: Cellular distribution of acetylated microtubules.

PC12 cells were differentiated with NGF for 7 days and grown in different conditions prior to fixation. Immunofluorescence showed the distribution of acetylated microtubules in PC12/PCDA and the reorganization induced by taxol or okadaic acid. The cells were fixed 48 hours after application of solvent, taxol or okadaic acid. The secondary label used was GAM-Cy3. The preparations were visualized on a Zeiss Axioplan microscope using appropriate optics. In PC12/ PCDA control cells (a) the distribution was identical to PC12/CL-7 cells (b). Taxol $10^{-6} \mathrm{M}$ induced microtubule bundling and increased the degree of acetylation in PCDAPC12 cells (c) these effects are less pronounced in the bcl-2 overexpressing cell line (d). Application of okadaic acid $10^{-8} \mathrm{M}$ for 2.4 hours induced a decrease in the density of acetylated microtubules in PC12/PCDA (e) and this was completely inhibited in PC12/CL-7 cells (f) 


\section{Post-translational tubulin modifications}

Given the qualitative observations above we wanted to quantify the degree of post-translational modifications with regard to acetylation of intact microtubules. In a cell ELISA, using specific antibodies, we quantified both total, polymerized tubulin and the degree of acetylation. By calculating the ratio of acetylated to total tubulin we obtained quantitative measures of the post-translational tubulin modifications induced by taxol or okadaic acid. As expected from the immunofluorescence data, taxol induced a significant time- and dose-dependent increase in acetylated tubulin which was most pronounced in PC12/PCDA cells. The increase (fig. 5) in the level of acetylated tubulin by taxol was most obvious after 48 hours, when the ratio of

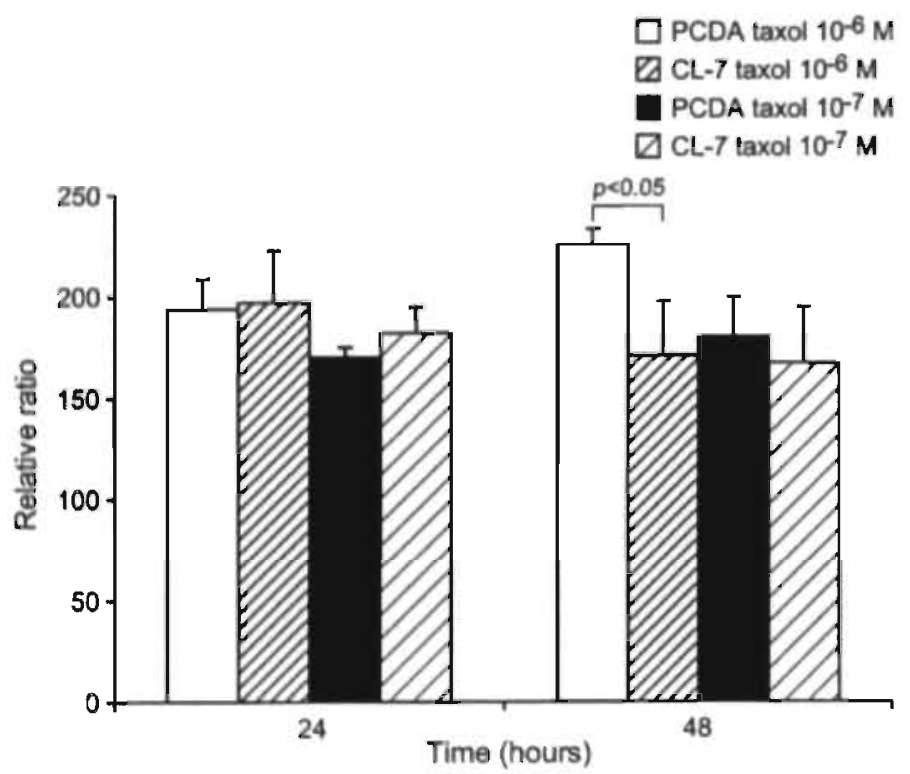

Figure 5: Bcl-2 inhibited taxol induced microtubuile acetylation.

PC 12 cells were differentiated with NGF for 7 days and grown in different conditions prior to fixation. In a cell ELISA we obtained quantitative measures of the microtubule post-translational modifications. The antibodies used were, monoclonal anti-acetylated tubulin and monoclonal anti- $\beta$-tubulin. By calculating the ratio of acetylated to total tubulin we obtained information with regard to the post-translational modifications in the various experimental conditions. In PC12/PCDA cells, taxol induced a significant increase in ratio, normalized to the solvent control $\mathrm{f}_{\mathrm{i}}$ of acetylated to total tubulin, which is completely inhibited by bcl-2. The data are mean and SD of 3 independent experiments each in quadruplicate. Analysis was performed by an ANOVA Student's t-test. 
acetylated to total tubulin reached 2.5 times the control values at $10^{-6} \mathrm{M}$. In the Bcl-2 overexpressing cells, there was a significant reduction of taxol induced changes in post-translational modifications and a normalization. In PC12/PCDA cells, application of okadaic acid induced a significant dose- and time-dependent decrease in acetylation (fig. 6). After 24 hours the observed decrease had reached $50 \%$ and $70 \%$ of the control values with $10^{-7}$ and $10^{-8} \mathrm{M}$ okadaic acid respectively. Again in PC12/CL-7 cells,

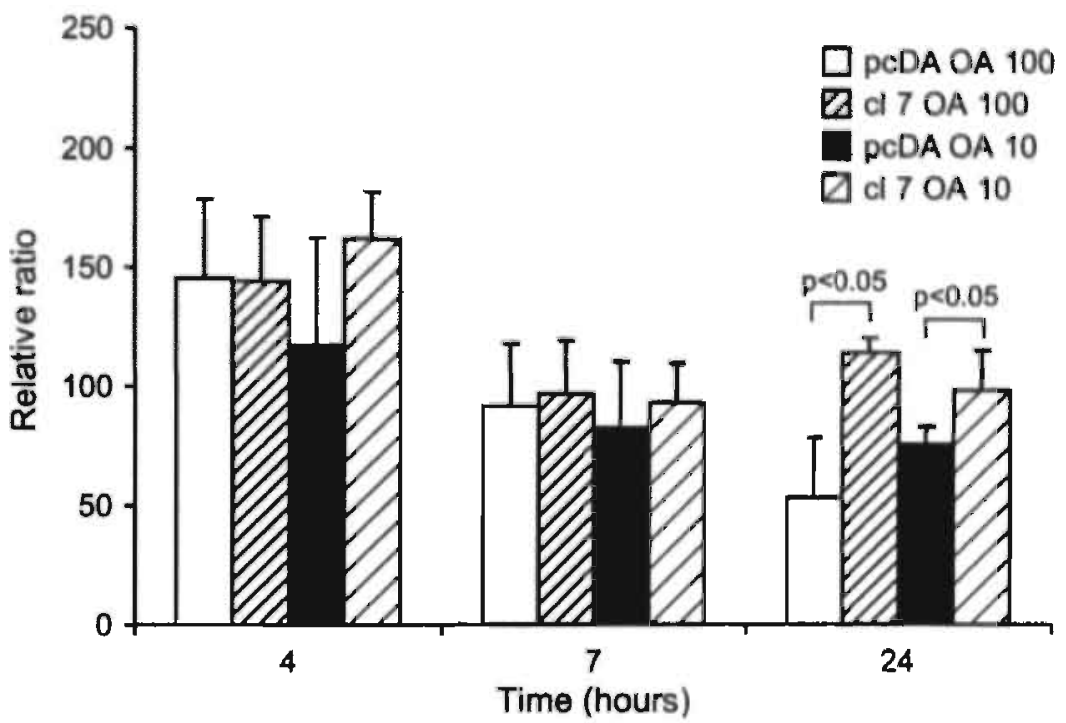

Figure 6: Bcl-2 inhibits okadaic acid induced microtubule de-acetylation.

PC12 cells were differentiated with NGF for 7 days and grown in different conditions prior to fixation. In a cell ELISA we obtainecl quantitative measures of the microtubule post-translational modifications. The antibodies used were monoclonal anti-acetylated tubulin and monocional anti- $B$-tubulin. By calculating the ratio of acetylated to total tubulin we obtained information with regard to the post-translational modifications in the various experimental conditions. Application of okadaic acid induced a rapid decrease in the ratio, normalized to the solvent control, of acetylated to total tubulin in PC12/PCDA cells, already after 24 hours. This decrease is completely inhibited by bcl-2, as shown for the PC12/Cl7 cells. The data are mean and stdev of 3 independent experiments each in quadruplicate. Analysis was performed by an ANOVA Student's t-test

the post-translational modifications were completely inhibited. This suggests that bcl-2 is able to normalize changes of the acetylated/total tubulin ratio in both directions. 


\section{Effect on okadaic acid induced tau phosphorylation}

Since okadaic acid has previously been shown to increase the degree of tau phosphorylation we studied the expression of the AT8 epitope, by monitoring phosphorylation of tau at Ser202/Thr205 using quantitative light microscopy both in PC12/PCDA and PC12/Ci7 cells. Table 2 shows that the expression of AT8 increased in both cell types on treatment with $10^{-7} \mathrm{M}$ okadaic acid for 12 hours. High expression levels of $\mathrm{Bcl}-2$ did not alter the relative increase in AT-8 signal at this high okadaic acid concentration. At $10^{-8} \mathrm{M}$ the degree of tau phosphorylation is not significantly different from control levels.

Table 2: Okadaic acid induced tau phosphorylation irrespective of bc:l-2 levels. NGF differentiated PC12/PCDA and $\mathrm{PC} 12 / \mathrm{Cl}$ cells were treated for 12 hours with two different okadaic acid concentrations. At the appropriate time-points the cells were fixed, further permeabilized and processed as described in the Materials and Methods section. The AT-8 antibody against phosphorylated tau was used at 1/100 dilution in combination with GAM-Uitra: Small Conjugates (Aurion, the Netherlands) followed by silver enhancement using Aurion R-Gent (Aurion, the Netherlands).

Preparations were mounted in gelvatol and viewed on a Zeiss Axiovert using epi-polarisation optics. The mean intensity of individual cells after background correction was calculated and from this the relative increases compared with the solvent controls were calculated. The data show the results of a typical experiment (out of two representative experiments) in which 300 to 1000 cells were analyzed per condition.

This analysis indicated that, although the basal levels of AT8 are somewhat lower in solvent treated $\mathrm{PC} 12 / \mathrm{Cl}_{7}$ cells, the relative increase in tau phosphorylation upon application of okadaic acid is similar in both cell types, suggesting that overexpression of bel-2 is unable to reduce the increase in AT8 immunoreactivity.

Condition

Control

Okadaic acid $10^{-8} \mathrm{M}$

Okadaic acid $10^{-7} \mathrm{M}$
PC12/PCDA

$100 \pm 6.22(n=241)$

$199.1 \pm 11.1(n=199)$

$134 \pm 6.5(n=379)$
$\mathrm{PC} 12 / \mathrm{Cl} 7$

$100 \pm 20.12(n=704)$

$174.2 \pm 28.9(n=973)$

$110 \pm 21.9(n=968)$ 


\section{Discussion}

\section{Cytotoxicity and bcl-2}

In this study we used PCI 2 cells which, when cultured in low serum supplemented with nerve growth factor (NGF), acquire a neuronal phenotype characterized by extended, long cellular processes. PC1 2 cells have been used in a large number of studies focusing on programmed cell death, induced by either NGF deprivation or DNA damage (Batistatou and Greene, 1991). It has also been established that $\mathrm{Bcl}-2$ overexpression protects cells against apoptosis induced by a wide variety of triggers (Reed, 1994). Bcl-2 is a member of a family of proto-oncogenes with a presumed activity during programmed cell death. Besides its in vitro activity, Bcl-2 also protects in vivo in a model of cerebral ischemia (Martinou et al., 1994) and in a genetic model for motor neuron disease (Sagot et al., 1995). Intriguingly, in these mice, Bcl-2 overexpression only rescued the affected neurons but it did not inhibit the axonal degeneration which is normaily seen in these animals nor did it prolong the animals life-span. As for cell survival, we previously showed that, in fully differentiated PC12 cells, excessive microtubule stabilization by taxol induces neuronal cell death through apoptosis which is inhibited by Bcl-2 (Nuydens et al., unpublished observations).

Inhibition of PP2A by okadaic acid induces apoptosis in a number of cell types including neurons (Nuydens et al., 1998). We extended these observations to differentiated PC12 cells where okadaic acid dose-dependently induced cell death through an apoptotic pathway. Cytotoxicity was completely abolished by overexpression of $\mathrm{Bcl}-2$ in these neuronal cells. An interesting observation in the viability studies was the increased XTT signal in the okadaic acid treated PC12/CL7 cells. This is in line with previous observations (Nuydens et al., 1998) were evidence is presented that, in human TR14 and NT2N neurons, okadaic acid induced a cellular attempt to reinitiate the cell cycle which ultimately ends with apoptotic cell death. The latter process is possibly inhibited in the bcl-2 overexpressing cells and subsequently the mitotic cycle might be completed. The same observations were done in taxol-treated cells, for which Bcl-2 overexpression creates an escape pathway by allowing the formation of 
multi-nucleated cells (Nuydens et al., unpublished observations). In oncology the formation of these multi-nucleated cells is observed in taxol-resistant tumor cell lines (Panvichian et al., 1998)

\section{Neuronal cyto architecture}

The maintenance of neuronal processes in differentiated cells is the result of growth and retraction governed by the flexibility of the neuronal cytoskeleton. Application of taxol induces an excessive stabilization of the cytoskeleton while the application of okadaic acid induces a reduction in microtubule stability (Gliksman et al., 1992). Therefore both interventions compromise the normal functioning of the neuronal cytoskeleton. Since microtubules in neurons subserve as tracks for the guidance of axonal transport, any malfunction results in a hampered supply of materials needed for the maintenance of the polarized cyto-architecture. This is reflected in a decrease in the overall neurite length. In this study we clearly established that over time, both a reduction or an increase in microtubule stability induce the retraction of the neuronal processes. As the net growth of neuronal processes is the sum of both retraction and extension any intervention altering the flexibility of the cytoskeleton reduces the overall neurite length. Bcl-2 overexpression protects against the retraction of neurites caused by either taxol or okadaic acid.

\section{Tau related changes in microtubule stability}

Alterations in the balance of kinase/phosphatase activity cause rapid alterations in the dynamic instability of microtubules both in vitro (Gliksman et al., 1992) and in living cells (Howell et al., 1997). In this study application of okadaic acid induced a rapid increase in the overall microtubule dynamics. A plausible explanation for these rapid changes is the phosphorylation of MAPs which reduces the association with and hence the stabilization of microtubules. Also in neurons it has been shown that upon phosphorylation tau loses its microtubule stabilizing properties (Shea and Fischer, 1996). Xie et al. (1998) established that in SH-SY5Y cells the phosphorylation of tau is regulated by microtubule dynamics and glycogen synthase kinase, but that only 
phosphorylation at Ser262/356 by protein kinase A prevented the association with microtubules. The same study shows that, at these sites, the phosphorylation is also modulated by PP2A activity. Another indication in this direction is the association of phosphatases and kinases with microtubules (Sontag et al., 1995) and their spatial segregation, especially in highly polarized cells like neurons, could be an important factor in the local regulation of microtubule stability. When microtubule stability is compromised, the intracellular organization of the associated kinases and phosphatases is lost and local changes may initiate inappropriate phosphorylation or dephosphorylation. This process is possibly mimicked by exposure to okadaic acid.

A study by Merrick et al. (1996) showed that the polymerization state of microtubules is an important determinant in the site-specific phosphorylation state of tau, under both normal and pathological conditions. An interesting observation was made in PC12 cells, where microtubules deacetylate and eventually depolymerize after initiating the execution phase of the apoptotic process. After microtubule depolymerization, PP2A is activated and can dephosphorylate tau during the execution phase of the apoptotic process (Mills et al., 1998). We had previously established that soon after application of the apoptotic trigger tau is hyperphosphorylated in PCI 2 cells deprived of NGF (Nuydens et al., 1997). This apparent discrepancy between both studies might be a reflection of the differences in experimental approach. Mills et al. used a single cell approach and focused on cells which already entered the execution phase of the apoptotic process. In our study we pursued overall levels of tau phosphorylation irrespective of their progression towards cell death. Since only a minor percentage of the total cell population is in the execution phase, the higher levels of tau phosphorylation might be indicative for early changes during the initiation rather than the execution of apoptosis. Short transient tau phosphorylation/dephosphorylation events have also been documented in SH-SY5Y cells after stimulation with insulin (Lesort et al., 1999).

In Alzheimer's disease, the aberrant phosphorylation of tau has been proposed as the major cause of microtubule destabilization (Alonso et al., 1994). It was, however, suggested that the reduction in acetylated microtubules precedes the 
neurofibrillary pathology (Hempen and Brion, 1996). Recently, it was also shown that the acute inactivation of tau by antibody injection has no effect on axon formation and some aspects of microtubule dynamics in rat sympathetic neurons (Tint et al., 1998).

\section{Microtubule stability and bcl-2}

Neuronal microtubules differ from microtubules in other cell types in respect to the degree of spatial organization and post-translational modifications. In axonal processes the microtubule stability increases and this is reflected by the appearance of acetylated microtubules in the axonal shaft (Brown et al., 1993). The more dynamic, tyrosinated subpopulation is mainly located in the cell soma and growth-cones, where they provide the flexibility necessary for the growth of the neuronal processes. Taxol has been shown to increase the degree of microtubule acetylation in a number of cell systems. Also in this study, vector transfected PC12-PCDA cells showed an almost three-fold increase in the ratio of acetylated to total tubulin.

This increase, however, was completely inhibited in the Bcl-2 overexpressing cell line. In several cell lines of neuronal origin it has been ascertained that inhibition of phosphatase $2 \mathrm{~A}$ by okadaic acid induces a selective breakdown of the more stable microtubule subpopulations. In SHSY-5Y cells there was an increase of tyrosinated over detyrosinated tubulin which is associated with an increased cytotoxicity (Tanaka et al., 1998). In NT2N cells, an association was established between a reduction of the stable microtubule subsets by PP2A inhibition and maintenance of axonal integrity (Merrick et al., 1997).

We confirmed these findings in differentiated PC1 2 cells and in addition we showed that these alterations in microtubule post-translational modifications are inhibited by high levels of $\mathrm{Bcl}-2$.

Combined, the data from our own investigation and various studies cited above, indicate that the stability of the cyto architecture is closely linked to the normal post-translational modifications of polymerized microtubules and that $\mathrm{Bcl}-2$ is able to protect against alterations imposed at this point. We also show that tau phosphorylation occurs upstream or independent of Bcl-2 indicating that the loss of tau microtubule interaction through this phosphorylation is not 
a major determining factor in the formation of neurites.

Changes in microtubule dynamics, which in vector transfected cells ultimately lead to apoptosis, are inhibited in cells overexpressing Bcl-2. In tumor cells it has been established that microtubule poisons induce a Raf-1 mediated Bcl-2 and $\mathrm{Bcl}-\mathrm{X}_{\mathrm{L}}$ phosphorylation and that this is a determining factor for the protective effects of the oncogenes (Poruchynski et al., 1998). In the system we set up in this study, the protective effects of Bcl-2 were already present at the level of microtubule stability indicating that Bcl-2 prohibits impairment of microtubule functioning at a site of action that is so far unknown. Bcl-2 might, in this regard, associate with microtubules and act as an entity regulating microtubule dynamics. Furthermore, in T cell leukemia cells it was shown that the development of a more stable microtubule network can suppress the cellular response towards apoptotic triggers (Geyp et al., 1996).

\section{Conclusions}

In conclusion, we have shown that Bcl-2 protects against taxol and okadaic acid induced neurite retraction. Bcl-2 overexpression also significantly normalizes the changes of acetylated tubulin induced by taxol or okadaic acid treatment. In addition, neurite retraction, cell death and nuclear fragmentation, is reduced in $\mathrm{Bcl}-2$ overexpressing cells. This protection is either downstream or independent of tau phosphorylation as quantitative immunocytochemistry with AT8 shows that Bcl-2 does not modify the level of tau phosphorylation. Our data further suggest that protection of $\mathrm{Bcl}-2$ against neuronal degeneration is probably linked to changes in the post-translational modification of tubulin. 


\section{References}

Alonso, A., Zaidi, T., Grundke-Iqbal, I., Iqbal, K. Role of abnormally phosphorylated tau in the breakdown of microtubules in Alzheimer disease. Proc. Natl. Acad. Sci. USA (1994) 91:5562-5566.

Audeberi, S., Desbruyeres, E., Gruszczynski, C., Koulakof, A., Gros, F., Denoulet, P., Edde, B. Reversible polyglutamylation of alpha- and beta-tubulin and microtubule dynamics in mouse brain neurons. Mol. Biol. Of the Cell (1993) 4:615-626.

Batistatou, A. and Greene, L. Aurintricarboxylic acid rescues PC12 cells and sympathetic neurons from cell death caused by nerve growth factor deprivation: correlation with suppression of endonuclease activity, J. Cell Biol, (1991) 115:46I-471.

Bonfoc6, E., Ceccatelli, S., Manzo, L., Nicotera, P. Colchicine induces apoptosis in cerebellar granule cells. Exp. Cell Res. (1996) 218:189-200.

Hempen, B., and Brion, J. Reduction of acetylated alpha-tubulin immunoreactivity in neurofibrillary tangle bearing neurons in Alzheimer's disease.

j. Neuropath. Exp. Neurol. (1996) 55:964-972.

Brown, A., LI, Y., Slaughter, T., Black, M. Composite microtubules of the axon: quantitative analysis of tyrosinated and acetylated tubulin along individual axonal microtubules. J. Cell Sci. (1993) 104:339-352.

Geyp, M., Ireland, C.M., Pitmann, S.M. Resistance to apoptotic cell death in a drug resistant T-cell leukaemia cell line. Leukemia (1996) 10:447-455.

Gliksman, N., Parsons, S., Salmon, E. Okadaic acid induces interphase to mitotic-like microtubule dynamic instability by inactivating rescue. J. Cell Biol. (1992) 119:1271-6.

Grundke-Iqbal, I., Iqbal, K., Tung. Y.C., Quinlan, M., Wisniewski, H.M., Binder L. Abnormal phosphorylation of the microtubule-associated protein tau in Alzheimer cytoskeletal pathology. Proc. Natl. Acad. Sci. USA (1986) 83:4913-4917.

Howell, B., Odde, D., Cassimeris, L. Kinase and phosphatase inhibitors cause rapid alterations in microtubule dynamic instability in living cells.

Cell Motil. Cytoskeleton (1997) 38:201-214.

Kroemer, G. The proto-oncogene $\mathbf{B c l}-2$ and it's role in regulating apoptosis. Nat. Med. (1997) 3:614-620. 
Lesort, M., Jope, R., Johnson, G. Insulin transiently increases tau phosphorylation: involvement of glycogen synthase kinase-3B and fyn tyrosine kinase. J. Neurochem. (1999) 72:576-584.

Martinou, J., Dubois-Dauphin, M., Staple, J., Rodriguez, I., Frankowski, H., Missotten, M., Albertini, P., Talabot, D., Catsicas, S., Pietra, C. Overexpression of BCL-2 in transgenic mice protects neurons from naturally occurring cell death and experimental ischemia. Neuron (1994) 13:1017-1030.

Merrick, S., Demoise, D., Lee, V. Site-specific dephosphorylation of tau protein at ser $202 /$ thr205 in response to microtubule depolymerization in cultured human neurons involves protein phosphatase 2A. J. Biol. Chem. (1996) 271:5589-5594.

Merrick, S., Trojanowski, J., Lee, V. Selective destruction of stable microtubules and axons by inhibitors of protein serine/threonine phosphatases in cultured human neurons (NT2N cells). J. Neurosci. (1997) 17:5726-5737.

Mills, J., Lee, V., Pittman, R. Activation of PP2A-like phosphatase and dephosphorylation of tau protein characterize onset of the execution phase of apoptosis.

J. Cell Sci. (1998) 111:625-636.

Nuydens, R., de Jong, M., Nuyens, R., Cornelissen, F., Geerts, H. Neuronal kinase stimulation leads to aberrant tau phosphorylation and neurotoxicity. Neurobiol. Aging (1995) 16:465-477.

Nuydens, R., de Jong, M., Van Den Kieboom, G., Heers, C., Dispersyn, G., Cornelissen, F., Nuyens, R., Borgers, M., Geerts, H. Okadaic acid-induced apoptosis in neuronal cells: Evidence for an abortive mitotic attempt. J. Neurochem. (1998) 70:1124-1133.

Nuydens, R., Dispersyn, G., de Jong, M., Van Den Kieboom, G., Borgers, M., Geeris, H. Aberrant tau phosphorylation and neurite retraction during NGF deprivation in PC12 cells. Biochem., Biophys. Res. Commun. (1997) 240:687-691.

Panvichian, R., Orth, K., Day, M.L., PIlat, M.J., Pienta, K.J. Paclitaxel-associated multimininucleation is permitted by the inhibition of caspase activation: a potential early step in drug resistance. Cancer Res. (1998) 58: 4667-4672.

Poruchynski, M.S.. Wang, E.E., Rudin, C.M., Elagosklonny, M.V., Fojo, T. Bcl-X is phosphorylated in malignant cells following microtubule disruption.

Cancer Res. (1998) 58:3331-3338.

Reed, J.C. Bcl-2 and the regulation of programmed cell death. J. Cell Biol. (1994) 124:1-6.

Sadot, E., Barg. J., Rasouly, P., Lazarovici, P., Ginzburg, I. Short- and long-term mechanisms of tau-regulation in PC12 cells. J. Cell Sci. (1995) 108:2857-2864. 
Sagot, Y., Dubois-Dauphin, M., Tan, S., de Bilbao, F., Aebischer, P., Martinou, J-C., Kato,

A. Bcl-2 overexpression prevents motoneuron cell body loss but not axonal degeneration in a mouse model of a neurodegenerative disease. J. Neurosci. (1995) 15:7727-7733.

Schliwa, M., Van Blerkom, J. Structural interaction of cytoskeletal elements.

J. Cell Biol. (1981) 90:222-235.

Shea, T., Fischer, I. Phosphatase inhibition in neuroblastoma. cells alters tau antigenicity and renders it incompetent to associate with exogenous microtubules.

FEBS Lett. (1996) 380:63-67.

Sontag, E., Nunbhakdi, V., Bloom, G., Mumby, M. A novel pool of protein phosphatase 2A is associated with microtubules and is regulated during the cell cycle.

J. Cell Biol. (1995) 128:1131-1144.

Steger, $C_{\text {. }}$ An unbiased detector of curvilinear structures.

IEEE Transactions on pattern analysis and machine intelligence (1998) 20:113-125.

Tanabe, H., Eguchi, Y., Kamada, S., Martinou, J., Tsujimoto, Y. Susceptibility of cerebellar neurons derived from Bcl-2-deficient and transgenic mice to cell death.

Eur. J. Neurosci. (1997) 9:848-856.

Tanaka, T., Zhong, J., Iqbal, K., Trenkner, E., Grundke-Iqbal, I. The regulation of phosphorylation of tau in SHSY neuroblastoma cells: the role of protein phosphatases.

FEBS Letr. (1998) 426:248-254.

Tint, I., Slaughter, T., Fischer, I., Black, M. I. Acute inactivation of Tau has no effect on dynamics of microtubules in growing axons of cultured sympathetic neurons.

J. Neurosci. (1998) 18:8660-8673.

Xie, H., LItersky, J.M., Hartigan, J.A., Jope, R.S., Johnson, G.V.W. The interrelationship between selective tau phosphorylation and microtubule association.

Brain Res. (1998) 798:173-183. 


General discussion 
Alzheimer's disease is characterized by two major pathological hallmarks: neurofibrillary tangles and B-amyloid deposits. Neurofibrillary tangles in Alzheimer's disease brain consist primarily of abnormally phosphorylated tau protein, a MAP (Brion et al., 1985). Changes in the balance of kinase and phosphatase activities are likely the reason for this aberrant phosphorylation (Gong et al., 1993). The primary function of tau is the stabilization of the microtubular cytoskeleton. Hyperphosphorylation of tau reduces the affinity for-and hence-the stabilization of the neuronal microtubules (Alonso et al., 1994).

With immortalized human neuronal cell lines and primary rat hippocampal neuron cultures, it was shown that excessive stimulation of neuronal kinase activity by application of a hyperstimulating cocktail induces aberrant tau phosphorylation. Quantitative immunocytochemistry, with phosphorylationdependent antibodies, showed that neuronal cell death was associated with the degree of tau phosphorylation. During the late phases of this hyperstimulation-induced cell death, some cells assumed a mitosis-like morphology (chapter 2). Hyperphosphorylation of tau had already been observed in mitotic human neuroblastoma cells (Pope et al., 1994).

Dissection of the composition of the hyperstimulating cocktail indicated that sodium butyrate by itself was sufficient to induce tau phosphorylation and subsequent cytotoxicity (chapter 3 ). Early on during the stimulation a more pronounced differentiation was observed in these human neuroblastoma cells, which points to a possible role of the cytoskeleton. Neurotoxicity, observed after chronic exposure to sodium butyrate, displayed features of programmed cell death: DNA fragmentation, presence of fragmented nuclei and inhibition by cycloheximide. Arguments have been put forward proposing that, also during some chronic neuropathological conditions like Alzheimer's disease, apoptosis contributes to the observed neuronal cell loss (Su et al., 1994). To further elucidate the relationship between tau phosphorylation, cytoskeletal stability and cell death, a well-characterized model of neuronal apoptosis was used. Differentiated PC12 cells, when deprived of nerve growth factor (NGF), initiate cell death through an apoptotic pathway (Batistatou and Greene, 1991). Quantitative light microscopy showed that, early on in this process, 
a prominent retraction of neurites took place, which was associated with an increase in aberrantly phosphorylated tau. Interestingly, inhibition of kinase activity by application of staurosporine reduced the degree of tau phosphorylation and the subsequent retraction of the neuronal processes. Also at the level of cell survival, staurosporine protected differentiated PC12 cells against NGF-deprivation-induced apoptosis. This indicated that during apoptosis activated kinases may compromise cytoskeletal stability and hence neurite integrity, which ultimately leads to cell death (chapter 4).

Arguments were advanced claiming that apoptosis is the consequence of the attempt of post-mitotic cells to re-enter the cell cycle (Colombel et al., 1992). Also, during neuronal apoptosis a number of proteins (cyclin B1, P34cdc2, cyclin D1) are upregulated to levels normally seen only in proliferating cells during mitosis (Freeman et al., 1994). In addition, in Alzheimer's disease brains, cell cycle disturbances have been observed (Nagy et al., 1998; Busser et al., 1998). It has even been postulated that mitotic kinase activation triggers neurofibrillary tangle formation in the course of the disease (Vincent et al., 1998).

In mitotic SH-SY5Y neuroblastoma and tau-transfected CHO cells, it was established that phosphorylation of tau at Ser/Thr-Pro motifs, as it is normally found in PHF tau, shows a cell-cycle-dependent pattern (Pope et al., 1994: Preuss et al., 1995).

Further insights into the mitosis-apoptosis hypothesis came from experiments in human neuronal cells. Inhibition of PP2A by application of okadaic acid induced aberrant tau phosphorylation (Vandermeeren et al., 1993) but it also induced apoptosis by forcing the post-mitotic cells to re-initiate the cell cycle (chapter 5). In these cells DNA synthesis and chromosome formation were started, but the mitotic cycle was not completed and ended with neuronal death through apoptosis. The formation of abnormal mitotic figures points to a role of a deficient microtubule system as possible mediator of these phenomena. The same cascade of events was documented in differentiated PC1 2 cells when deprived of NGF (chapter 5). Induction of tau phosphorylation, either by al teration of the kinase/phosphatase balance or by NGF deprivation, reduced the tau-microtubule association and thereby the overall stability of 
the microtubule cytoskeleton.

Taxol is a low molecular weight plant derivative that enhances microtubule assembly in vitro, and has the unique ability to promote the formation of discrete microtubule bundles in cells (Manfredi et al., 1982). In proliferating ceilis, taxol causes the cells to halt at the $\mathrm{G}_{2} / \mathrm{M}$ transition phase of the cell cycle, presumably through its interference with the mitotic spindle. This mitotic block eventually leads to cell death through activation of an apoptotic pathway (Shu et al., 1997) initiated by cell cycle checkpoint controls. In PC12 cells, taxol induced apoptosis irrespective of the differentiation state of the cells, as evidenced by the appearance of apoptosis-specific features. In both proliferating and differentiated cells this was accompanied by a re-initiation of the cell cycle which indicated that deregulation of microtubule dynamics may play an important role in the initiation of the apoptotic cascade (chapter 6).

Bcl-2 is a prototype member of a large family of proteins with considerable amino acid sequence homology and is presumed to play a central role during programmed cell death. Among the members of the family are proteins with pro-apoptotic (bax, bad) and anti-apoptotic (bcl-2, bcl- $x_{L}$ ) properties. Their precise roles remain elusive although cumulative evidence points to the mitochondria as a possible target. Bcl-2 confers protection in a number of in vivo and in vitro assays through a wide variety of apoptotic stimuli (Garcia et al., 1992).

PC12 cells expressing high levels of $\mathrm{Bel}-2$ show a reduced sensitivity to taxol induced cytotoxicity. Re-initiation of the cell cycle in these cells is the same as with their vector-transfected counterparts, but the transition from G2/M to apoptosis, as evidenced by the appearance of chromatin condensation and nuclear fragmentation is however modified. Bcl-2 creates an alternative pathway by allowing the formation of multi-nucleated cells thereby inhibiting cell death. This provides a first indication that $\mathrm{Bcl}-2$ confers protection possibly by maintaining some cytoskeletal function(s) during taxol-induced apoptosis (chapter 6).

When neuronal cells are somehow compromised in their normal function, for instance by growth factor deprivation, they readily retract their neurites. This 
probably reflects the integrity of the cytoskeleton as this is a major determinant of the neuronal cyto-architecture. By altering microtubule dynamics, we further clarified the role of the cytoskeleton during the apoptotic process in differentiated PC12 cells. Taxol induced microtubule stabilization, while okadaic acid induced destabilization. Both interventions induced a time- and dose-dependent neurite retraction and neurotoxicity, which was inhibited by Bcl-2. Microtubule dynamics are regulated by the association with MAPs like tau, but the stability of microtubules is also reflected in the degree of post-translational modifications (MacRae, 1997). In cells treated with taxol, the ratio of acetylated tubulin (the more stable subtype) to total tubulin increased. This increase in tubulin acetylation was significantly reduced in Bcl-2 overexpressing PC12 cells (chapter 7). Bcl-2 overexpression significantly inhibited the decrease in acetylation after application of okadaic acid. This suggests that bcl- 2 has some kind of regulatory function with regard to post-translational modifications of tubulin. Application of okadaic acid not only altered tubulin modifications, but it induced aberrant tau phosphorylation in differentiated PC12 cells, as shown before in human neuroblastoma cells. By quantitative immunocytochemistry we demonstrated that Bcl-2 levels had no effect on the level of phosphorylated tau after okadaic acid.

In conclusion, we can state that microtubules are a prominent target during the apoptotic process. However, the exact nature of the regulatory function of this process remains elusive and the possible role of tau phosphorylation (cause or effect) in the apoptotic process is still not clear. In this investigation we have shown that alterations in microtubule dynamics induce apoptosis in neuronal cells. This has also been reported in cerebellar granule cells, in which case colchicine was shown to induce apoptosis (Bonfoco et al., 1996). On the other hand, in T cell leukemia cells, development of a more stable microtubule system protects against apoptosis (Geyp et al., 1996). The change in the dynamic equilibrium might trigger downstream events like re-activation of the mitotic equipment through cell cycle check points. The association of microtubules with phosphatases (Sontag et al., 1995) and the cell-cycle-dependent enzymatic activity might be an important factor in this process.

The observation that, in $\mathrm{Bcl}-2$ protected cells, tubulin post-translational 
modifications are normalized irrespective of the nature of the microtubule poison is consistent with this hypothesis. More elaborate studies on the possible interaction of bcl-2 with microtubules and/or microtubule associated (regulatory) proteins might shed more light on these questions.

\section{References}

Alonso, A. C., Zaidi, T., Grundke-Iqbal, I., Iqbal, K. Role of abnormally phosphorylated tau in the breakdown of microtubules in Alzheimer disease.

Proc. Natl. Acad.Sci. USA (1994) 91:5562-5566.

Batistatou, A. and Greene, L.A. Aurintricarboxylic acid rescues. PC12 cells and sympathetic neurons from cell death caused by nerve growth factor deprivation: correlation with suppression of endonuclease activity. J. Cell Biol. (1991) 115:461-471.

Bonfoco,E., Ceccatelli, S., Manzo, L., Nicotera, P. Colchicine induces apoptosis in cerebellar granule cells. Exp. Cell Res.(1996) 218:189-200.

Brion, J.F., Passareiro, H., Nunez, J., Flament-Durand, J. Mise en evidence immunologique at niveau des lesions de degenerescence neurofibrillaire de la maladie d' Alzheimer. Arch. Biol.(1985) 95:229.235.

Busser, J., Geldmacher, D.S., Herrup, K. Ectopic cel! cycle proteins predict the sites of neuronal cell death in Alzheimer"s disease brain. J. Neurosc. (1998) 18:2801-2807.

Colombel, M., Ollson, C.A., Ng. P.Y. Buttyan, R. Hormone-regulated apoptosis results from reentry of differentiated prostate cell onto a defective cell cycle.

Cancer Res. (1992) 52:4313-4319.

Freemun, R.S., Estus, S., Johnson, E.M.Jr. Analysis of cell cycle-related gene expression in post-mitotic neurons: Selective induction of cyclin DI during programmed cell death. Neuron (1994) 12:343-355.

Garcia, I. Martinou, I., Tsujimoto, Y., Martinou, J.C. Prevention of programmed cell death of sympathetic neurons by the bcl-2 proto-oncogene. Science (1992) 258:302-304. 
Geyp, M., Ireland, C.M., Pitmann, S.M. Resistance to apoptotic cell death in a drug resistant T-cell leukaemia cell line. Leukemia (1996) 10:447-455.

Gong, C.-X., Sing, T., Wang, J., Grundke-Iqbai, I., Iqbal, K. Phosphoprotein phosphatase activity in Alzheimer disease brain. J. Neurochem. (1993) 61:921-927.

MacRae, T.H. Tubulin post-translational modifications. Eur. J. Biochem. (1997) 244:265-278.

Manfredi, J.J., Parness, J., Horwitz, S.B. Taxol binds to cellular microtubules. J. Cell Biol. (1982) 94:688-696.

Nagy, Z.S., Esiriu, M.M., Smith, A.D. The cell division cycle and the pathophysiology of Alzheimer's disease. Neurosc. (1998) 87:731-739.

Pope, W.B., Lambert, M.P., Leypold, B., Seupaul, R., Sletten, L., Kraft, G., Klein, W.L. Microtubule-associated protein tau is hyperphosphorylated during mitosis in the human neuroblastoma cell line SH-SY5Y. Exp. Neur. (1994) 126:185-194.

Preuss, U., Doring, F., Illenberger, S., Mandelkow, E.-MI. Cell cycle-dependent phosphorylation and microtubule binding of tau protein stably transfected into Chinese Hamster Ovary cells. Mol. Biol. of the Cell (1995) 6:1397-1410.

Sontag, E., Nunbhakdí, V., Bloom, G., Mumby, M. A novel pool of protein phosphatase 2A is associated with microtubules and is regulated during the cell cycle.

J. Cell Biol. (1995) 128:1131-1144.

Shu, C., Yang, W.. Kuo, M.-L. and Huang, T.-S. Cell cycle G,/M arrest and activation of cyclin-dependent kinases associated with low-dose paclitaxel-induced sub-Gll apoptosis. Apoptosis (1997) 2:463-470.

Su, J.H., Anderson, A.J., Cummings, B.J., Cotman, C.W., Immunohistochemical evidence for apoptosis in Alzheimer's disease. Neuroreport (1994) 5:2529-2533.

Vandermeeren, M., Lubke, U., Six, J. and Cras, P. The phosphatase inhibitor okadaic acid induces a phosphorylated helical filament epitope in human LA-N-5 neuroblastoma cells. Neurosci. Lett. (1993) 153:57-60.

Vincent, I., Zheng, J.-H., Dickson, D.W., Kress, Y., Davies, P. Mitotic phosphoepitopes precede paired helical filaments in Alzheimer's disease.

Neurobiol. Of Aging (1998) 19:287-296. 



\section{Samenvatting}

De ziekte van Alzheimer wordt gekarakteriseerd door de aanwezigheid van twee specifieke pathologische kenmerken: neurofibrillaire kluwens en neerslag van B-amyloid. De neurofibrillaire kluwens in de hersenen van Alzheimer patiënten bestaan vooral uit abnormaal gefosforyleerd tau, een microtubuli geassocieerd eiwit. Veranderingen in de balans van de activiteit van kinases en fosfatases zijn meer dan waarschijnlijk de reden voor deze abnormale fosforylatie. Tau fungeert in de eerste plaats als stabilisator van microtubuli. Door de hoge mate van fosforylatie vermindert de bindingscapaciteit en dus ook de stabiliserende werking van tau op de neuronale microtubuli. Door gebruik te maken van geïmmortaliseerde cellijnen van neuronale oorsprong samen met primaire culturen van rat hippocampale neuronen werd aangetoond dat overmatige stimulatie van de neuronale kinase activiteit, door applicatie van een stimulerende cocktail, tau fosforylatie induceert.

Kwantitatieve immunocytochemie met fosforylatie gevoelige antilichamen toonde aan dat de neuronale celdood gerelateerd is aan de mate van tau fosforylatie. Tijdens de laatste stadia van deze celdood nemen sommige cellen de vorm aan van cellen in deling (hoofdstuk 2). Overmatige fosforylatie van 
tau werd reeds eerder waargenomen in mitotische humane neuroblastoma cellen.

Verdere studie van de samenstelling van de hyperstimulerende cocktail toonde aan dat applicatie van natriumbutyraat alleen voldoende was om tau fosforylatie te induceren gevolgd door celdood (hoofdstuk 3). Deze vorm van celdood vertoont veel kenmerken met geprogrammeerde celdood.

NGF gedifferentieerde PC12 cellen zijn een goed gekarakteriseerd cel systeem vaak gebruikt in de studie van apoptosis of geprogrammeerde celdood. Iñ dit systeem is de retractie van de neuronale uitlopers, vroeg tijdens het apoptotisch proces, geassocieerd met de fosforylatie van tati (hoofdstuk 4). Inhibitie van de kinase activiteit remt ook de progressie van het apoptotisch proces. Recent zijn er een aantal argumenten naar voor geschoven waarin apoptose wordt aangeduid als het gevolg van een post-mitotische cel die probeert terug de celcyclus op te starten. Ook in humane neuronale cellen is hier evidentie voor. Inductie van apoptosis loopt nauw samen met het aanmaken van DNA en met de initiatie van de mitotische cyclus welke echter niet kan worden afgewerkt en eindigt met celdood (hoofdstuk 5). Microtubuli spelen blijkbaar een centrale rol in de progressie van dit proces.

Taxol is een stof die de vorming van microtubuli stimuleert en op deze manier een cytostatisch effect heeft in prolifererende cellen. Het blokkeren van de celcyclus in de G2/M phase heeft uiteindelijk tot gevolg dat de cellen afsterven via apoptose. $\mathrm{Bcl}-2$ is een eiwit met een inhiberend effect op het apoptotisch proces. $\mathrm{PCl} 2$ cellen behandeld met Taxol sterven via apoptose maar deze cellen initiëren de celcyclus ongeacht het feit of ze al dan niet gedifferentieerd zijn. Cellen die een hoger expressieniveau hebben van Bcl-2 zijn duidelijk beschermd tegen dit soort van agressie. Deze cellen hebben een alternatieve ontsnappingsroute door de vorming van meerkernige cellen na de G2/M fase van de celcyclus (hoofdstuk 6). Dit wijst op een mogelijk verband tussen de integriteit van het cytoskelet en de bescherming tegen neuronale celdood. Microtubuli dynamiek en stabiliteit worden gemoduleerd door de associatie met MAPs zoals tau. De stabiliteit van microtubuli wordt ook aangegeven door de mate van post-translationele modificaties. Hogere expressieniveaus van $\mathrm{Bcl}-2$ inhiberen de verandering in post-translationele modificaties 
geïnduceerd door enerzijds taxol (toename) of anderzijds door okadaic acid (afname). De fosforylatie van tau is echter niet afhankelijk van Bcl-2 niveaus in de cellen (hoofdstuk 7).

In conclusie kunnen we stellen dat microtubuli een centrale positie innemen tijdens het apoptotisch proces. De exacte rol is echter nog niet duidelijk maar deze en andere studies tonen aan dat veranderingen in microtubuli dynamiek apoptose kunnen induceren in neuronale cellen. Veranderingen in het dynamisch evenwicht kunnen de celcyclus terug activeren, de hiermee gepaard gaande veranderingen in enzymatische activiteit zouden hierbij een belangrijke factor kunnen zijn. Het feit dat $\mathrm{Bcl}-2$ de veranderingen in tubuline post-translationele modificaties kan normaliseren wijst in deze richting. Verdere studies over de associatie tussen Bcl-2 en microtubuli zouden hierover meer informatie kunnen opleveren. 



\section{Dankwoord}

Een proefschrift schrijven is geen soloproject. Over de jaren heen heb ik het geluk gehad om te mogen samenwerken met enthousiaste en bekwame mensen. Aan allen mijn dank.

In het bijzonder wil ik mijn promotor Prof. Dr. M. Borgers bedanken om me de kans te hebben gegeven dit werk te voltooien binnen de Janssen Research Foundation. Marcel, bedankt voor het stimulerende enthousiasme en de interesse voor dit en andere onderzoeksprojecten.

Ook mijn tweede promotor Prof. Dr. F. Ramaekers wil ik bedanken voor de begeleiding en belangstelling tijdens het verloop van dit promotie-onderzoek. Frans, bedankt voor het vertrouwen!

Mijn co-promotor Dr. H. Geerts bedanken in enkele regels is haast niet mogelijk. Hugo, jaren geleden wakkerde je, samen met Marc De Brabander, de celbiologische interesses al aan, wat uiteindelijk resulteerde in dit proefschrift. De mogelijkheden die je me bood om nieuwe onderzoeksveiden te verkennen en de vrijheid die ik in mijn werk had, heb ik steeds gewaardeerd. Bedankt ook voor de kritische blik op het geleverde werk en de manuscripten.

Het komt me zeker ten goede.

Verder will ik Gerd en Mirjam bedanken voor hun belangrijke bijdragen aan dit werk, ook voor die experimenten welke niet in publikaties terecht zijn 
gekomen. Zonder jullie handigheid en zorgvuldige afwerking van de experimenten was het allemaal veel moeilijker geweest.

Dr. Gwenda Dispersyn, je ideeën en suggesties bij het PC12 werk heb ik altijd zeer kunnen waarderen. Gwenda, al is dit geen "calcium geladen" apoptose verhaal, toch leverde je een aanzieniijke bijdrage aan het tot stand komen van dit boekje. Mijn dank hiervoor.

Roger, bedankt voor je hulp bij het "tunen" van de microscopen en de veelvuldige Paragon analyses.

Marc en Eddy wil ik bedanken voor hun wetenschappelijke inbreng en voor het verduidelijken van het begrip "Limburger, wereldburger".

Frans, Peter en Jan-Mark, bedankt om mij Silicon Graphics-compatibel te houden.

De groep van Lambert Leijssen zou ik willen bedanken voor de figuren, foto"s en de layout van dit werk.

Greet, mijn dank voor het administratieve werk.

De leden van de beoordelingscommissie wil ik bedanken voor het kritisch doomemen van het manuscript.

Tenslotte wil ik mijn familie en vrienden bedanken voor de steun en interesse en voor de leuke momenten buiten het werk.

May, Tom en Sanne, jullie wil ik vooral bedanken voor het begrip bij de momenten dat ik "in afzondering" was. 




\section{Curriculum vitae}

Rony Nuydens werd geboren op 17 oktober 1958 te Beerse. Na het behalen van het TSO-diploma aan het Hoger Rijksinstituut voor Technisch Onderwijs te Turnhout in 1977, werkte hij als research-analist binnen de afdeling Oncologie van de Janssen Research Foundation onder leiding van Dr. M. De Brabander. Sinds 1990 werkte hij als onderzoeksassistent op de afdeling Celfysiologie onder leiding van Dr. H. Geerts. Van 1990 tot 1992 volgde hij de opleiding H.L.O. ingenieur richting biochemie aan de Hogeschool West-Brabant te Etten-Leur. Dit werd afgesloten na het schrijven en verdedigen van een proefschrift. 



\section{List of publications}

Nuydens R. Dispersyn G. Van Den Kieboom G. de Jong M. Connors R. Ramaekers F. Borgers M. and Geerts H. Bcl-2 protects neuronal cells against taxol induced apoptosis by inducing multi-nucleation.

under review Exp Neurology

Nuydens R. Dispersyn G. Van Den Kieboom G. de Jong M. Connors R. Ramaekers F. Borgers M. and Geerts H. Bcl-2 protects against apoptosis-related microtubule alterations. (Submitted),

Dispersyn G. Nuydens R. Borgers M. and Hugo Geerts. Modulating intracellular calcium concentration has a differential effect on survival and morphology of PC12 cells during nerve growth factor deprivation. Eur. J. Pharmacol in press

Nuydens R. Novalbos J. Dispersyn G. Weber C. Borgers M. and Geerts H. A rapid method for the evaluation of compounds with mitochondrial-protective properties. J. of Neurosci. Methods in press

Dispersyn G. Nuydens R. Connors R. Borgers M. and Geerts H. Bcl-2 protects against FCCP-induced apoptosis and mitochondrial membrane potential depolarization in PCI2 cells. Bioch. Biophys. Acta, in press

Dispersyn G. Nuydens R. Connors R. Borgers M. and Geerts H. Bcl-2 prevents nerve growth factor deprivation induced cell death of $\mathrm{PC} 12$ cells through redistribution of endoplasmic reticulum $\mathrm{Ca} 2+$ to a non-mitochondrial store. submitted 
Dispersyn G. Nuydens R. Duimel H. Thone F. Connors R. Borgers M. and Geerts H. Cytochemical evidence for the existence of a Bcl-2-induced non-mitochondrial/non-endoplasmic reticulum $\mathrm{Ca} 2+$ store which protects against nerve growth factor induced apoptosis. submitted

Schutte B. Nuydens R. Geerts H. and Ramaekers F. Annexin V binding assay as a tool to measure apoptosis in differentiated neuronal cells. J. Neurosci. Methods 86, 63-69. 1998

Hens J. Nuydens R. Geerts H. Senden NH. Van de Ven WJ, Roebroek AJ. van de Velde HJ. Ramaekers FC. Broers JL. Neuronal differentiation is accompanied by NSP-C expression. Cell \& Tissue Research. 292(2):229-37, 1998

Dispersyn G. Nuydens R. de Jong M. Borgers M. Geerts H. Altered [Ca2+] homeostasis in PC12 cells after nerve growth factor deprivation. Brain Research. 779(1-2):350-3, 1998

Nuydens R. de Jong M. Van Den Kieboom G. Heers C. Dispersyn G. Comelissen F. Nuyens R. Borgers M. Geerts H. Okadaic acid-induced apoptosis in neuronal cells: evidence for an abortive mitotic attempt. Journal of Neurochemistry. 70(3):1124-33, 1998

Nuydens R. Dispersyn G. de Jong M. van den Kieboom G. Borgers M. Geerts. H. Aberrant tau phosphorylation and neurite retraction during NGF deprivation in PC12 cells. Biochemical \& Biophysical Research Communications. 240(3):687-91, 1997

Geerts H., Nuydens R. Apoptosis in Alzheimer's disease: walking the small line between life and death. In: Alzheimer's Disease: Biology, Diagnosis and Therapeutics. ed. Iqbal, Winblad, Nishimura, Takeda and Wisniewski, 1997

Geerts H. Nuydens R. De Jong M. Van de Kieboom G. A new focus on cytoskeletal therapy in Alzheimer's disease. in Alzheimer disease: from molecular biology to therapy. eds. Giacobini and Becker Birkhauser, Boston, USA, 1997

Geerts H. Nuydens R. De Jong M. Cornelissen F. Nuyens R. Wouters L. Sabeluzole stabilizes the neuronal cytoskeleton. Neurobiology of Aging. 17(4):573-81, 1996

Van Gool D. Lesage A. Nuydens R. Geerts H. Godderts J. Dom R. Leysen J.

No further evidence for the abscence of a growth inhibitory factor in the brains of patients with Alzheimer's Disease. Alzheimer's Research 1, 49-52, 1995

Nuydens R. Heers C. Chadarevian A. De Jong M. Nuyens R. Cornelissen F. Geerts H. Sodium butyrate induces aberrant tau phosphorylation and programmed cell death in human neuroblastoma cells. Brain Research. 688(1-2):86-94, 1995 
Nuydens R. De Jong M. Nuyens R. Comelissen E. Geerts H. Neuronal kinase stimulation leads to aberrant tau phosphorylation and neurotoxicity. Neurobiology of Aging. 16(3):465-75, 1995

Katsuhito M. Hirobume A. Kyozo H. Nuydens R. , Nuyens R. Cornelissen F. Geerts H. Sabeluzole potentiates the effect of NGF on cell survival and neuronal differentiation in PC12 cells and sympathetic nerve cells. Neurodegeneration 2, pp 173-181, 1993

Nuydens R. Nuyens R. Comelissen F. Geerts H. The fast axonal transport in hippocampal neurones is acutely enhanced by db-cAMP. Neuroreport. 4(2):179-82, 1993

De Brabander M. Geerts H. Nuyens R. Nuydens R. Cornelissen F. Nanovid Microscopy: Imaging and Quantification of Colloidal Gold Labels in Living Cells. in Electronic Light Microscopy, 141-155, Wiley-Liss, Inc. 1993

Geerts H. Nuydens R. Nuyens R. Cornelissen F. De Brabander M. Pauwels P. Janssen PA. Song YH. Mandelkow EM. Sabeluzole, a memory-enhancing molecule, increases fast axonal transport in neuronal cell cultures. Experimental Neurology. I17(1):36-43, 1992

Geerts H. Nuydens R. Nuyens R. Comelissen F. Sabeluzole accelerates neurite outgrowth in different neuronal cell lines. Restorative Neurology and Neuroscience, 4: 21-32, 1992

Coopman P. Nuydens R. Leunissen J. De Brabander M. Bortier H. Foidart JM. Mareel M. Laminin binding and internalization by human and murine mammary gland cell lines in vitro. European Journal of Cell Biology. 56(2):251-9. 1991

Geerts H. de Brabander M. Nuydens R. Nanovid microscopy. Nature. 351(6329):765-6, 1991

De Brabander M. Nuydens R. Ishihara A. Holifield B. Jacobson K. Geerts H. Lateral diffusion and retrograde movements of individual cell surface components on single motile cells observed with Nanovid microscopy. Journal of Cell Biology, 112(1):111-24, 1991.

Cornelissen F. Nuyens R. Nuydens R. Geerts H. Automatic quantification of fast axonal transport in neuronal cell cultures. Journal of Neuroscience Methods. 35(1):79-88, 1990

Geerts H. Nuydens R. Nuyens R. Ver Donck L. The effect of flunarizine on intracellular calcium in isolated rat cardiomyocytes. A digital image processing study [published erratum appears in Cardiovasc Res 1989 Nov;23(11):992]. Cardiovascular Research. 23(9):797-806, 1989

De Brabander M. Geerts H. Nuydens R. Nuyens R. Detection of gold probes with videoenhanced contrast microscopy: nanovid microscopy. American Journal of Anatomy. 185(2-3):282-95, 1989 
De Brabander M. Nuydens R. Geerts H. Hopkins CR. Dynamic behavior of the transferrin receptor followed in living epidermoid carcinoma (A431) cells with nanovid microscopy. Cell Motility \& the Cytoskeleton. 9(1):30-47, 1988

Geerts H. De Brabander M. Nuydens, R. Geuens S. Moeremans M. De Mey J. Hollenbeck P. Nanovid tracking: a new automatic method for the study of mobility in living cells based on colloidal gold and video microscopy. Biophysical Journal. 52(5):775-82, 1987

De Mey J. Langanger G. Geuens G. Nuydens R. De Brabander M. Preembedding for localization by electron microscopy of cytoskeletal antigens in cultured cell monolayers using gold-labeled antibodies. Methods in Enzymology. 134:592-7, 1986

Geuens G. Gundersen G. Nuydens R. Cornelissen F. Bulinski JC. DeBrabander M. Ultrastructural colocalization of tyrosinated and detyrosinated alpha-tubulin in interphase and mitotic cells. Journal of Cell Biology. 103(5):1883-93, 1986

De Brabander M. Geuens G. Nuydens R. Moeremans M. De Mey J. Microtubule-dependent intracellular motility investigated with nanometer particle video ultramicroscopy (nanovid ultramicroscopy). Annals of the New York Academy of Sciences. 466:666-8. 1986

De Brabander M. Geuens G. Nuydens R. Willebrords R. Moeremans M. Van Ginckel R. Distelmans W. Dragoneti C. Mareel M. Tubulozole: a new stereoselective microtubule inhibitor. Annals of the New York Academy of Sciences. 466:757-66, 1986

De Brabander M. Nuydens R. Geuens G. Moeremans M. De Mey J. The use of submicroscopic gold particles combined with video contrast enhancement as a simple molecular probe for the living cell. Cell Motility \& the Cytoskeleton. 6(2): 105-13, 1986

De Brabander M. Geuens G. Nuydens. R. Willebrords R. Aerts F. De Mey J. Microtubule dynamics during the cell cycle: the effects of taxol and nocodazole on the microtubule system of Pt K.2 cells at different stages of the mitotic cycle. International Review of Cytology. 101:215-74, 1986

De Brabander M. Aerts F. De Mey J. Geuens G. Moeremans M. Nuydens R. Willebrords R. Microtubule dynamics and the mitotic cycle: a model. Basic Life Sciences. $36: 269-78,1985$

De Brabander M. Geuens G. Nuydens R. Moeremans M. De Mey J. Probing microtubule-dependent intracellular motility with nanometre particle video ultramicroscopy (nanovid ultramicroscopy), Cytobios. 43(174S):273-83, 1985

Geuens G. de Brabander M. Nuydens R. De Mey J. The interaction between microtubules and intermediate filaments in cuitured cells treated with taxol and nocodazole. Cell Biology International Reports. 7(1):35-47, 1983 
De Brabander M. Geuens G. Nuydens R. Willebrords R. De Mey J. Microtubule stability and assembly in living cells: the influence of metabolic inhibitors, taxol and $\mathrm{pH}$. Cold Spring Harbor Symposia on Quantitative Biology. $46 \mathrm{Pr}$ 1:227-40, 1982

De Mey J. Moeremans M. Geuens G. Nuydens R. De Brabander M. High resolution light and electron microscopic localization of tubulin with the IGS (immuno gold staining) method. Cell Biology International Reports. 5(9):889-99, 1981

De Brabander M. Geuens G. Nuydens R. Willebrords R. De Mey J. Taxol induces the assembly of free microtubules in living cells and blocks the organizing capacity of the centrosomes and kinetochores. Proceedings of the National Academy of Sciences of the United States of America. 78(9):5608-612, 1981

De Brabander M. Geuens G. Nuydens R. Willebrords R. De Mey J. Microtubule assembly in living cells after release from nocodazole block: the effects of metabolic inhibitors, taxol and PH. Cell Biology International Reports. 5(9):913-20, 1981 
